Argon mational laboratory

\title{
A CASE STUDY ON SEVERE ACCIDENT WATER ADDITION AND WATER MANAGEMENT FOR A MARK I CONTAINMENT
}

Nuclear Science and Engineering Division 


\section{About Argonne National Laboratory}

Argonne is a U.S. Department of Energy laboratory managed by UChicago Argonne, LLC under contract DE-AC02-06CH11357. The Laboratory's main facility is outside Chicago, at 9700 South Cass Avenue, Argonne, Illinois 60439. For information about Argonne and its pioneering science and technology programs, see www.anl.gov.

\section{DOCUMENT AVAILABILITY}

Online Access: U.S. Department of Energy (DOE) reports produced after 1991 and a growing number of pre-1991 documents are available free at OSTI.GOV (http://www.osti.gov/), a service of the US Dept. of Energy's Office of Scientific and Technical Information.

Reports not in digital format may be purchased by the public from the National Technical Information Service (NTIS):

U.S. Department of Commerce

National Technical Information

Service 5301 Shawnee Rd

Alexandria, VA 22312

www.ntis.gov

Phone: (800) 553-NTIS (6847) or (703) 605-6000

Fax: (703) 605-6900

Email: orders@ntis.gov

Reports not in digital format are available to DOE and DOE contractors from the Office of Scientific and Technical Information (OSTI):

U.S. Department of Energy

Office of Scientific and Technical Information

P.O. Box 62

Oak Ridge, TN 37831-0062

www.osti.gov

Phone: (865) 576-8401

Fax: (865) 576-5728

Email: reports@osti.gov

\section{Disclaimer}

This report was prepared as an account of work sponsored by an agency of the United States Government. Neither the United States Government nor any agency thereof, nor UChicago Argonne, LLC, nor any of their employees or officers, makes any warranty, express or implied, or assumes any legal liability or responsibility for the accuracy, completeness, or usefulness of any information, apparatus, product, or process disclosed, or represents that its use would not infringe privately owned rights. Reference herein to any specific commercial product, process, or service by trade name, trademark, manufacturer, or otherwise, does not necessarily constitute or imply its endorsement, recommendation, or favoring by the United States Government or any agency thereof. The views and opinions of document authors expressed herein do not necessarily state or reflect those of the United States Government or any agency thereof, Argonne National Laboratory, or UChicago Argonne, LLC. 


\section{A CASE STUDY ON SEVERE ACCIDENT WATER ADDITION AND WATER MANAGEMENT FOR A MARK I CONTAINMENT}

prepared by

M.T. Farmer

Nuclear Science and Engineering Division, Argonne National Laboratory

September 2018 



\section{ACKNOWLEDGEMENTS}

Successful preparation of this report required input and support from several individuals and organizations. In particular, thanks are due to Dr. David Luxat and Mr. Matthew Griffiths at Jensen Hughes for providing the MAAP melt pour data used in this study, and Mr. Richard Wachowiak at the Electric Power Research Institute for supporting Jensen Hughes in this effort. Thanks are also due to Dr. Nathan Andrews at Sandia National Laboratories for providing the analogous MELCOR melt pour data used in this study. Model development and analysis activities carried out at Argonne National Laboratory as part of this work were funded by the U.S. Department of Energy's Office of Nuclear Energy Light Water Reactor Sustainability Program and the Electric Power Research Institute. This support is greatly appreciated. 


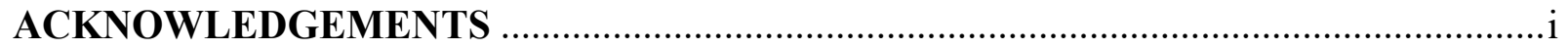

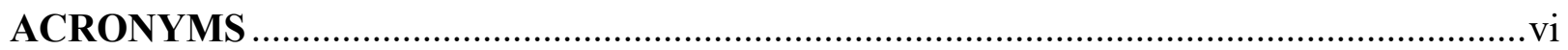

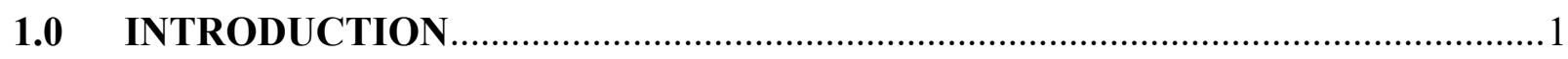

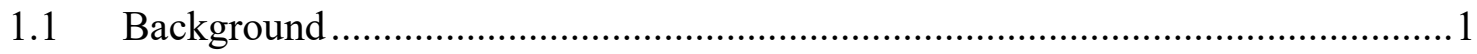

1.2 Technical Objective ...............................................................................

2.0 MELTSPREAD ANAL YSES OF CORE DEBRIS SPREADING ........................4

2.1 MAAP and MELCOR Melt Pour Conditions ....................................................4

2.2 Modelling Assumptions ................................................................................ 9

2.3 Definition of Parametric Cases for MAAP and MELCOR Scenarios .................. 12

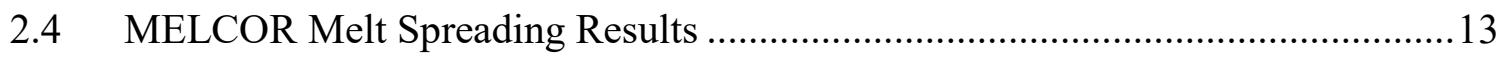

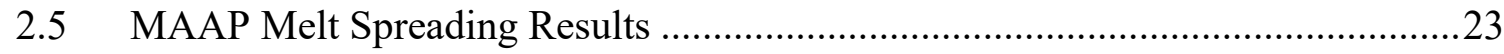

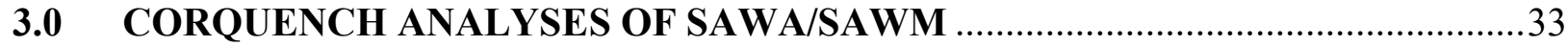

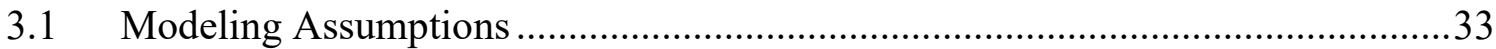

3.2 Definition of Parametric Cases for MAAP and MELCOR Scenarios ...................35

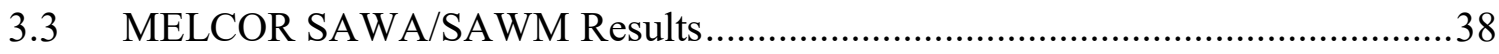

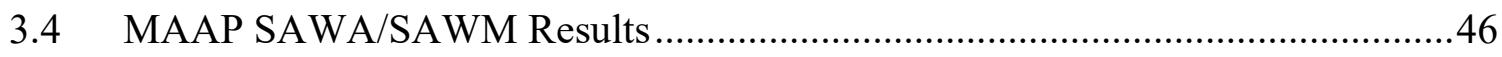

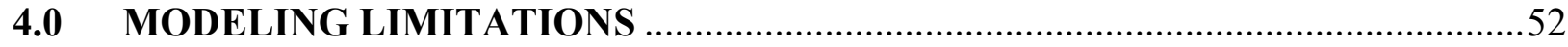

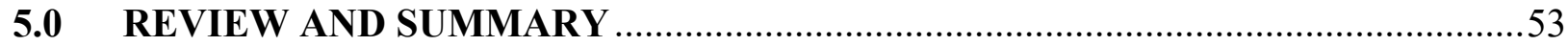

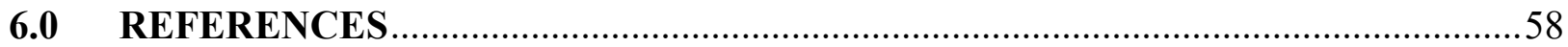




\section{List of Figures}

$\underline{\text { Figure }}$

$\underline{\text { Page }}$

1-1 Illustration of Melt Stream Interaction with BWR Bellow Vessel Structure (left) and Water Present on Pedestal Floor 1

1-2 Plan (top) and Elevation (bottom) Views of Peach Bottom Containment (Units 2-3).....3

2-1 MELCOR Prediction of Melt Pour Rate for an SBO sequence at Peach Bottom ...........6

2-2 MELCOR Prediction of Cumulative Melt Pour Mass for an SBO sequence at Peach Bottom.

2-3 MELCOR Prediction of Melt Pour Temperature for an SBO sequence at Peach

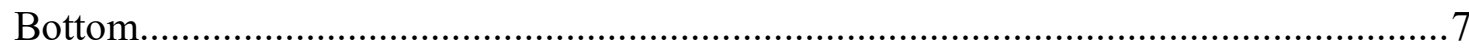

2-4 MAAP Prediction of Melt Pour Rate for an SBO sequence at Peach Bottom ................7

2-5 MAAP Prediction of Cumulative Melt Pour Mass for an SBO sequence at Peach

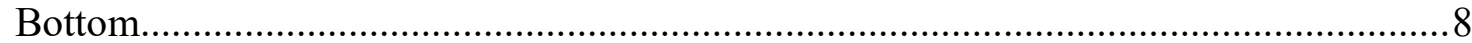

2-6 MAAP Prediction of Melt Pour Temperature for an SBO sequence at Peach Bottom....8

2-7 Basemat Floor Area Covered by Core Debris for the MELCOR Cases ........................ 14

2-8 Debris Upper Surface Elevation Profiles for MELCOR Cases at 2400 seconds. ............14

2-9 Temperature and Depth Profiles at Sequential Times for MELCOR Base Case............15

2-10 Core Debris Depth Adjacent to Shell Outside Pedestal Doorway for MELCOR Cases..20

2-11 Core Debris Temperature Adjacent to Shell for MELCOR Cases...............................20

2-12 Water Depth over Core Debris Adjacent to Shell for MELCOR Cases.......................21

2-13 Peak Shell Surface Temperature for the MELCOR Cases ..........................................21

2-14 Particulate Mass Formed in Pedestal Region by Jet Fragmentation for MELCOR

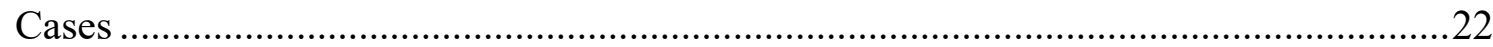

2-15 Remaining Water Depth in Jet Impingement Zone for MELCOR Cases ....................23

2-16 Basemat Floor Area Covered by Core Debris for the MAAP Cases...........................22

2-17 Debris Upper Surface Elevation Profiles for MAAP Cases at 300 seconds. ................24

2-18 Temperature and Depth Profiles at Sequential Times for MAAP Base Case. ..............25

2-19 Core Debris Depth Adjacent to Shell Outside Pedestal Doorway for MAAP Cases ......29

2-20 Core Debris Temperature Adjacent to Shell for MAAP Cases ....................................30

2-21 Water Depth over Core Debris Adjacent to Shell for MAAP Cases.............................30 


\section{List of Figures (Contd.)}

Figure

$\underline{\text { Page }}$

2-22 Peak Shell Surface Temperature for the MAAP Cases 31

2-23 Particulate Mass Formed in Pedestal Region by Jet Fragmentation for MELCOR

Cases .32

2-24 Remaining Water Depth in Jet Impingement Zone for MELCOR Cases 32

3-1 Initial Conditions for CORQUENCH Analysis Based on MELTSPREAD Results for MAAP Scenario

3-2 Initial Conditions for CORQUENCH Analysis Based on MELTSPREAD Results for MELCOR Scenario....

3-3 Integrated Power, Debris Mass, and Water/Steam Distribution Results for

MELCOR 'CI, 0 hr' Case

3-4 Integrated Power, Debris Mass, and Water/Steam Distribution Results for

MELCOR 'DI, 0 hr' Case

3-5 Upper Surface Elevations of Core Debris in Pedestal and Drywell Regions for the MELCOR 'DI, 0 hr' Case.....

3-6 Debris Stabilization Times for MELCOR CI and DI Cases. .43

3-7 Sump Axial Ablation Depths at Stabilization for MELCOR CI and DI Cases ..............43

3-8 Axial Ablation Depths Outside Pedestal Door for MELCOR CI and DI Cases .............44

3-9 Predicted Water Overflow into the Wetwell for MELCOR Parametric Cases ...............45

3-10 Predicted Non-condensable Gas Production for MELCOR Parametric Cases ...............45

3-11 Integrated Power, Debris Mass, and Water/Steam Distribution Results for MAAP 'CI, 0 hr' Case .

3-12 Integrated Power, Debris Mass, and Water/Steam Distribution Results for MAAP 'DI, 0 hr' Case.

3-13 Comparison of Debris Stabilization Times for MAAP and MELCOR

CI and DI Cases

3-14 Comparison of Sump Axial Ablation Depths at Stabilization for MAAP and MELCOR CI and DI Cases

3-15 Comparison of Axial Ablation Depths Outside Pedestal Door for MAAP and MELCOR CI and DI Cases. .50

3-16 Predicted Water Overflow into the Wetwell for MAAP Parametric Cases .50

3-17 Predicted Non-condensable Gas Production for MAAP Parametric Cases 51 


\section{List of Tables}

$\underline{\text { Table }}$

$\underline{\text { Page }}$

2-1 Melt Spreading Input Data from MELCOR and MAAP5 Simulations for

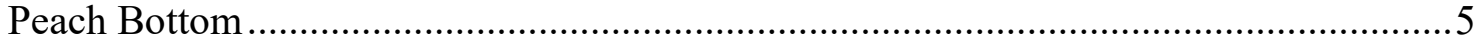

2-2 Assumed Peach Bottom Concrete Composition (Limestone-common sand [9]).............11

2-3 Melt Pour Temperatures and Cavity Water Levels for Parametric Studies .....................13

2-4 Key Results for MELCOR Cases at 2410 seconds..................................................... 17

2-5 Key Results for MAAP Cases at 300 seconds.........................................................2 27

3-1 Spatial Variation of Core Debris Composition for MELCOR Melt Pour Scenario ..........36

3-2 Timing of Water Injection (relative to completion of the transient spreading phase) and Injection Location for Parametric Studies. 


\section{ACRONYMS}

$\begin{array}{ll}\text { BWR } & \text { Boiling Water Reactor } \\ \text { CRD } & \text { Control Rod Drive } \\ \text { DOE } & \text { Department of Energy } \\ \text { EPRI } & \text { Electric Power Research Institute } \\ \text { LWRS } & \text { Light Water Reactor Sustainability } \\ \text { MCCI } & \text { Molten Corium Concrete Interaction } \\ \text { MT } & \text { Metric Ton } \\ \text { OECD } & \text { Organization for Economic Cooperation and Development } \\ \text { RPV } & \text { Reactor Pressure Vessel } \\ \text { RST } & \text { Reactor Safety Technologies } \\ \text { SAWA } & \text { Severe Accident Water Addition } \\ \text { SBO } & \text { Station Blackout } \\ \text { SAWM } & \text { Severe Accident Water Management }\end{array}$


A CASE STUDY ON SEVERE ACCIDENT WATER ADDITION AND WATER MANAGEMENT (SAWA/SAWM) FOR A MARK I CONTAINMENT

\subsection{INTRODUCTION}

\subsection{Background}

For BWR plants, accident management guidance prior to the reactor accidents at Fukushima Daiichi called for flooding the drywell to a level of approximately $1.2 \mathrm{~m}$ (4 feet) above the drywell floor once vessel breach has been determined. While this action can help to submerge ex-vessel core debris, it can also result in flooding the wetwell and thereby rendering equipment in the drywell unusable for recovery and the wetwell vent path unavailable. An alternate strategy has been developed in the industry guidance [1] for responding to the severe accident capable vent Order, EA-13-109 [2]. The alternate strategy consists of throttling the flooding rate to achieve a stable wetwell water level that preserves the wetwell vent path.

To support industry efforts in this area, the Light Water Reactor Sustainability (LWRS) program has supported modeling enhancements to existing analytical tools (i.e. MELTSPREAD and CORQUENCH - which were used as part of the DOE-sponsored Fukushima accident analyses [3]) in order to provide flexible, analytically capable, and validated models for the analysis of SAWA/SAWM strategies that aim to keep ex-vessel core debris covered with water while preserving the wetwell vent path. In particular, knowledge gaps were indentified in analysis capability for evaluating core melt relocation and cooling behavior that accounts for several important factors that include:

i) the influence of below vessel structure and pre-existing water on the containment floor on melt stream breakup and subsequent spreading behavior (see Figure 1-1), and

ii) the effect of water throttling on spreading and long term debris coolability.

These gaps were identified by an industry-lab advisory group [4] as high priority items to address.
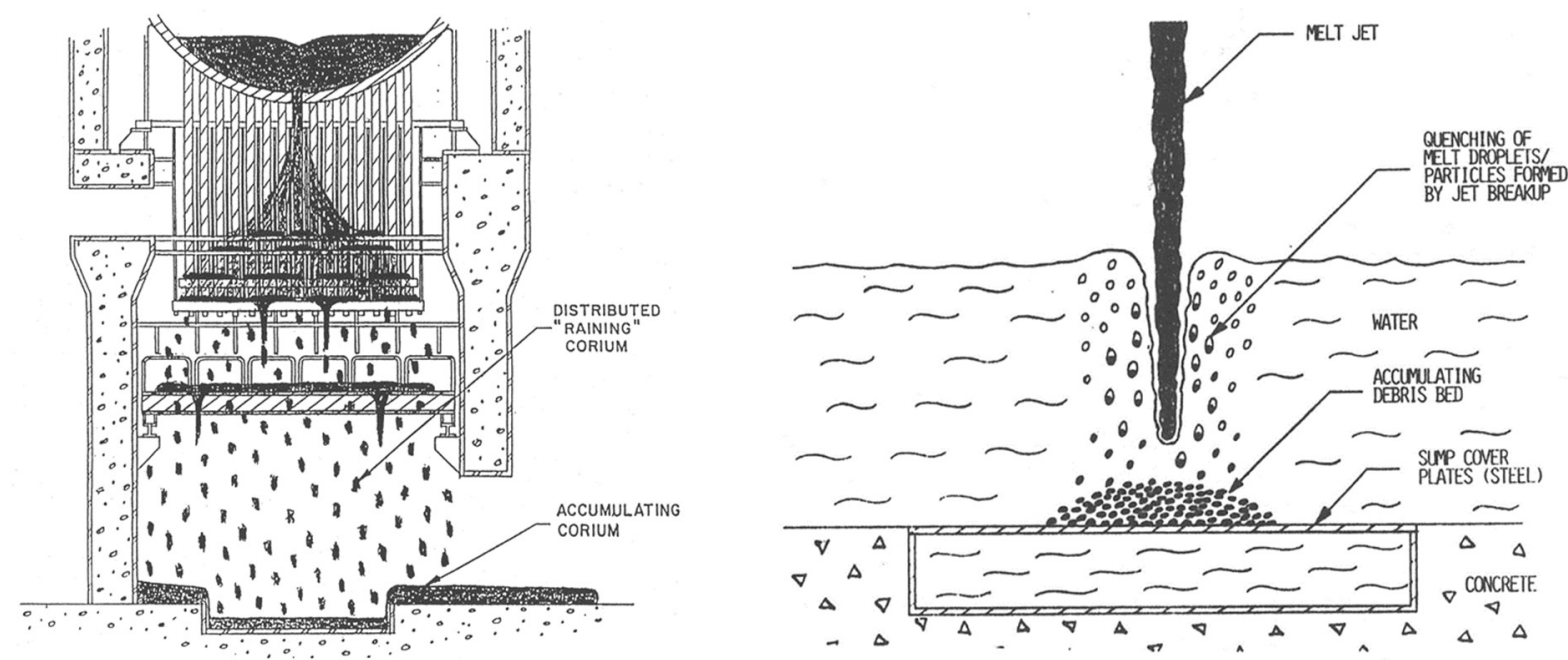

Figure 1-1. Illustration of Melt Stream Interaction with BWR Bellow Vessel Structure (left) and Water Present on Pedestal Floor. 
A related factor that can impact flooding strategy is the spatial distribution of core melt in containment following vessel failure and melt spreading. For instance, a localized accumulation of melt in the pedestal region may require a more specific flooding approach in comparision to the situation in which core melt is spread uniformly over the pedstal and drywell floor areas. In the former case, the localized core melt accumulation could form a dam preventing adequate debris flooding and cooling if the water is not injected directly on top the core debris, whereas in the latter case, effective debris flooding is expected regardless of injection point(s) as long as the injection flowrate is high enough to remove both sensible energy and decay heat. These spatial distribution questions, coupled with the overall effectiveness of the debris cooling process, impact the water injection requirements for achieving a balance between injection flowrate versus water boil-off, thereby minimizing overflow of water injected into the containment into the wetwell.

In order to adequately address questions that arise due to these considerations, there was a recognized need to develop a multi-nodal modeling capability to address localized coreconcrete interaction behavior given realistic containment features (e.g., sumps and compartments), as well as a realistic water inventory model capable of evaluating water injection strategies given realistic (i.e., non-uniform) debris distributions within containment. Note that a multi-nodal core-concrete interaction analysis capability was first implemented as part of the earlier Fukushima analyses [3]. However, this work was carried out manually (i.e., the containment was nodalized and individual CORQUENCH cases were run for each node, and then the results were combined using a spread sheet). Furthermore, this early effort did not include a realistic water inventory model. Thus, the current work has further aimed to automate the multi-nodal CORQUENCH analysis capability, and to interface this capability with a realistic water inventory model to provide an integrated modelling framework for assessing longterm water throttling strategies for BWRs. The status of these model improvement and validation efforts have been documented in several technical reports [5-7].

\subsection{Technical Objective}

With this background, the specific objective of this study is to apply these upgraded modeling tools (i.e., MELTSPREAD [6] and CORQUENCH [7]) to perform a parametric case study on SAWA/SAWM using the well-studied Peach Bottom nuclear power plant as the basis (see Figure 1-2) in order to provide insights related to cavity flooding strategies. To this end, Section 2 summarizes the ex-vessel melt pour conditions predicted by MAAP and MELCOR for an SBO sequence at Peach Bottom. This data is used as input to MELTSPREAD that is exercised to determine the extent of melt spreading in containment under various conditions that parameterize on initial water depth on the drywell floor and melt pour temperature. In turn, the post-spread melt distributions are used as input to CORQUENCH in Section 3 of this report to evaluate long term debris coolability and water overflow (after reaching the inlet height of the downcomers) into the wetwell under various conditions that parmeterize on the timing of water addition and water addition location (i.e., core injection vs. drywell sprays). Modeling limitations are described in Section 4, while a summary and review of findings from this study are provided in Section 5. 


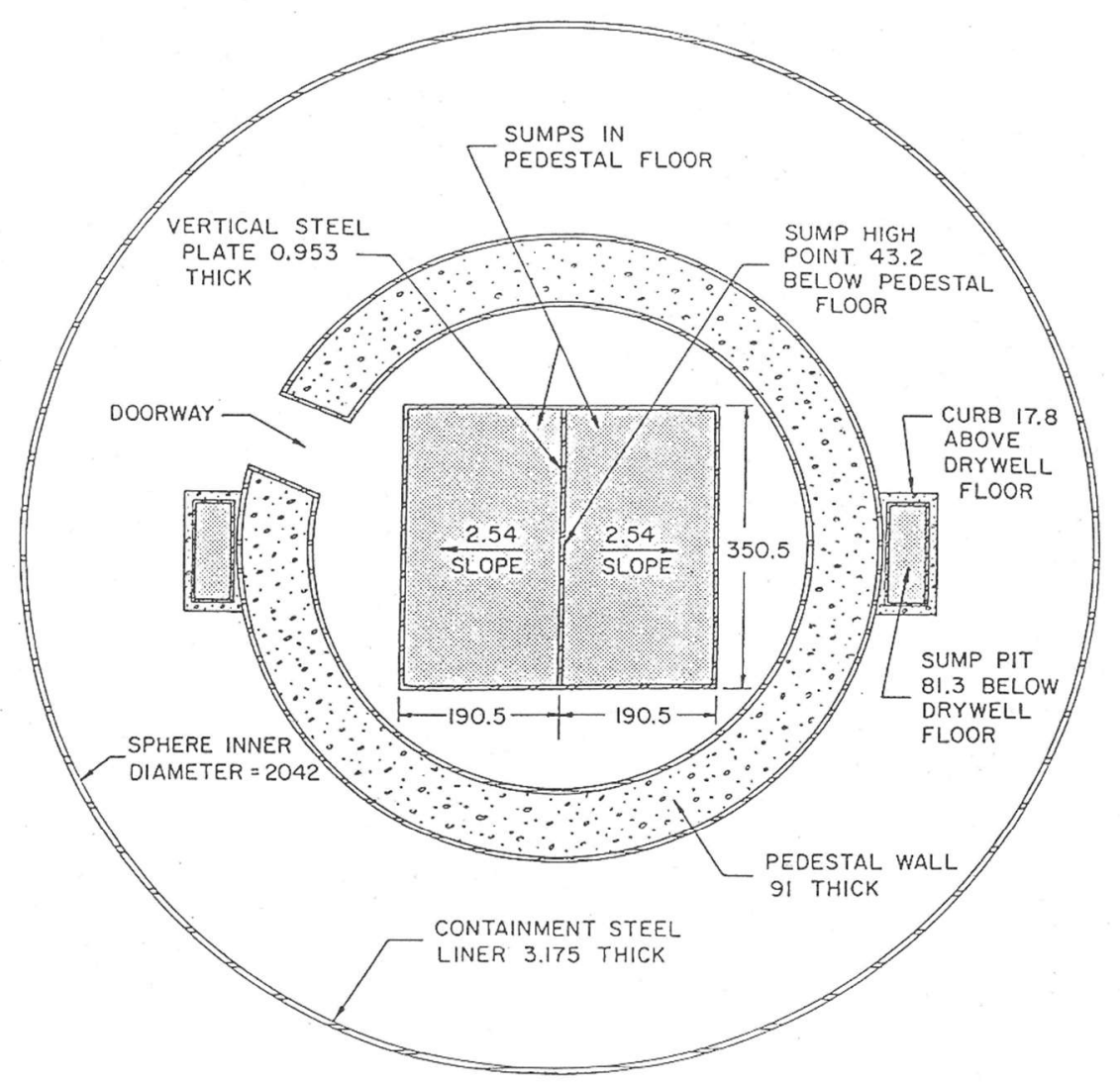

NOTE-ALL DIMENSIONS IN CENTIMETERS

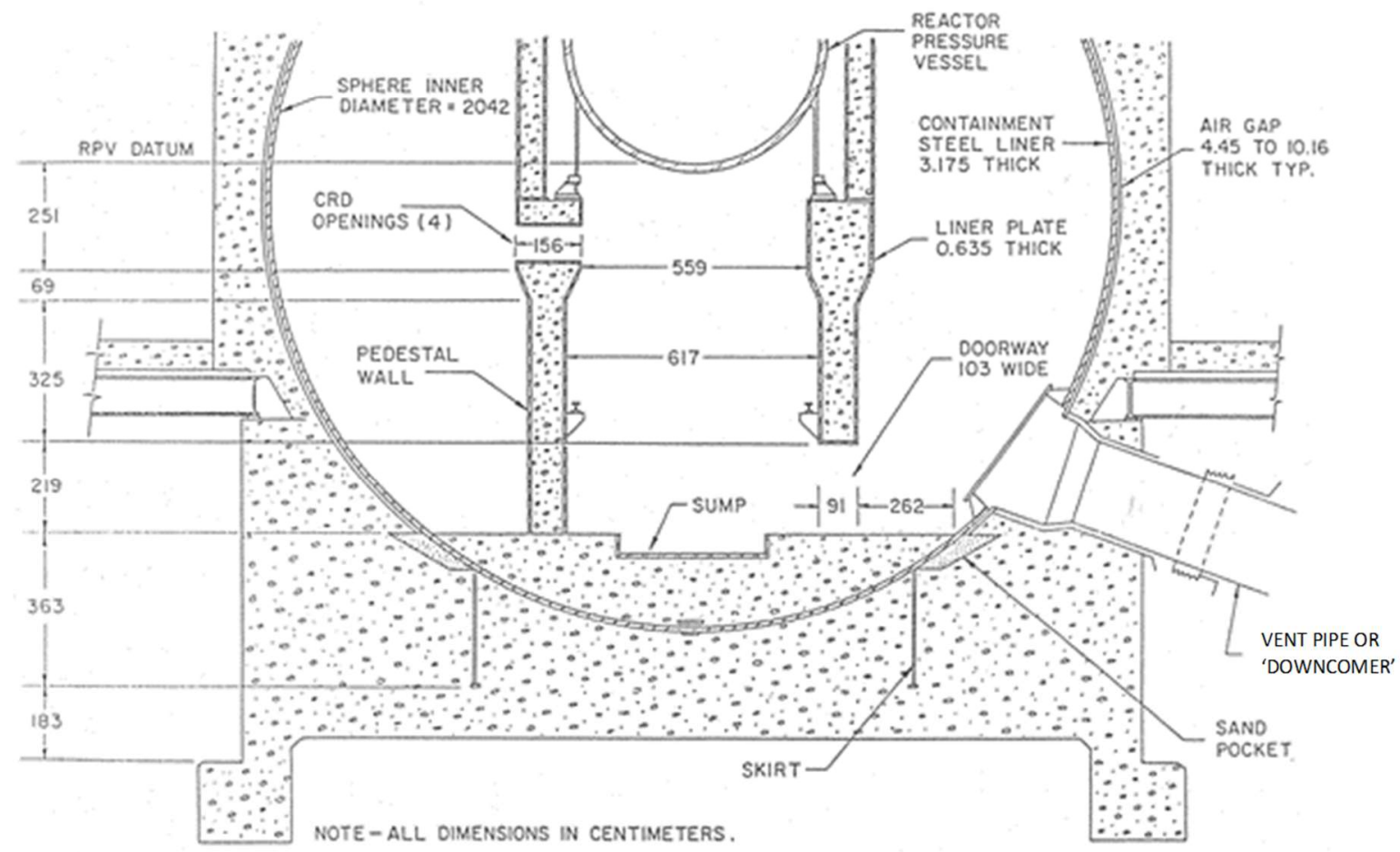

Figure 1-2. Plan (top) and Elevation (bottom) Views of Peach Bottom Containment (Units 2-3). 


\subsection{MELTSPREAD ANALYSES OF CORE DEBRIS SPREADING}

\subsection{MAAP and MELCOR Melt Pour Conditions}

The MAAP5.05 beta [8] and MELCOR v2.1 [9] codes were independently exercised under support from EPRI and DOE-NE, respectively, to evaluate the overall plant response for Peach Bottom during an SBO sequence. These analyses were carried out through the point of reactor vessel failure and discharge of the core melt into the containment. These code results thus provide the time-dependent melt pour rate, temperature, and composition as the material relocates ex-vessel. This information was used as input to MELTSPREAD that was then exercised to evaluate the extent of melt spreading, concrete attack, and combustible gas production during the transient spreading phase following vessel failure. Key input data for the spreading analyses deduced from MELCOR and MAAP outputs are summarized in Table 2-1.

The MELCOR scenario is a low-pressure sequence in which the vessel fails at 12.95 hours, leading to discharge of $\sim 327 \mathrm{MT}$ of core debris into containment over the course of 37 minutes. MELCOR predicts a water depth of $\sim 58 \mathrm{~cm}$ over the cavity floor at onset of the pour. The presence of water is due to steam condensation on cold structures inside containment as well as recirculation pump seal leakage prior to vessel failure. The melt pour rate and cumulative pour mass as the pour progresses are shown in Figures 2-1 and 2-2, respectively. The debris pour rate is highest right after the vessel fails, averaging $13,200 \mathrm{~kg} / \mathrm{sec}$ over the first seven seconds of the transient. The balance of the material ( $240 \mathrm{MT})$ relocates over the following half hour at varying rates, all of which are less than the initial rate. Relocation of most core material (i.e., (U, $\mathrm{Zr}) \mathrm{O}_{2-\mathrm{x}}$ ) occurs over the first 320 seconds; after that time, the pour consists almost entirely of molten stainless steel (see Figure 2-2). Note that this time-dependent composition variation is modeled as part of the MELTPSREAD input and has a significant impact on the results, as is discussed in Section 2.3. The final melt composition (see Table 2-1) consists primarily of core materials with $\sim 15 \%$ of the cladding oxidized. The bulk composition of the debris contains $\sim 29 \mathrm{wt} \%$ structural steel. The temperature of the relocating material is quite low (see Figure 2-3), in the range of 1758 to $1770 \mathrm{~K}$. For the purposes of this analysis, an average core debris temperature of $1765 \mathrm{~K}$ is assumed. Given the debris temperature range predicted by MELCOR for this scenario, the metal phase is predicted to be fully liquid, while the oxide is predicted to be fully solid. The resultant solids content in the material at the time of vessel failure is thus estimated to be $\sim 70$ vol\% (see Table $2-1$ ). The melt is expected (and is calculated) to be quite viscous with this solids fraction content. The decay heat level in the debris at failure (12.95 hours) is equivalent to $120 \mathrm{~W} / \mathrm{kg} \mathrm{UO}_{2}$.

The MAAP scenario is also a low-pressure sequence in which the vessel fails at 14.51 hours, leading to discharge of $\sim 298$ MT of core debris into containment over a time interval of 53 seconds. Ricirculation pump seal leakage is not modeled in this simulation, and so the cavity floor is essentially dry at the time of vessel failure. The melt pour rate and cumulative pour mass as the pour progresses are shown in Figures 2-4 and 2-5, respectively. The pour rate peaks at 8.6 MT/sec at 33 seconds into the transient. In contrast to the MELCOR prediction, the MAAP melt composition is constant (viz. uniformly mixed) over the duration of the pour. As for the 
MELCOR case, the core melt composition (see Table 2-1) consists primarily of core oxides $\left(\mathrm{UO}_{2}-\mathrm{ZrO}_{2}\right)$, but with more cladding oxidation (i.e., $48 \%$ vs. $15 \%$ for MELCOR). In addition, the MAAP prediction of molten steel content is less than MELCOR (i.e., $14 \mathrm{wt} \% \mathrm{vs} .29 \mathrm{wt} \%$ for MELCOR). The debris temperature during the pour is $\sim 2240 \mathrm{~K}$ over most of the transient until near the end, at which point the temperature drops substantially; see Figure 2-6. Given the core debris temperature range predicted by MAAP, the metal phase is predicted to be fully liquid, while the oxide is predicted to be fully solid (i.e., same as the MELCOR prediction). The resultant solids content in the core debris at the time of vessel failure is thus estimated to be $\sim 69$ vol\%, virtually the same as with the MELCOR model (see Table 2-1). As for the MELCOR pour, the melt is quite viscous with this solids content. The decay heat level in the debris at the time of vessel failure (14.51 hours) is equivalent to $104 \mathrm{~W} / \mathrm{kg} \mathrm{UO}_{2}$, which is $\sim 13 \%$ less than the MELCOR prediction.

Table 2-1. Melt Spreading Input Data from MELCOR and MAAP Simulations for Peach Bottom.

\begin{tabular}{|c|c|c|}
\hline Case Designator & MELCOR & MAAP \\
\hline Sequence description & $\begin{array}{l}\text { Vessel failure at } \\
\text { low pressure }\end{array}$ & $\begin{array}{l}\text { Vessel failure at } \\
\text { low pressure }\end{array}$ \\
\hline Onset of Pour (hours) & 12.95 & 14.51 \\
\hline Pour Duration (sec) & 2223 & 53 \\
\hline Containment Pressure (MPa) & 0.40 & 0.44 \\
\hline Water level/temp. on cavity floor at vessel failure $(\mathrm{cm} / \mathrm{K})$ & $58 / 336$ & 'Dry' \\
\hline Melt Pour Temperature (K) & $\begin{array}{l}1758-1770 \\
\text { Figure 2-3 }\end{array}$ & $\begin{array}{c}934-2240 \\
\text { See Figure 2-6 }\end{array}$ \\
\hline Oxide Phase Solidus-Liquidus Temperatures $(\mathrm{K}-\mathrm{K})^{\mathrm{a}}$ & $2127-2505$ & $2249-2595$ \\
\hline Metal Phase Solidus-Liquidus Temperatures $(\mathrm{K}-\mathrm{K})^{\mathrm{a}}$ & $1723-1748$ & $1808-1820$ \\
\hline Melt Solid Fraction at Temperature $(-)^{\mathrm{a}}$ & 0.696 & 0.689 \\
\hline Opening size in vessel at end of pour $(\mathrm{cm})$ & Not calculated & $30 \mathrm{~cm}$ \\
\hline Decay Heat at Relocation (W/kg fuel) & 120 & 104 \\
\hline \multicolumn{3}{|l|}{ Total Pour Mass of Melt Constituent (kg) } \\
\hline $\mathrm{UO}_{2}$ & 154760 & 158870 \\
\hline $\mathrm{Zr}$ & 48684 & 36398 \\
\hline $\mathrm{ZrO}_{2}$ & 11932 & 44864 \\
\hline $\mathrm{Cr}$ & 18856 & 3208 \\
\hline $\mathrm{Cr}_{2} \mathrm{O}_{3}$ & 1429 & 2481 \\
\hline $\mathrm{Fe}$ & 77521 & 38292 \\
\hline $\mathrm{FeO}$ & 5199 & 9884 \\
\hline $\mathrm{Ni}$ & 8381 & 1595 \\
\hline $\mathrm{NiO}$ & 553 & 1013 \\
\hline $\mathrm{B}_{4} \mathrm{C}$ & 0 & 1788 \\
\hline Total & 327315 & 298393 \\
\hline
\end{tabular}

${ }^{\mathrm{a}}$ Calculated with CORQUENCH subroutines given composition and melt pour temperature. 


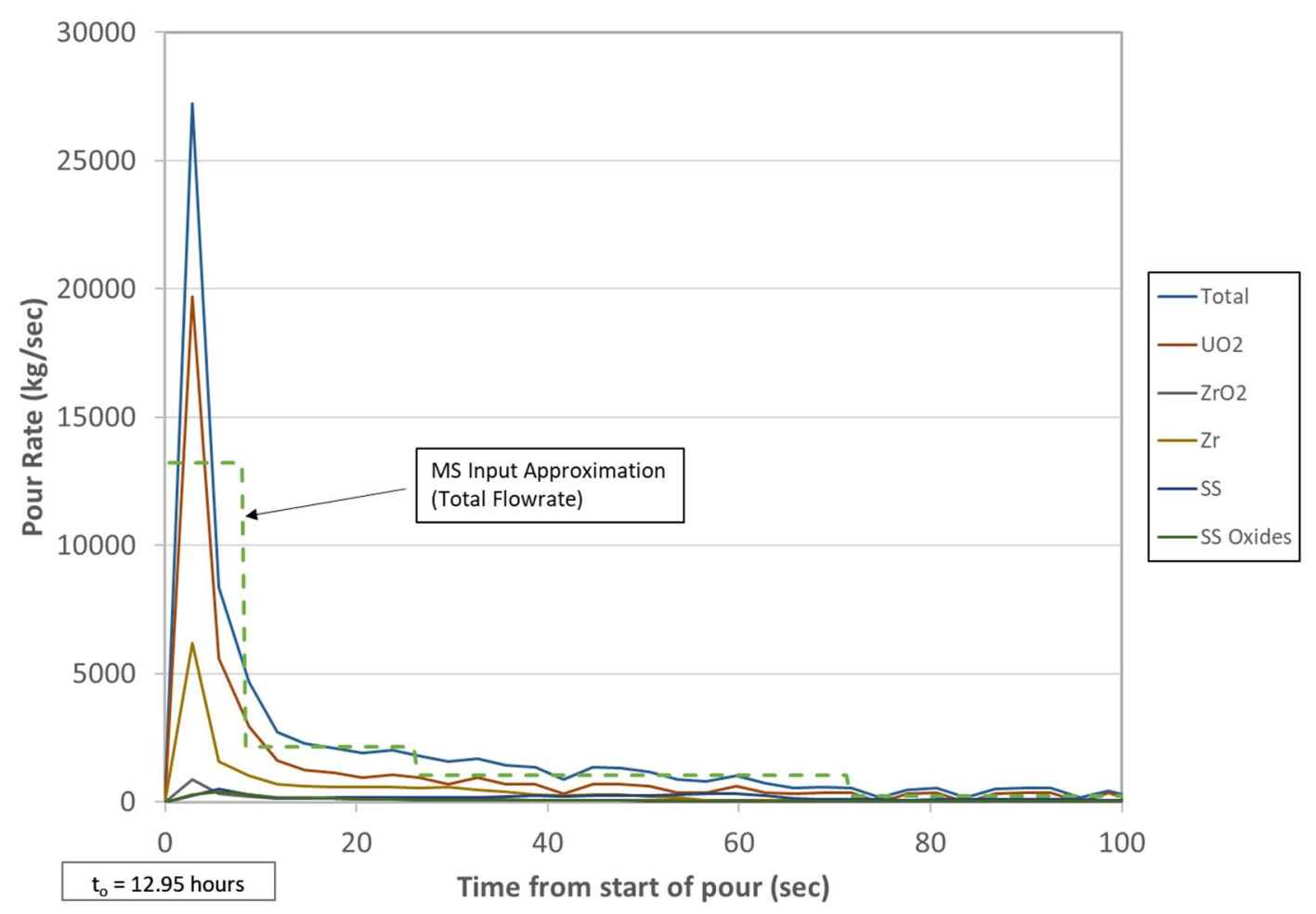

Figure 2-1. MELCOR Prediction of Melt Pour Rate for an SBO sequence at Peach Bottom.

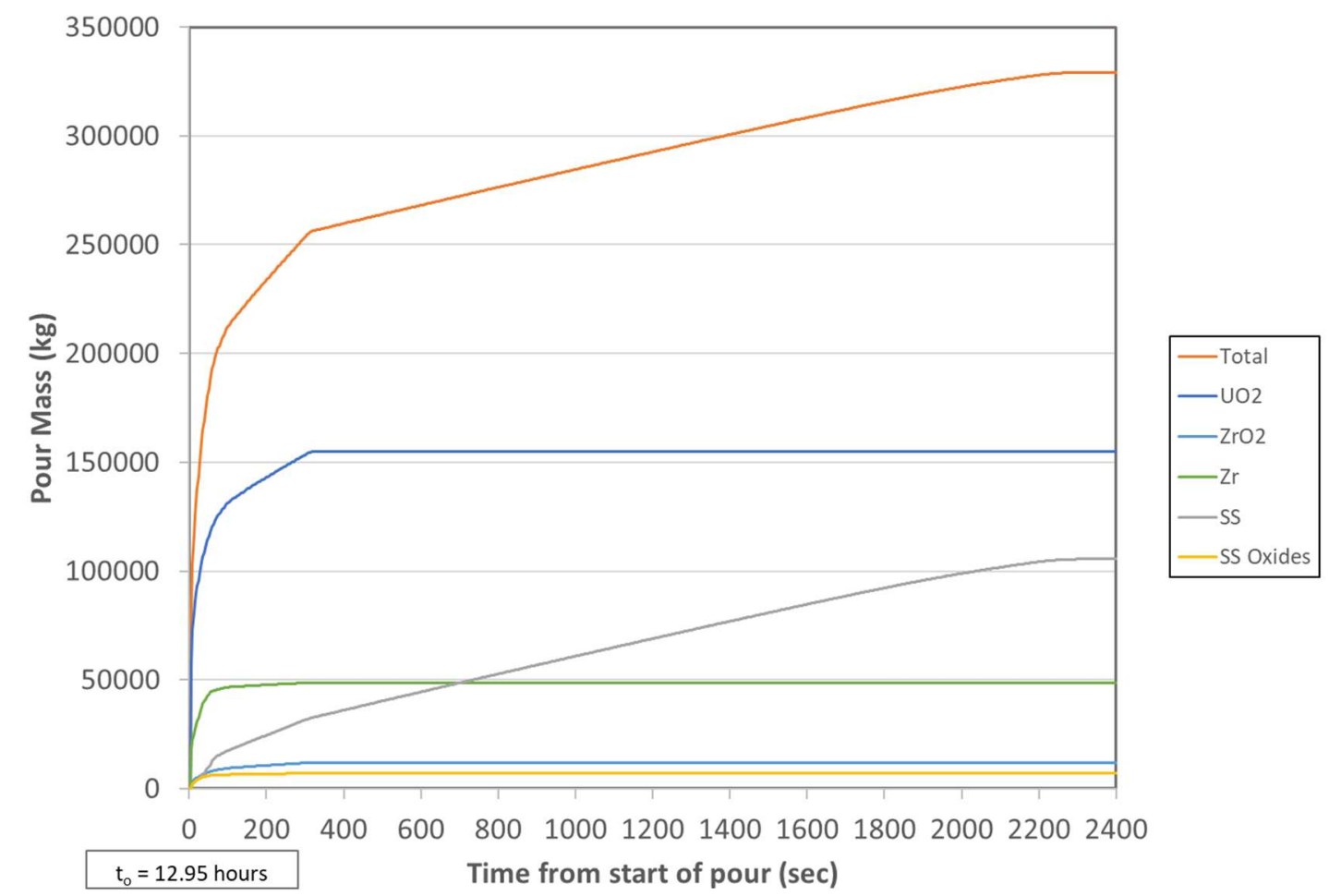

Figure 2-2. MELCOR Prediction of Cumulative Melt Pour Mass for an SBO sequence at Peach Bottom. 


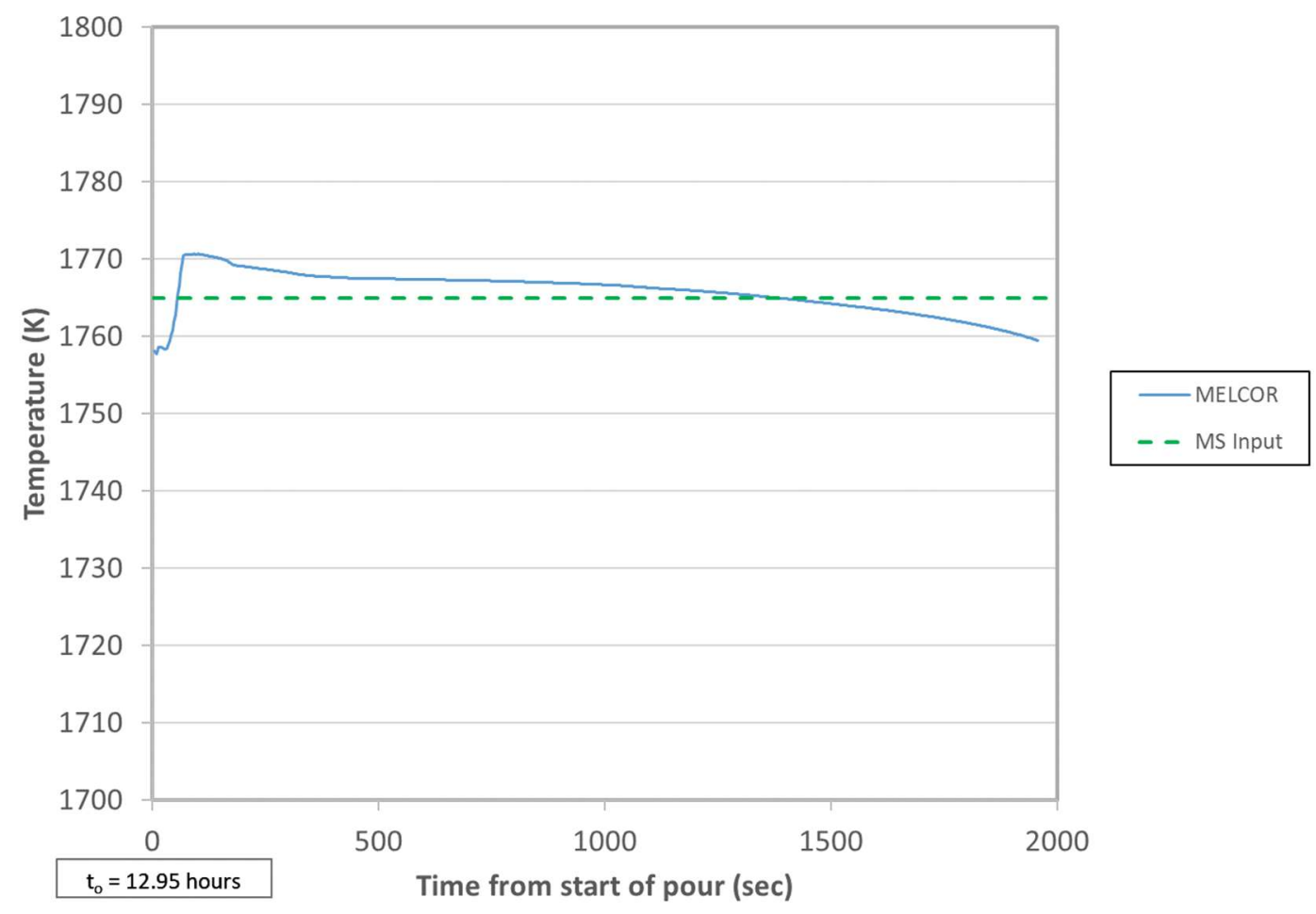

Figure 2-3. MELCOR Prediction of Melt Pour Temperature for an SBO sequence at Peach Bottom.

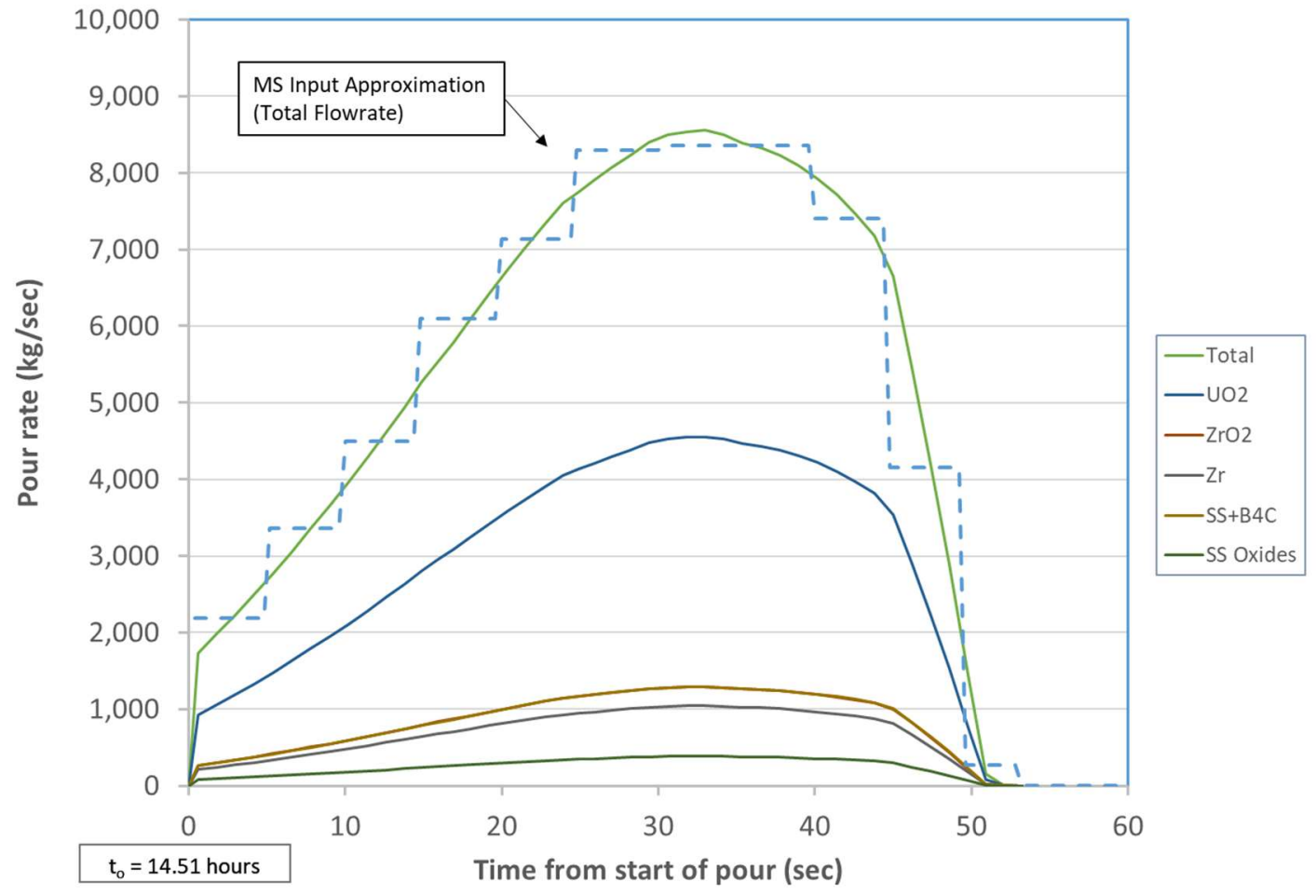

Figure 2-4. MAAP Prediction of Melt Pour Rate for an SBO sequence at Peach Bottom. 


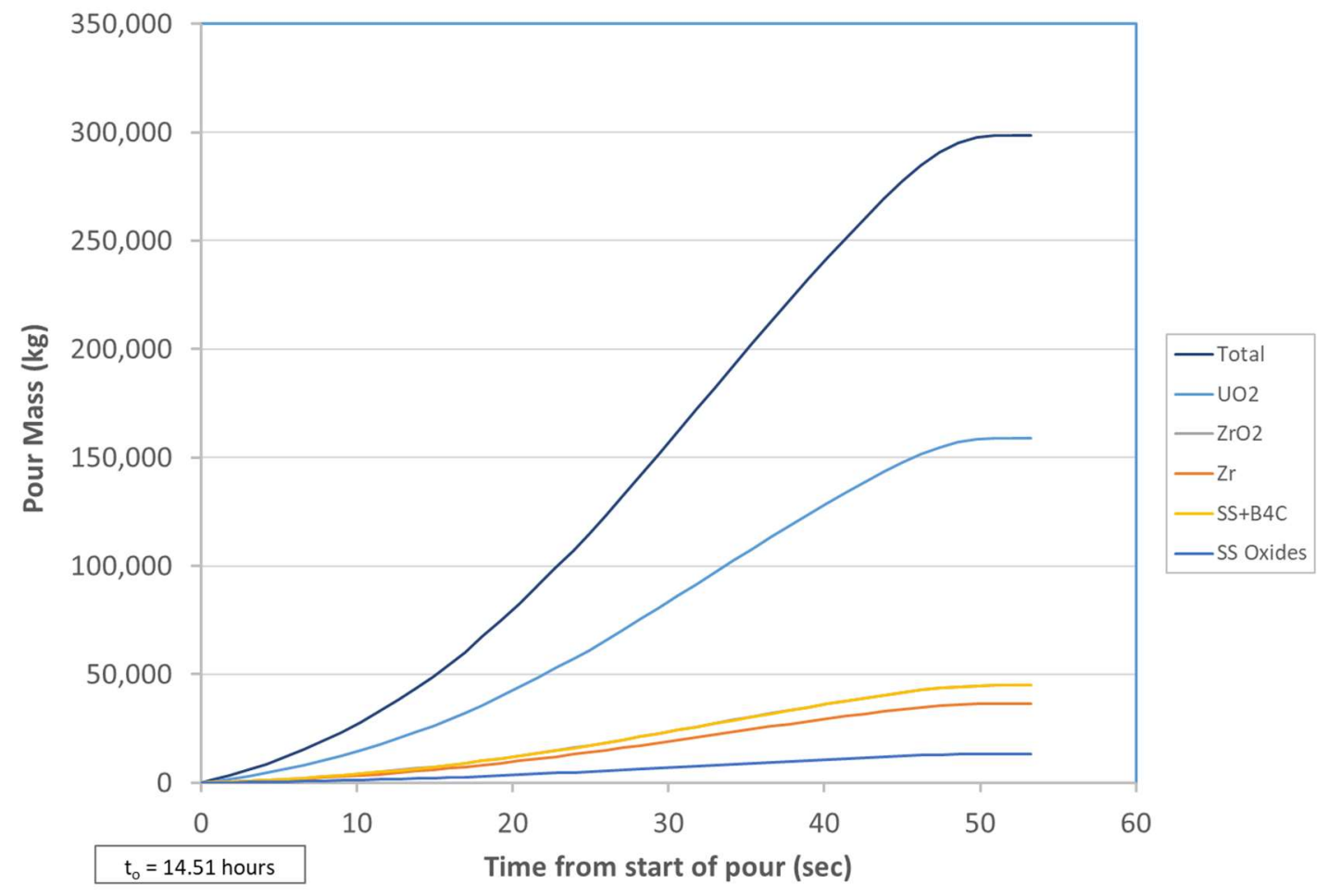

Figure 2-5. MAAP Prediction of Cumulative Melt Pour Mass for an SBO sequence at Peach Bottom.

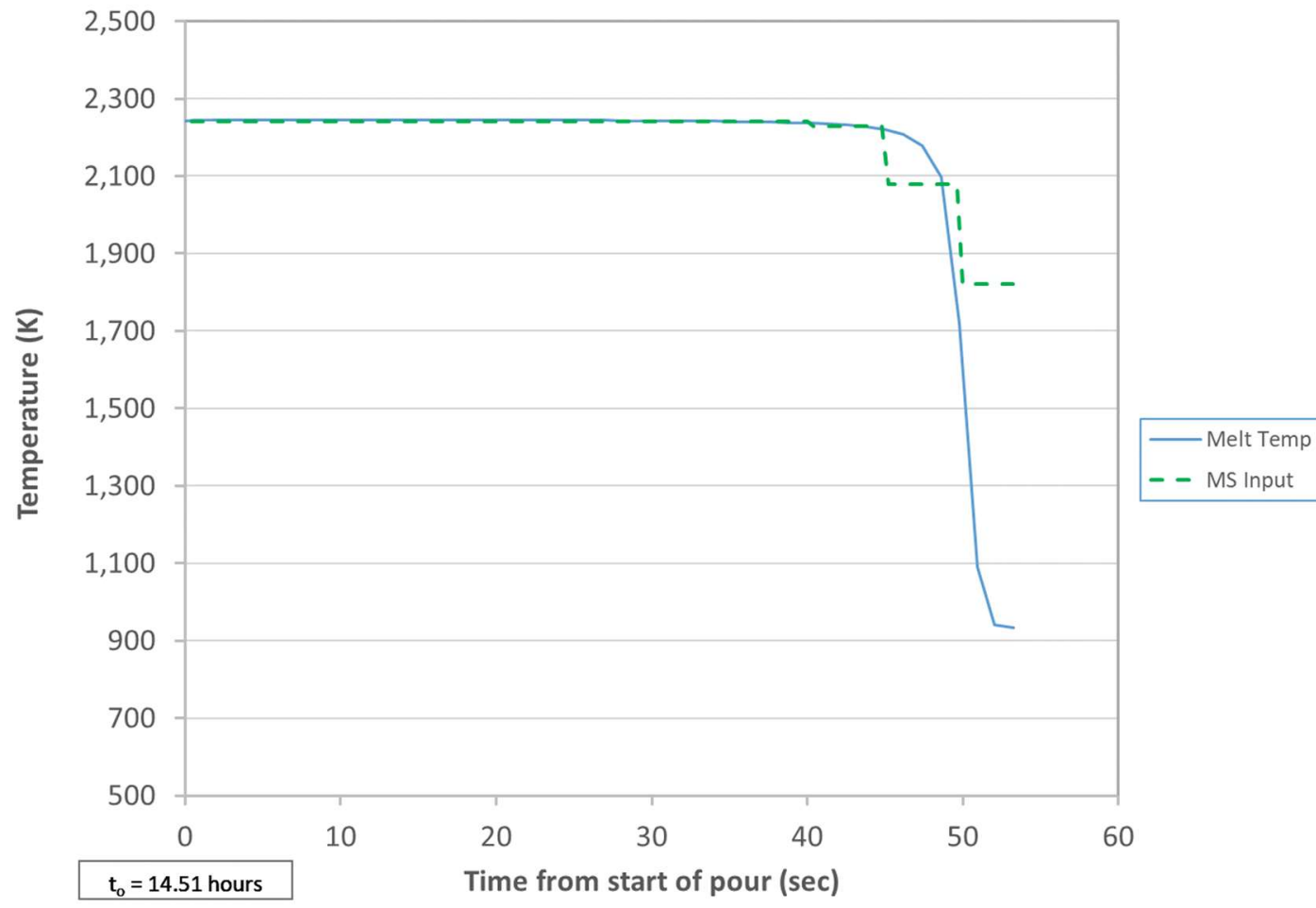

Figure 2-6. MAAP Prediction of Melt Pour Temperature for an SBO sequence at Peach Bottom. 
In an earlier ex-vessel study conducted soon after the accidents at Fukushima Daiichi occurred [3], MAAP and MELCOR were exercised to provide melt pour data following vessel failure for Unit 1. In that study [3], it was noted the melt pour conditions predicted by these two codes varied considerably for the given accident sequence. In particular, the conditions ranged from a slow, gradual pour of a viscous low-temperature melt (MELCOR scenario) to the rapid pour of superheated core material with low viscosity (MAAP scenario). Since that time, additional model development work has been carried out on both codes. The results of this more recent comparison for an SBO sequence at Peach Bottom indicates that the pour conditions for the two codes are tending towards one another, with the MELCOR pour occurring at a slightly increased rate but still at low temperature, while the MAAP pour is of slightly lower flowrate and significantly lower temperature. Data to determine which scenario is more realistic are currently lacking, but the hope is that insights from the ongoing Fukushima Forensics [10] program will provide some modelling guidance.

\subsection{Modelling Assumptions}

In terms of the cavity characteristics, the Peach Bottom containment is a General Electric Mark I design (Figure 1-2). The reactor vessel lower head is $8 \mathrm{~m}$ above the pedestal floor. Interior to the pedestal, there are two adjoined sumps located directly beneath the reactor vessel. Both sumps are rectilinear in cross section $(1.9 \mathrm{~m}$ by $3.5 \mathrm{~m})$ and have an average depth of 44.5

$\mathrm{cm}$. During normal operations, the sumps are covered with steel plates that are $6.35 \mathrm{~mm}(5 / 8$ inch) thick. The internal radius of the pedestal wall is $3.09 \mathrm{~m}$, and the pedestal wall thickness is $91 \mathrm{~cm}$. There is a single doorway from the pedestal to the drywell annulus that is $91 \mathrm{~cm}$ wide. The radius of the drywell shell is $6.62 \mathrm{~m}$ where the shell contacts the drywell floor. The steel liner is $3.18 \mathrm{~cm}$ thick. There are 8 uniformly spaced downcomers from the drywell to the wetwell, each of which is $2.06 \mathrm{~m}$ (81 inches) in diameter with the lower lip of the downcomer located $61 \mathrm{~cm}$ (24 inches) above the drywell floor.

Due to the one-dimensional modelling limitations of the code, the two drywell sumps are combined into a single geometric entity that consists of cylinder located at the pedestal centerline that is $2.06 \mathrm{~m}$ in diameter and $44.5 \mathrm{~cm}$ deep. Thus, in the nodalization process the sump volume, cross-sectional areas, and depth are conserved. Core material relocating from the reactor pressure vessel is assumed to drain directly into the sump. Although MELTSPREAD is able to calculate heatup, ablation, and subsequent failure of the sump cover plates, that option was not invoked as part of this study. The sump is discretized into 10 cylindrical mesh cells with a uniform radial incremental thickness of $20.6 \mathrm{~cm}$. Melt flow from the vessel is assumed to be deposited in the first node located directly below the RPV. The balance of the drywell floor from the sump edge to the pedestal inner wall is discretized into 10 cylindrical mesh cells with a uniform radial incremental thickness of $10.3 \mathrm{~cm}$. Flow through the pedestal doorway is assumed to occur in a one-dimensional channel; the $0.91 \mathrm{~m}$ flow distance is discretized into 10 nodes of equal size $(9.1 \mathrm{~cm})$. Outside the pedestal doorway, the core melt is assumed to spread in a $90^{\circ}$ sector to the shell. The total distance of $2.62 \mathrm{~m}$ from the pedestal outer wall to the drywell shell 
is discretized into 26 nodes of equal size $(10.08 \mathrm{~cm})$. After the melt contacts the liner, the flow is assumed to be diverted symmetrically into the two sides of the annulus. A courser discretization was used in the annulus that was treated as a 1-D flow channel; i.e., 80 nodes were used to model this area resulting in a uniform cell size of $19.13 \mathrm{~cm}$ long by $5.24 \mathrm{~m}$ wide $(5.24 \mathrm{~m}$ is equivalent to twice the drywell annulus thickness, which is based on the assumption of symmetrical flow diversion outside the pedestal doorway). Inlets to the 'four' (i.e., two symmetrically combined) downcomers are uniformly distributed at discrete nodes within the drywell in order to capture water overflow to the wetwell during the spreading phase for those cases in which water is initially present on the drywell floor. The new detailed water inventory model [6] was used for all cases with water initially present.

MELTSPREAD is equipped with a model that can calculate the heat-up of the drywell liner due to impingement heat transfer from the relocating melt by solving the two-dimensional transient heat conduction equation in the shell, including the effects of transient crust growth on the shell surface. To this end, the $3.18 \mathrm{~cm}$ thick shell is discretized into 5 mesh cells of $6.3 \mathrm{~mm}$ size perpendicular to the shell surface, and 100 cells that are $1.5 \mathrm{~cm}$ long $(150 \mathrm{~cm}$ total length) parallel to the shell surface. The shell is assumed to be inclined at an angle of $45^{\circ}$ with respect to vertical where it makes contact with the drywell floor (this assumption is important since it affects the length of the shell covered by melt given the actual depth of material adjacent to the shell). The heat transfer coefficient from the melt to the shell surface is conservatively modeled as the sum of forced convection (i.e., slot jet impingement; see Martin [11]) and bubble-driven recirculation (see Theofanous et al. [12]) correlations. Conversely, if the debris solidifies adjacent to the shell, then the long-term heat transfer is evaluated using a simplified 1-D transient heat transfer model from the debris to the shell.

Below-vessel structure is extensive in BWRs, primarily consisting of CRDs and instrument tube penetrations, as well as a catwalk for personnel access to this equipment. These structures may impact melt relocation behavior by providing heat sink for freeze-out of material, as well as potentially creating a rain-drop effect that can reduce impingement heat transfer (see Figure 1-1). Recent robotic examinations at Fukushima Daichii seem to indicate a significant amount of debris holdup on this structure [13]. Stand-alone models for evaluating this behavior are currently under development [5] but have not yet been completed. Thus, this effect is neglected in the current study.

For cases in which water is present on the drywell floor as an initial condition, melt jet fragmentation and cooling prior to impact with the drywell floor is calculated. In terms of modelling assumptions regarding this behavior, the melt jet fall height is taken equal to the RPV height of $8 \mathrm{~m}$ over the pedestal floor. As noted above, core debris is assumed to drain from the RPV into the sump. MAAP calculates the time-dependent hole size in the reactor vessel during the pour. For the case described in Section 2.1, the hole is ablated from the initial CRD opening size (i.e., diameter) of $20 \mathrm{~cm}$ to a final size of $\sim 30 \mathrm{~cm}$ at the end of the pour (see Table 2-1). For the purposes of this study the diameter is assumed constant at the final hole size of 30 $\mathrm{cm}$. MELCOR does not perform a mechanistic analysis of the melt pour involving hole ablation 
of the RPV lower head. Thus, a constant hole diameter of $30 \mathrm{~cm}$ is assumed for this scenario also. Two modelling options are provided in MELTSPREAD for assessing the impact of jet fragmentation on the melt arrival conditions on the pedestal floor. In the first approach, any particulate formed is assumed to re-mix with the melt, which acts to lower (through a thermal equilibration calculation) the effective melt temperature at impact with the floor. This increases viscosity which acts to lower the spreading velocity. In the second approach, the debris fragmented from the jet is assumed to be rendered as a particle bed that resides on top of the remaining coherent melt material that lands and then spreads on the concrete. The assumption is made that the cooling of the remaining coherent jet is minimal, and this material impacts and spreads at the vessel exit temperature. Thus, in this scenario melt temperature is the same, but the melt mass available for spreading is reduced. Based on physical observations from reactor material jet fragmentation tests (i.e. the Argonne Corium Coolant Mixing (CCM) [14] and FARO tests conducted at ISPRA [15]), the latter scenario is deemed to be more realistic and is invoked as part of this study. The fragmented debris is assumed to be uniformly deposited over all nodes within the pedestal with a uniform porosity of $40 \%$.

The basemat concrete in Peach Bottom is a limestone-common sand type. The specific composition for this study was taken equal to the default limestone-common sand concrete composition that can be selected as part of the MELCOR input [9]; see Table 2-2. The concrete is noted to have an iron content of $13.5 \mathrm{wt} \%$ in the form of rebar.

Table 2-2. Assumed Peach Bottom Concrete Composition (Limestone-common sand [9]).

\begin{tabular}{|c|c|}
\hline Constituent & Weight \% \\
\hline $\mathrm{Al}_{2} \mathrm{O}_{3}$ & 0.79 \\
\hline $\mathrm{FeO}$ & 0.54 \\
\hline $\mathrm{CaO}$ & 29.27 \\
\hline $\mathrm{MgO}$ & 0.38 \\
\hline $\mathrm{CO}_{2}$ & 17.82 \\
\hline $\mathrm{SiO}_{2}$ & 31.53 \\
\hline $\mathrm{H}_{2} \mathrm{O}($ free $)$ & 3.88 \\
\hline $\mathrm{H}_{2} \mathrm{O}$ (bound) & 2.29 \\
\hline Fe & 13.50 \\
\hline Total & 100.00 \\
\hline
\end{tabular}

Other important modelling assumptions are as follows. The heat transfer coefficient from the melt to the surface of the core debris is calculated as the larger of the following two correlations: i) the well-known Dittus-Boelter forced convection correlation with the hydraulic diameter based on local melt depth, and ii) Bradley's bubble agitation-driven heat transfer model that is applicable to MCCI conditions [16]. This is the same modelling option used in the MELTSPREAD validation exercises [6] for cases involving melt spreading over concrete surfaces. With this assumption, the code is expected to provide a best estimate of the melt 
penetration distance in containment. In addition, the empirical constant in the Ramacciotti melt viscosity correlation [17] that is used in MELTSPREAD is set equal to the best-estimate value in all analyses carried out as part of this study. This best estimate value was deduced on the basis of the code validation exercises. This assumption is again consistent with providing best estimate melt penetration distances in containment.

Aside from these assumptions, the containment pressure during the spreading transient was assumed to be $0.4 \mathrm{MPa}$ for both scenarios. For dry situations, the debris is cooled by radiation heat transfer to overlying structure that is assumed to have an emissivity of 0.3 (typical of steel). In this case, the boundary temperature is also assumed to be at containment saturation temperature. MELTSPREAD currently does not model heat-up of overlying structure during the spreading transient. Thus, the use of the low radiation boundary temperature $(414 \mathrm{~K})$ is roughly equivalent to assuming radiation heat transfer to an infinite heat sink. The initial basemat concrete temperature was set to the same values assumed in the MAAP and MELCOR code runs. For dry cases, the initial shell temperature was set to the initial concrete temperature. For flooded cavity cases, the initial shell temperature was set to the initial water temperature. For all flooded cavity cases, the initial water temperature was set to the value calculated by MELCOR; i.e., $384 \mathrm{~K}$. The time step for all cases was $5 \mathrm{~ms}$; this value has been shown to provide rapid convergence in all applications of this type.

\subsection{Definition of Parametric Cases for MAAP and MELCOR Scenarios}

Given the input data and modelling assumptions described above, a base case plus eight additional cases that parameterized on melt pour temperature and initial water depth were carried out for both MAAP and MELCOR scenarios; see Table 2-3. The 'base case' for each scenario corresponds to the initial and boundary conditions summarized at a high level in Table 2-1. Given the specific melt pour rates described in Section 2.1, cases were carried out with $0 \mathrm{~cm}, 30$ $\mathrm{cm}$, and $58 \mathrm{~cm}$ water depths on the cavity floor. The dry floor condition is the base case for the MAAP scenario, whereas the $58 \mathrm{~cm}$ water depth condition is the base case for the MELCOR scenario. For both scenarios, the initial melt temperature is below the oxide phase solidus based on CORQUENCH [7] core debris material property models. Thus, the parametric runs cover the base cases for which the melt temperatures are those calculated by MAAP and MELCOR, as well as cases in which the melt temperature is slightly superheated by 25 and $50 \mathrm{~K}$, respectively, above the oxide solidus. Thus, in total 18 calculations were performed spanning dry cavity conditions to conditions in which the cavity is flooded with subcooled water to just below the inlet to the downcomers. In addition, initial melt temperatures range from below the oxide solidus (with $\sim 70 \%$ solids fraction) to $50 \mathrm{~K}$ above the oxide solidus, at which point the solids fraction has been reduced to $\sim 50$ vol\%. 
Table 2-3. Melt Pour Temperatures and Cavity Water Levels for Parametric Studies.

\begin{tabular}{|c|c|c|}
\hline Case & MAAP & MELCOR \\
\hline $0 \mathrm{~K}-0 \mathrm{~cm}$ & $\begin{array}{l}\text { Base Case: } \\
\text { - } \mathrm{T}_{\text {melt }} \text { per Figure 2-6 } \\
\text { - Dry cavity }\end{array}$ & $\begin{array}{l}\text { - } \mathrm{T}_{\text {melt }} \text { per Figure } 2-3 \\
\text { - } \text { Dry cavity }\end{array}$ \\
\hline $0 \mathrm{~K}-30 \mathrm{~cm}$ & $\begin{array}{l}\text { - } \mathrm{T}_{\text {melt }} \text { per Figure } 2-6 \\
\text { - Initial water depth on floor }=30 \mathrm{~cm}\end{array}$ & $\begin{array}{l}\text { - } \mathrm{T}_{\text {melt }} \text { per Figure } 2-3 \\
\text { - Initial water depth on floor }=30 \mathrm{~cm}\end{array}$ \\
\hline $0 \mathrm{~K}-58 \mathrm{~cm}$ & $\begin{array}{l}\text { - } \mathrm{T}_{\text {melt }} \text { per Figure 2-6 } \\
\text { - } \text { Initial water depth on floor }=58 \mathrm{~cm}\end{array}$ & $\begin{array}{l}\text { Base Case: } \\
\text { - } \quad \mathrm{T}_{\text {melt }} \text { per Figure } 2-3 \\
\text { - } \quad \text { Initial water depth on floor }=58 \mathrm{~cm}\end{array}$ \\
\hline $25 \mathrm{~K}-0 \mathrm{~cm}$ & $\begin{array}{l}\text { - } \mathrm{T}_{\text {melt }}=2274 \mathrm{~K}\left(\mathrm{~T}_{\mathrm{ox}, \mathrm{sol}}+25 \mathrm{~K}\right) \\
\text { - Dry cavity }\end{array}$ & $\begin{array}{l}\left.\text { - } \mathrm{T}_{\text {melt }}=2152 \mathrm{~K} \text { (oxide solidus }+25 \mathrm{~K}\right) \\
\text { - Dry cavity }\end{array}$ \\
\hline $25 \mathrm{~K}-30 \mathrm{~cm}$ & $\begin{array}{l}\left.\text { - } \mathrm{T}_{\text {melt }}=2274 \mathrm{~K} \text { (oxide solidus }+25 \mathrm{~K}\right) \\
\text { - } \quad \text { Initial water depth on floor }=30 \mathrm{~cm}\end{array}$ & $\begin{array}{ll} & \left.\mathrm{T}_{\text {melt }}=2152 \mathrm{~K} \text { (oxide solidus }+25 \mathrm{~K}\right) \\
\text { - } & \text { Initial water depth on floor }=30 \mathrm{~cm}\end{array}$ \\
\hline $25 \mathrm{~K}-58 \mathrm{~cm}$ & $\begin{array}{l}\text { - } \mathrm{T}_{\text {melt }}=2274 \mathrm{~K} \text { (oxide solidus }+25 \mathrm{~K} \text { ) } \\
\text { - Initial water depth on floor }=58 \mathrm{~cm}\end{array}$ & $\begin{array}{ll}\text { - } & \left.\mathrm{T}_{\text {melt }}=2152 \mathrm{~K} \text { (oxide solidus }+25 \mathrm{~K}\right) \\
\text { - } & \text { Initial water depth on floor }=58 \mathrm{~cm}\end{array}$ \\
\hline $50 \mathrm{~K}-0 \mathrm{~cm}$ & $\begin{array}{l}\left.\text { - } \mathrm{T}_{\text {melt }}=2299 \mathrm{~K} \text { (oxide solidus }+50 \mathrm{~K}\right) \\
\text { - Dry cavity }\end{array}$ & $\begin{array}{l}\text { - } \mathrm{T}_{\text {melt }}=2177 \mathrm{~K}(\text { oxide solidus }+50 \mathrm{~K}) \\
\text { - Dry cavity }\end{array}$ \\
\hline $50 \mathrm{~K}-30 \mathrm{~cm}$ & $\begin{array}{l}\left.\text { - } \mathrm{T}_{\text {melt }}=2299 \mathrm{~K} \text { (oxide solidus }+50 \mathrm{~K}\right) \\
\text { - Initial water depth on floor }=30 \mathrm{~cm}\end{array}$ & $\begin{array}{ll} & \mathrm{T}_{\text {melt }}=2177 \mathrm{~K} \text { (oxide solidus }+50 \mathrm{~K} \text { ) } \\
\text { - } & \text { Initial water depth on floor }=30 \mathrm{~cm}\end{array}$ \\
\hline $50 \mathrm{~K}-58 \mathrm{~cm}$ & $\begin{array}{l}\left.\text { - } \mathrm{T}_{\text {melt }}=2299 \mathrm{~K} \text { (oxide solidus }+50 \mathrm{~K}\right) \\
\text { - Initial water depth on floor }=58 \mathrm{~cm}\end{array}$ & $\begin{array}{l}\left.\text { - } \mathrm{T}_{\text {melt }}=2177 \mathrm{~K} \text { (oxide solidus }+50 \mathrm{~K}\right) \\
\text { - Initial water depth on floor }=58 \mathrm{~cm}\end{array}$ \\
\hline
\end{tabular}

\subsection{MELCOR Melt Spreading Results}

To review, in this scenario vessel failure leads to an initial, relatively rapid discharge of a low temperature, predominately oxidic core melt into the pedestal region. This is followed by a longer duration, predominately metallic, low flowrate pour that eventually ends at 37 minutes (see Table 2-1 and Figures 2-1 through 2-3). The pour temperature is relatively constant and in the range where the metal phase is expected to be entirely liquid, while the oxide is solid. According to the MELTSPREAD property routines, during the initial oxidic pour phase the viscosity of the core debris is $\sim 1100 \mathrm{~Pa} \cdot \mathrm{sec}$, which is the same order-of-magnitude as molten glass. ${ }^{1}$ Thus, the flow is expected to be dominated by viscous effects during this interval. However, during the latter metal pour phase the melt is a liquid with a viscosity that is approximately five orders of magnitude less (i.e., to $\sim 50 \mathrm{~m} \mathrm{~Pa} \cdot \mathrm{sec}$ ).

Plots showing the cumulative floor area coverage as a function of time and final (postspread) debris distributions in containment for all nine MELCOR cases are provided in Figures 2-7 and 2-8, respectively. To illustrate the dynamic spreading behavior, a series of snapshots showing the evolution of melt and water depths as well as melt temperature for the MELCOR base case are provided in Figure 2-9. Finally, key thermal hydraulic results are tabulated in Table 2-4 for all cases.

\footnotetext{
${ }^{1}$ See e.g. http://en.wikipedia.org/wiki/Viscosity
} 


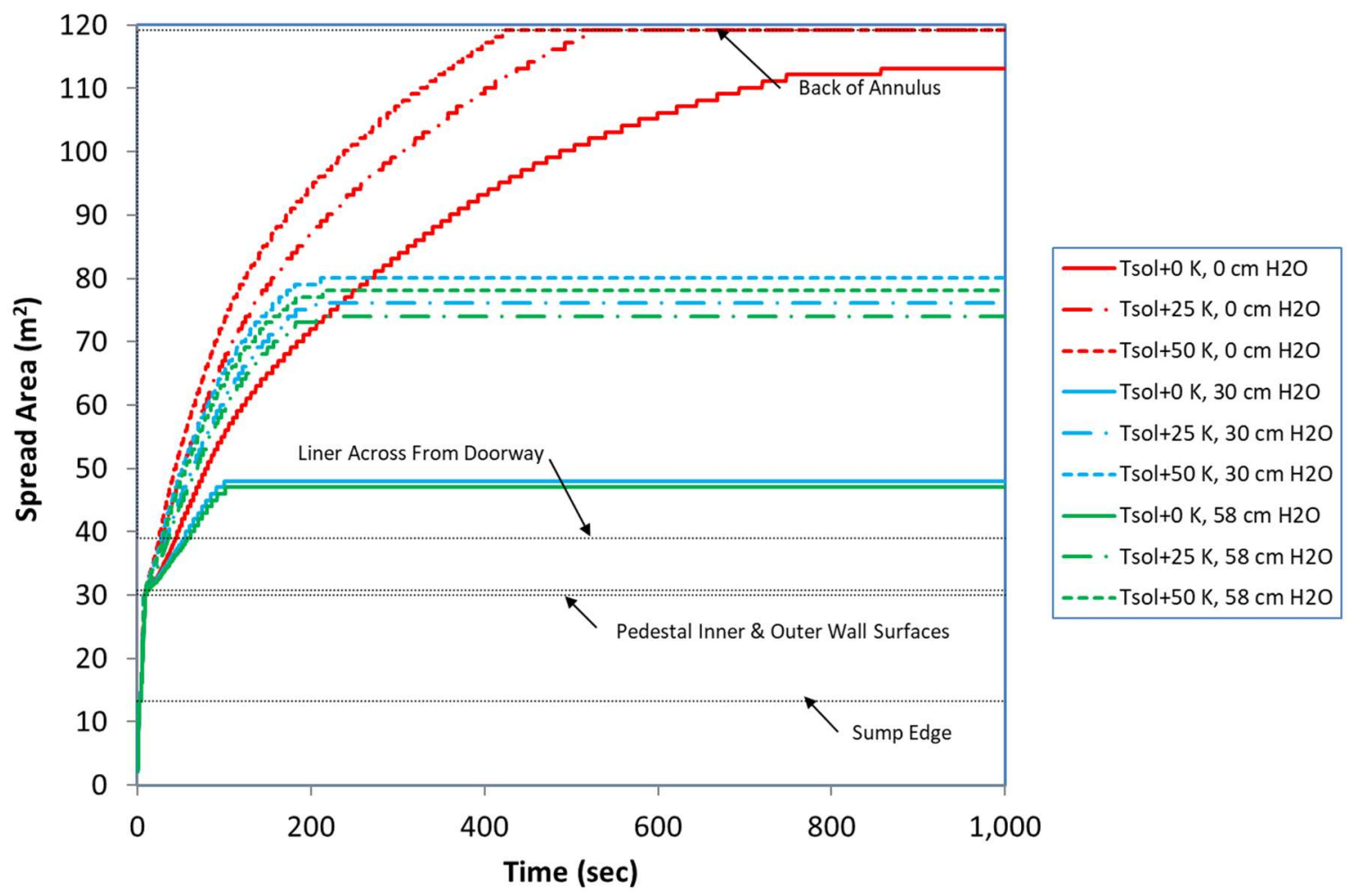

Figure 2-7. Basemat Floor Area Covered by Core Debris for the MELCOR Cases.

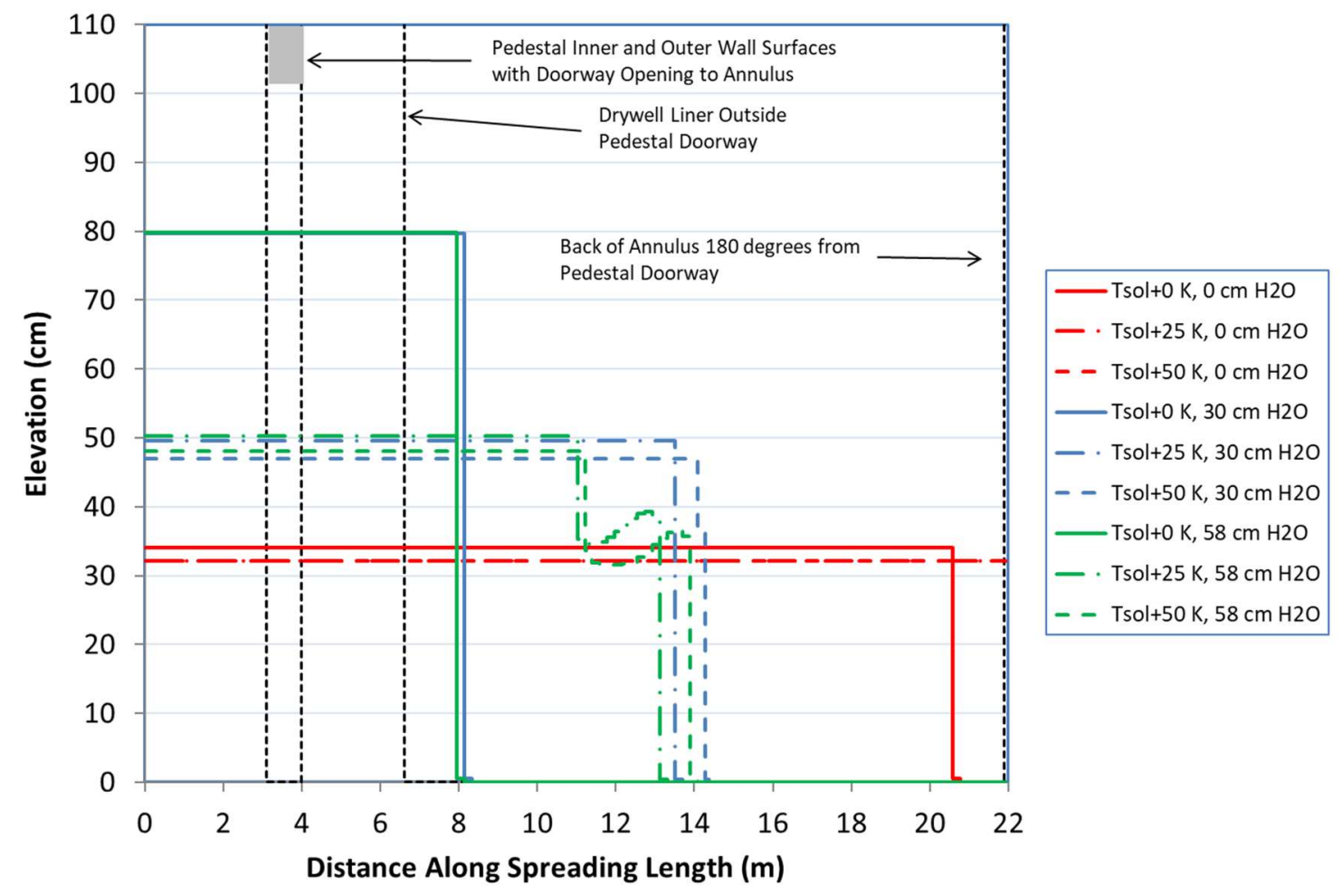

Figure 2-8. Debris Upper Surface Elevation Profiles for MELCOR Cases at 2400 seconds. 

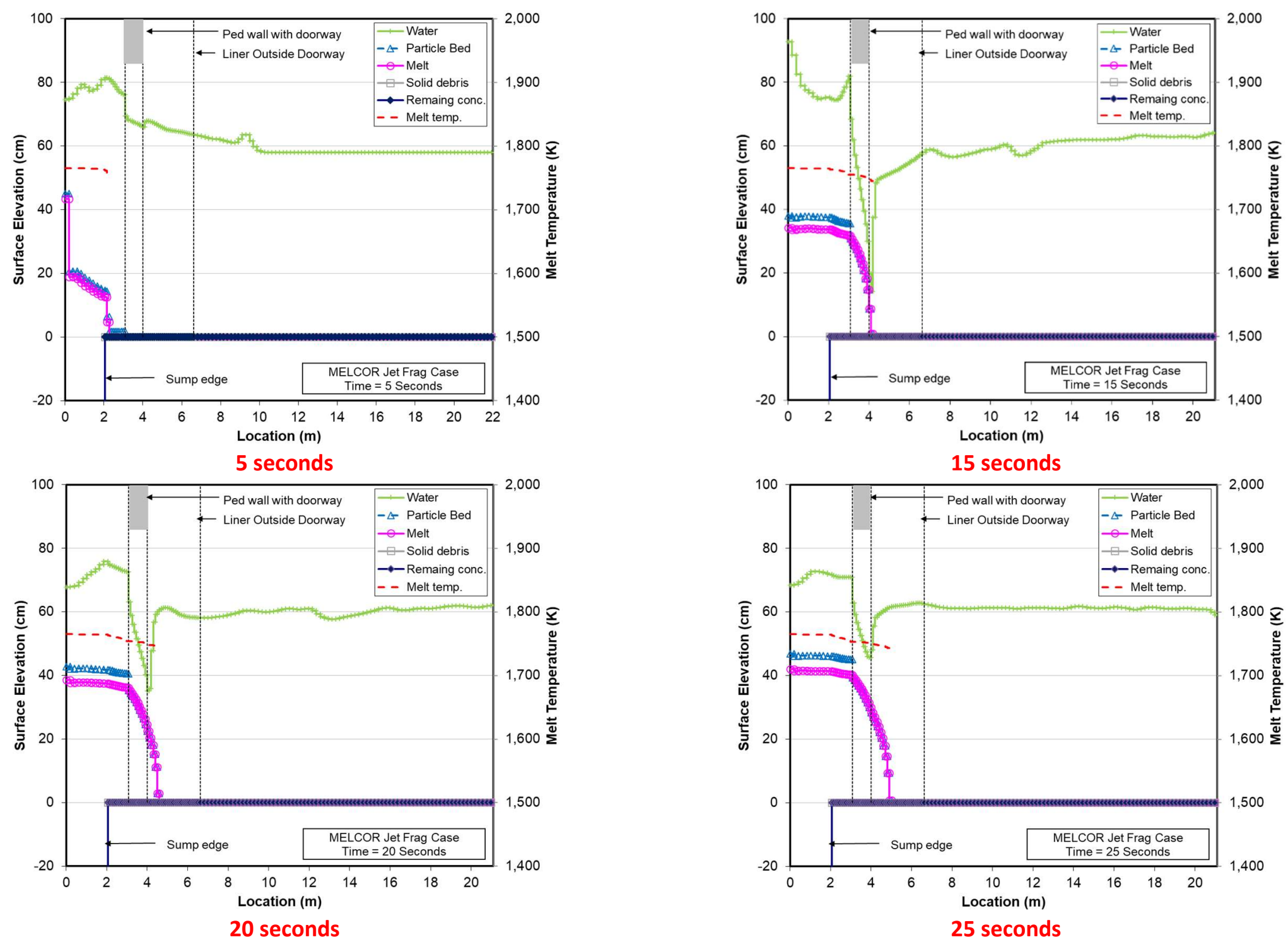

Figure 2-9. Temperature and Depth Profiles at Sequential Times for MELCOR Base Case. 

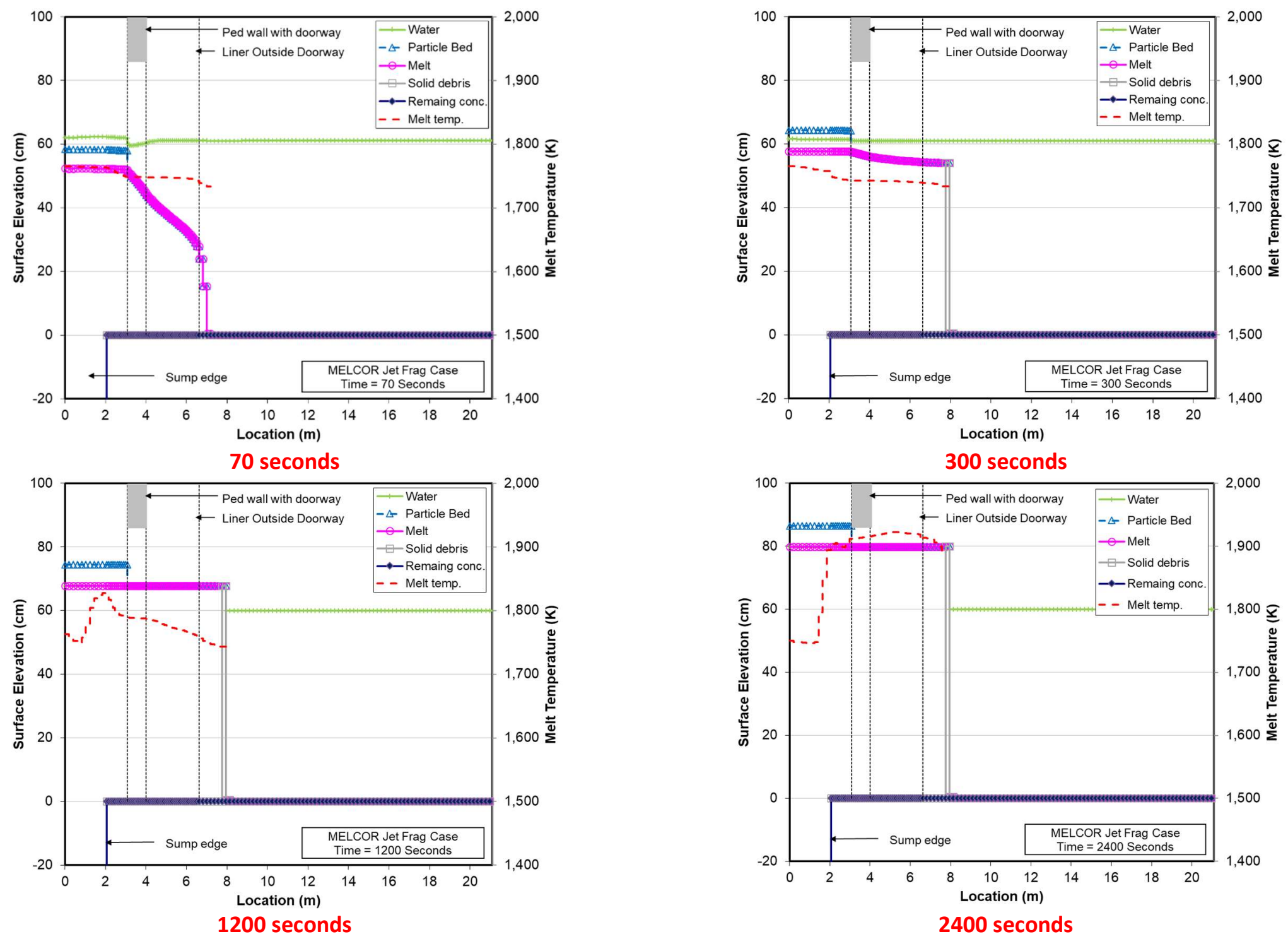

Figure 2-9 (Contd.). Temperature and Depth Profiles at Sequential Times for MELCOR Base Case. 
Table 2-4. Key Results for MELCOR Cases at 2410 seconds.

\begin{tabular}{|c|c|c|c|c|c|c|c|}
\hline \multirow[b]{2}{*}{ Case } & \multicolumn{4}{|c|}{ Water/Steam Distribution After Spreading (kg) } & \multirow[b]{2}{*}{$\begin{array}{c}\text { Total Particle } \\
\text { Bed Mass } \\
\quad(k g)\end{array}$} & \multirow{2}{*}{$\begin{array}{c}\text { Total Floor } \\
\text { Area Covered } \\
\text { by Core } \\
\text { Debris* } \\
\left(\mathrm{m}^{2} / \%\right)\end{array}$} & \multirow{2}{*}{$\begin{array}{c}\text { Debris Depth } \\
\text { Adjacent to } \\
\text { Drywell } \\
\text { Liner** } \\
\text { (cm) }\end{array}$} \\
\hline & $\begin{array}{c}\text { Steam from } \\
\text { Jet Frag. }\end{array}$ & $\begin{array}{l}\text { Total Steam } \\
\text { Production }\end{array}$ & $\begin{array}{c}\text { Water } \\
\text { Overflow } \\
\text { into Wetwell }\end{array}$ & $\begin{array}{c}\text { Water } \\
\text { Remaining } \\
\text { on Floor }\end{array}$ & & & \\
\hline $0 \mathrm{~K}-0 \mathrm{~cm}$ & $N / A$ & $N / A$ & $N / A$ & $N / A$ & $N / A$ & $113.2 / 95.0$ & 34.1 \\
\hline $0 \mathrm{~K}-30 \mathrm{~cm}$ & 1329 & 3848 & 0 & 34693 & 4705 & $48.0 / 40.3$ & 79.7 \\
\hline $\begin{array}{c}0 \mathrm{~K}-58 \mathrm{~cm} \\
\text { (Base Case) }\end{array}$ & 2819 & 8327 & 20542 & 40524 & 10318 & $47.0 / 39.4$ & 79.8 \\
\hline $25 \mathrm{~K}-0 \mathrm{~cm}$ & $N / A$ & $N / A$ & $N / A$ & $N / A$ & $N / A$ & Complete & 32.2 \\
\hline $25 \mathrm{~K}-30 \mathrm{~cm}$ & 2862 & 22635 & 0 & 15905 & 7250 & $76.1 / 63.8$ & 49.5 \\
\hline $25 \mathrm{~K}-58 \mathrm{~cm}$ & 6341 & 36322 & 16326 & 16731 & 15995 & $74.1 / 62.2$ & 50.3 \\
\hline $50 \mathrm{~K}-0 \mathrm{~cm}$ & $N / A$ & $N / A$ & $N / A$ & $N / A$ & $N / A$ & Complete & 32.2 \\
\hline $50 \mathrm{~K}-30 \mathrm{~cm}$ & 3233 & 24944 & 0 & 13597 & 7916 & $80.1 / 67.2$ & 47.0 \\
\hline $50 \mathrm{~K}-58 \mathrm{~cm}$ & 6941 & 39378 & 157391 & 14254 & 16960 & $78.1 / 65.5$ & 48.1 \\
\hline
\end{tabular}

*Complete floor coverage is equal to $119.2 \mathrm{~m}^{2}$; **Across from pedestal doorway. 
For the base case (Figure 2-9), the melt gradually fills the sump and then begins to spread as a thick layer (due the viscous nature of the oxidic material) first in the pedestal region and then out the pedestal doorway, eventually making contact with the shell at $\sim 58$ seconds. After contacting the shell, the flow is diverted (symmetrically by assumption) into the annulus where the debris travels a small distance $(\sim 100 \mathrm{~cm})$ before spreading is halted by freezing at the leading edge. This corresponds to the end of the spreading transient; see Figure 2-9 at 300 seconds. The debris profile at this point consists of a fairly uniform layer of material at a depth of $\sim 58 \mathrm{~cm}$ over the pedestal floor, and a slightly reduced depth in the drywell area. Due to the high viscosity and low spreading velocity of the material, the local convective heat transfer coefficients are small. Thus, the code predicts no concrete ablation during this initial spreading phase (although there is concrete degassing due to local heat up in the thermal boundary layer).

Over the next 30 minutes, core debris that is effectively molten steel gradually drains from the vessel, displacing core oxide in the sump and pushing that material onto the pedestal floor and out the doorway into the drywell, leading to pooling of the bulk material behind the previously frozen material at the leading edge. This causes a gradual increase in pool depth with no increase in floor area covered. By the end of the transient, the pool depth is essentially constant at $80 \mathrm{~cm}$ over the pedestal and covered drywell floor areas; the melt accumulation is deeper (i.e., $\sim 125 \mathrm{~cm}$ ) in the sump. The peak ablation depth at 2400 seconds has reached $15 \mathrm{~cm}$ at the sump centerline, with less ablation as the sump edge is approached. There is very little ablation of the pedestal and drywell floors at this time. Onset of ablation in the sump is caused by the accumulation of steel within that acts to lower melt viscosity, thereby increasing the heat transfer coefficient to concrete. However, the lack of ablation of the pedestal and drywell floors is due to the prediction that the material in these regions is mostly oxide. Thus, this material needs to reheat (thereby lowering the viscosity) before onset of ablation can begin.

One of the basic modelling assumptions within MELTSPREAD (and CORQUENCH) is that the fission products predominately reside in the oxide phase. The modelling approach [6,7] is thus to partition the decay heat in the core debris in direct proportion to the amount of fuel (i.e. $\mathrm{UO}_{2}$ ) that is locally present. This has an impact on the results, as can be seen in Figure 2-9 (e.g., see later snapshots at 1200 and 2400 seconds). In particular, the code predicts that the later metal pour acts to push core oxide out of the sump and onto the pedestal floor, leading to a situation in which the sump contains the majority of the metal, while the majority of the core oxide (bearing the fission products) is distributed on the pedestal and drywell floors. Thus, even though the sump contains a deeper accumulation of core debris, after debris dryout at $\sim 10$ minutes this material heats up more slowly in comparison to the shallower accumulations on the pedestal and drywell floors since the latter locations contain a majority of the fission products. This non-uniform distribution has an impact on the long-term debris cooling behavior (see Section 3).

Two additional points are drawn from Figures 2-7 and 2-8 regarding the effects of melt pour temperature and water level on spreading behavior given the MELCOR pour conditions. The first is that, as one would expect, the spreading extent increases with increasing melt temperature regardless of whether the cavity is wet or dry. This is due to two factors: i) melt 
viscosity decreases as temperature increases, and ii) the amount of energy that must be removed from the core debris to reach the solidification point increases as melt temperature increases.

The second observation is that the presence or absence of water as an initial condition on the cavity floor impacts spreading behavior for MELCOR melt pour conditions; i.e., the extent of spreading is significantly reduced if water is present. The spreading extent is also noted to decrease with increasing water depth, but the dependence is weak. This may be due in part to the coupled way in which MELTSPREAD calculates the melt-water relocation transient along with the fact that the maximum water level in the drywell is limited by the downcomer height when the wetwell vent is preserved. For both the 30 and $58 \mathrm{~cm}$ water level cases, MELTSPREAD calculates that the water would be pushed downstream into the drywell and elevated over the core melt as the debris spreads (e.g., see Figure 2-9). However, as can be seen from Table 2-4, the resultant water waves that form do not reach the level of the downcomer inlets for the $30 \mathrm{~cm}$ cases, as no overflow into the wetwell is predicted. In contrast, significant overflow is predicted (as one would expect) for the $58 \mathrm{~cm}$ cases because of displacement of the water with core debris. Thus, these results seem to indicate that since the downcomers limit water level on the floor during spreading, the overall impact of the initial water level on spread area is reduced, at least in the parameter range investigated in this study.

Plots of the melt depth, temperature, and water level over the melt adjacent to the shell outside the pedestal doorway are shown in Figures 2-10 to 2-12, respectively, while predictions of peak shell surface temperature at this location are shown in Figure 2-13. This information indicates that for a given cavity flooding condition (i.e., dry, $30 \mathrm{~cm}$, or $58 \mathrm{~cm}$ water depth), the rate of shell surface temperature heatup due to contact by melt during the spreading transient increases systematically with the core melt pour temperature. However, the situation is not as clear regarding the impact of water depth on peak shell temperature for a given pour temperature. This is due to the prediction that the reduction in spreading area when water is present results in an increase in melt depth adjacent to the shell relative to the dry case (see Figure 2-10). The additional melt depth, coupled with dryout and reheating of melt adjacent to the shell fairly early in the transient that increases the shell thermal loading (see Figures 2-11 and 2-12), results in a situation in which the initially flooded cases achieve higher peak shell temperatures in comparison to the dry cases. As a reminder, this analysis assumes that there is no water addition during the transient. Under these conditions, it is noted from Figure 2-13 that the shell surface temperature reaches the assumed steel solidus $(1810 \mathrm{~K})$ by $\sim 30$ minutes, but the shell does not completely melt through by the end of the transient. However, note that this analysis does not consider other potential failure modes such as creep rupture. ${ }^{2}$

\footnotetext{
${ }^{2}$ The liner creep rupture failure mode was investigated as part of the Mark-I liner attack study [18]. In this study, creep rupture occurred at a failure temperature of 1511 to $1583 \mathrm{~K}$ ( 95 percent confidence bounds), but the work only considered a single accident scenario. Creep is a function of time, temperature, variations in heating rate, peak temperature, and extent of liner contact with core debris, which could affect the prediction of the liner failure temperature [18].
} 


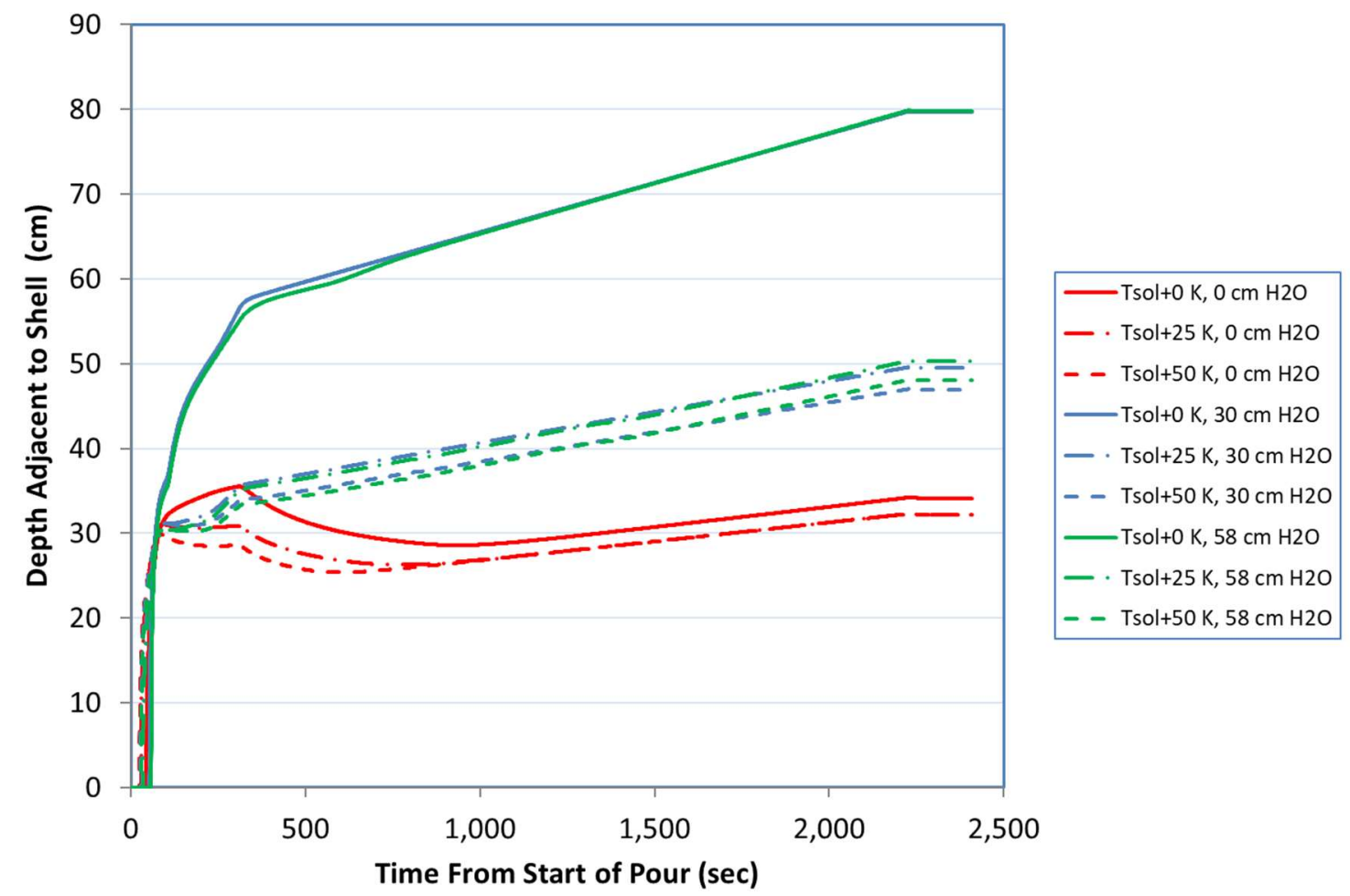

Figure 2-10. Core Debris Depth Adjacent to Shell Outside Pedestal Doorway for MELCOR Cases.

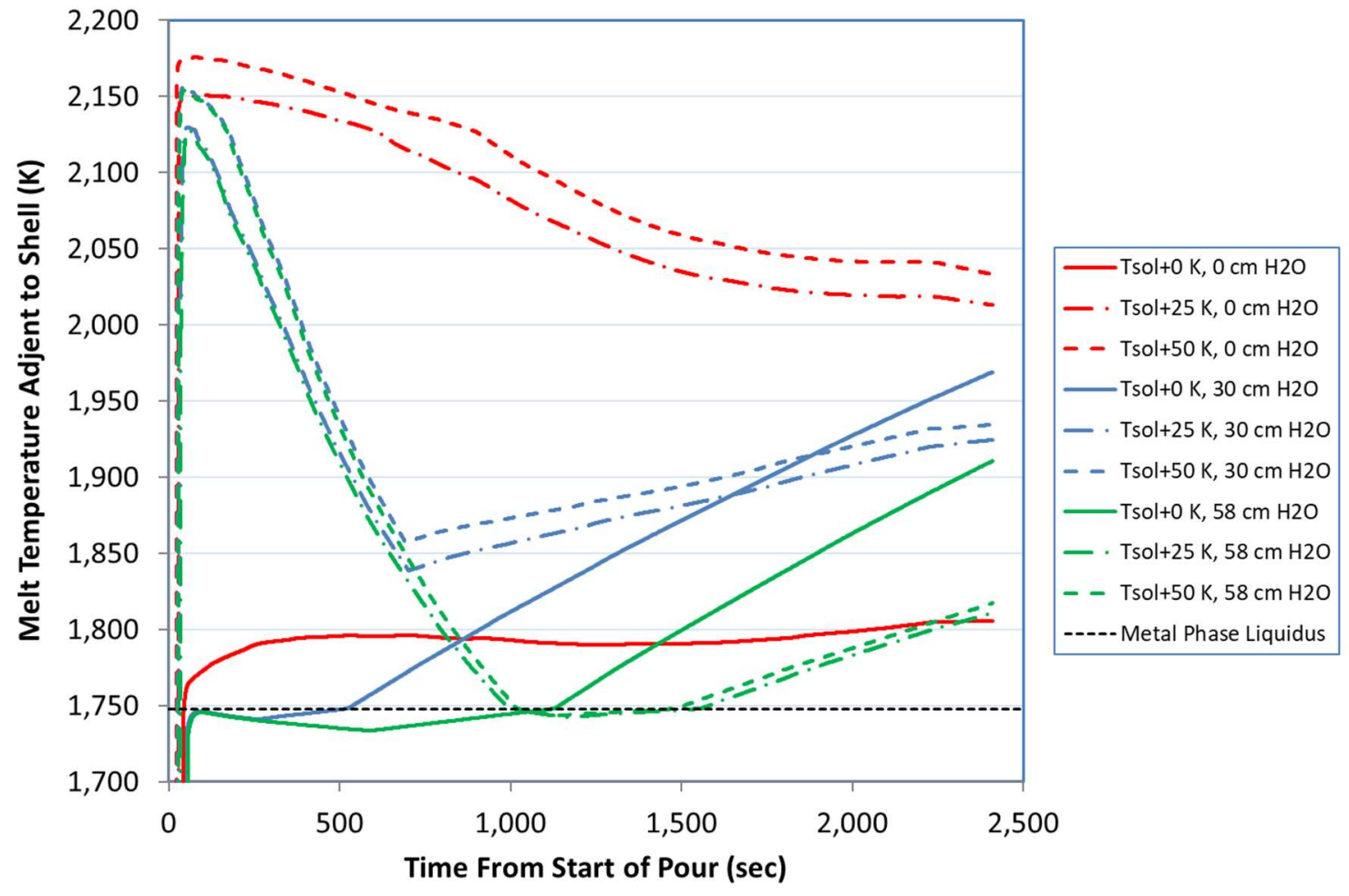

Figure 2-11. Core Debris Temperature Adjacent to Shell for MELCOR Cases. 


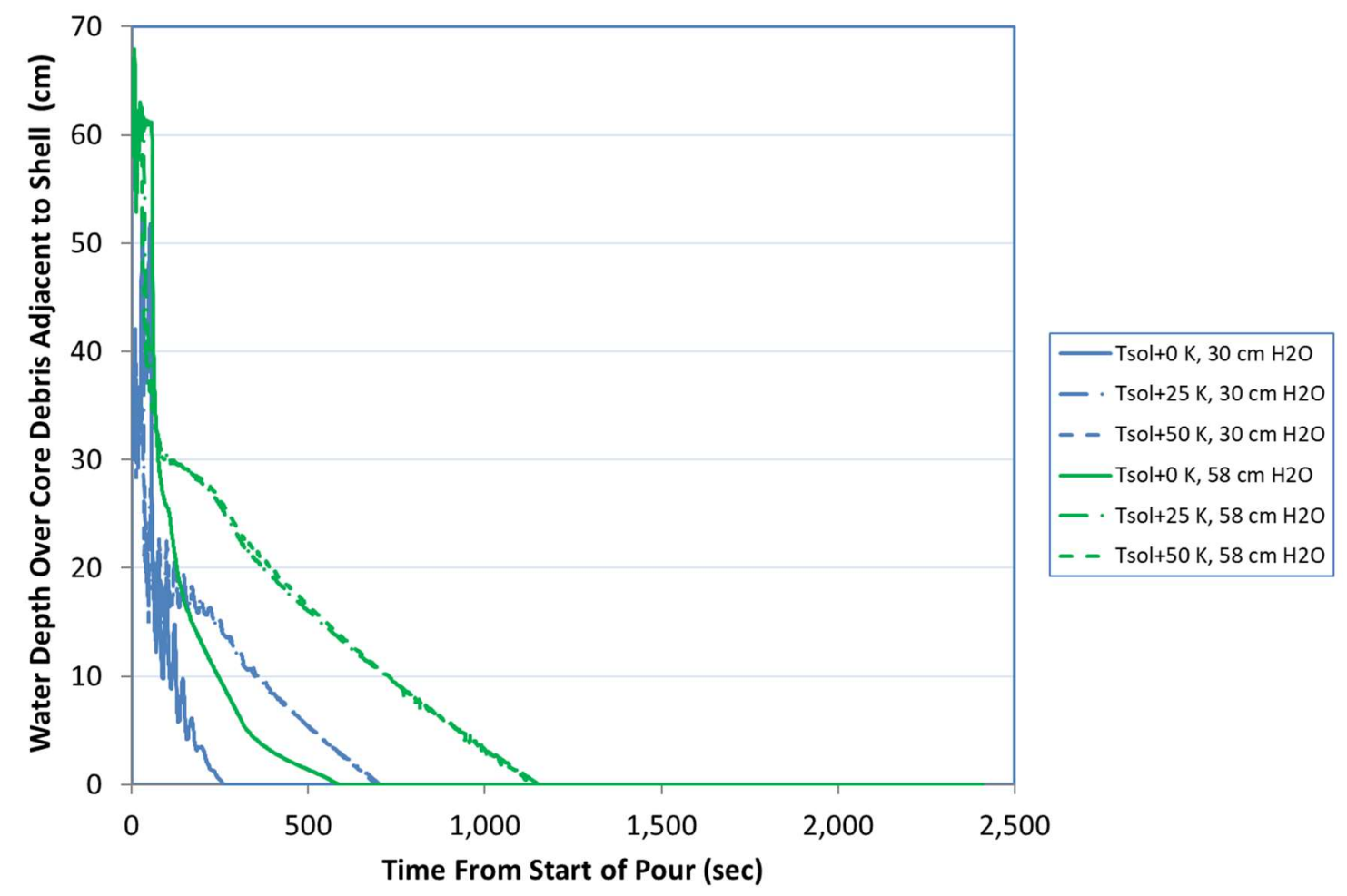

Figure 2-12. Water Depth over Core Debris Adjacent to Shell for MELCOR Cases.

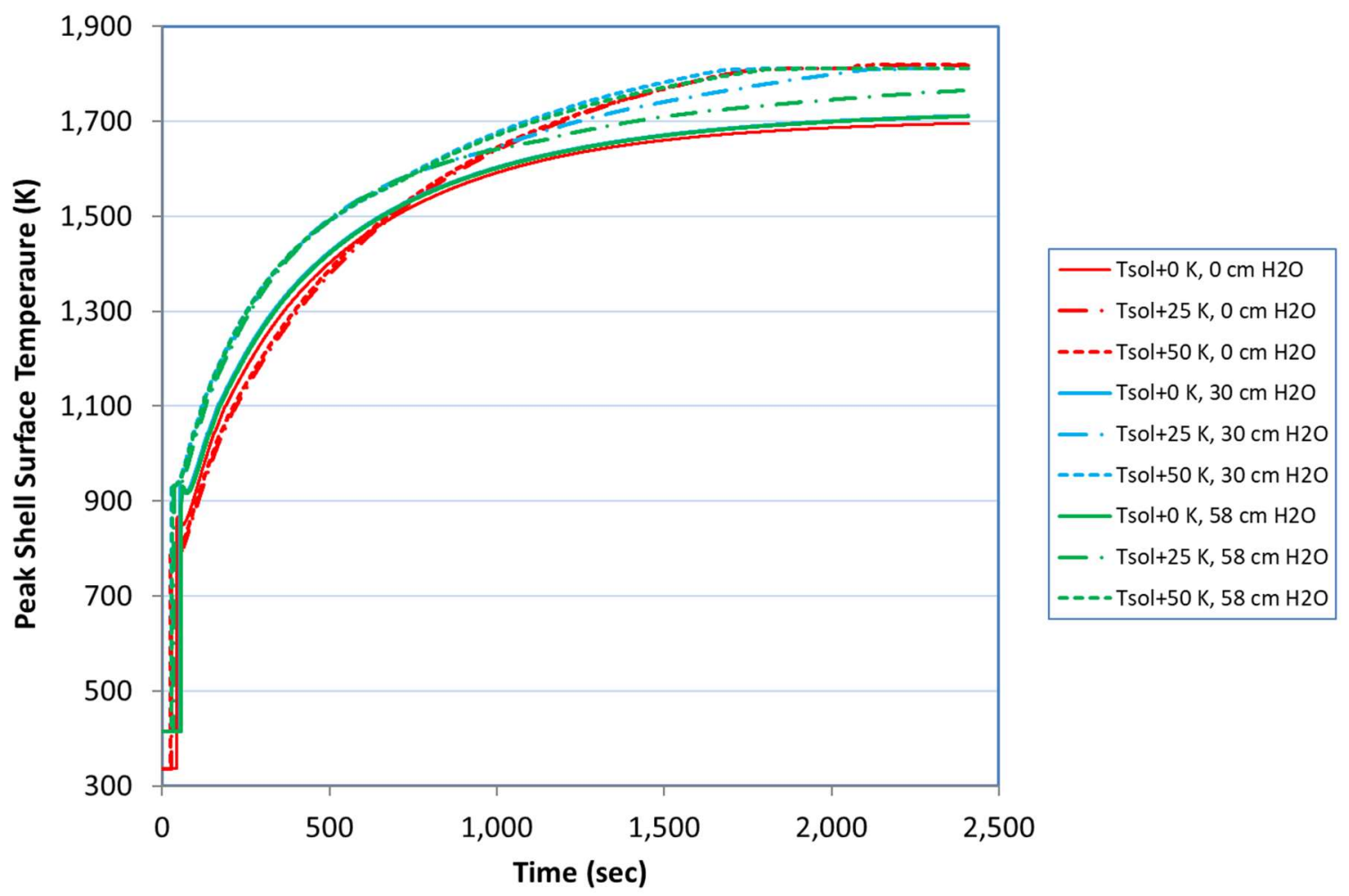

Figure 2-13. Peak Shell Surface Temperature for the MELCOR Cases. 
The final point to consider for the MELCOR cases is the potential impact of particle bed formation due to melt stream breakup in water present on the containment floor on the overall spreading behavior. The predicted particle bed mass formed in the pedestal region by this mechanism is shown in Figure 2-14 for the flooded cavity cases. To support the discussion, the remaining water depth in the jet impingement zone (i.e. Node 1 in the spreading mesh, which is within the sump) is shown in Figure 2-15. As one would expect, the particle bed mass is found to increase with increasing initial water depth on the containment floor. For a given water depth, the bed mass is further found to decrease with decreasing melt pour temperature. This latter trend is due to the prediction that the spreading rate as well as the final spreading area both decrease with decreasing melt pour temperature. This results in the core debris mounding at a faster rate in the jet impingement zone, thereby displacing the water that is causing the jet to fragment. As can be seen from Figure 2-14, the initial particle bed formation rate is quite high for all cases, but the fragmentation rate rapidly decreases as material accumulates in the sump. By 700 seconds, the water is locally depleted for all cases, causing fragmentation to cease. The largest particle bed mass is noted from Figure 2-14 to be $\sim 17$ MT. This mass amounts to $\sim 5 \%$ of the total pour mass (see Table 2-1). The particle bed is composed mostly of core oxide material.

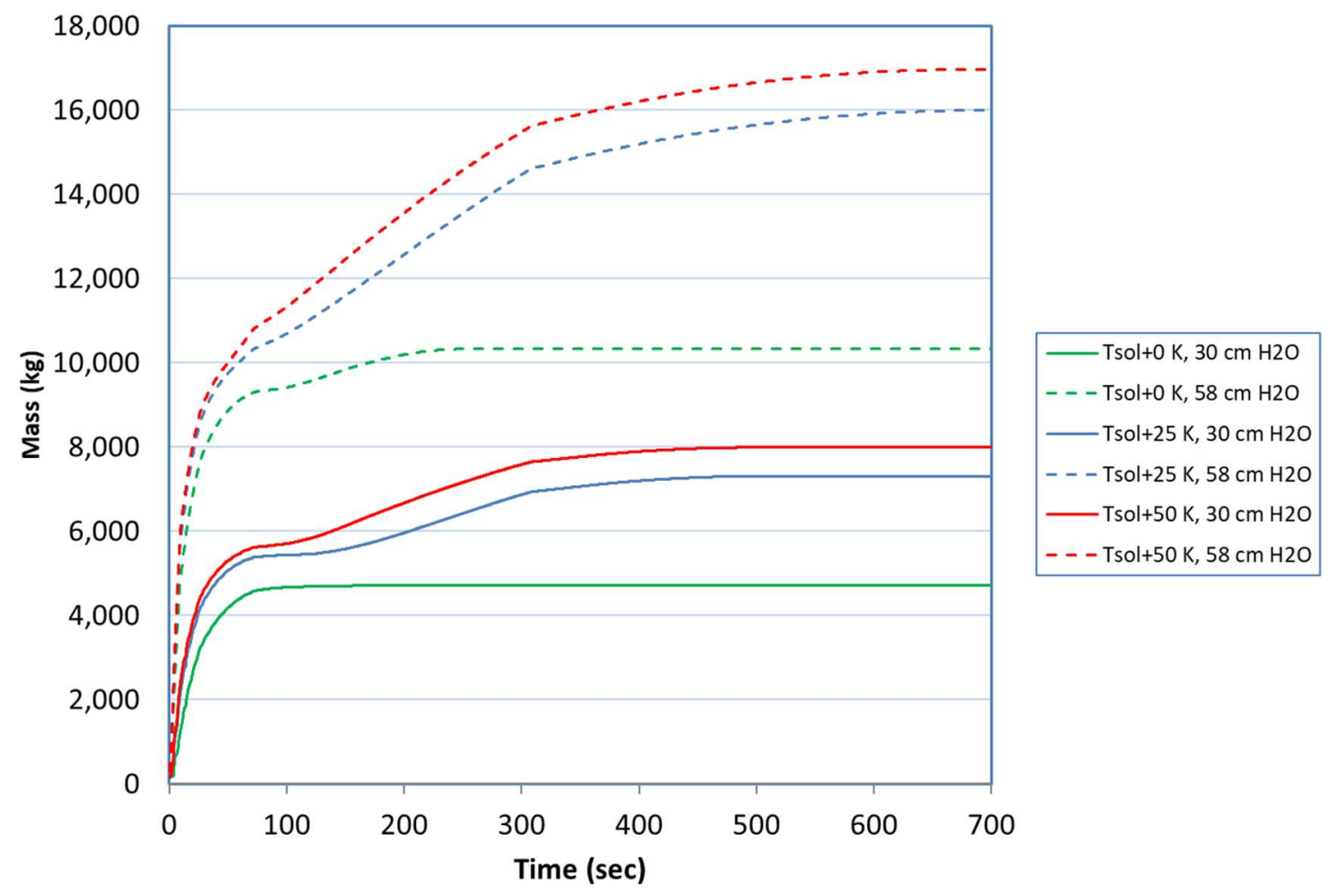

Figure 2-14. Particulate Mass Formed in Pedestal Region by Jet Fragmentation for MELCOR Cases. 


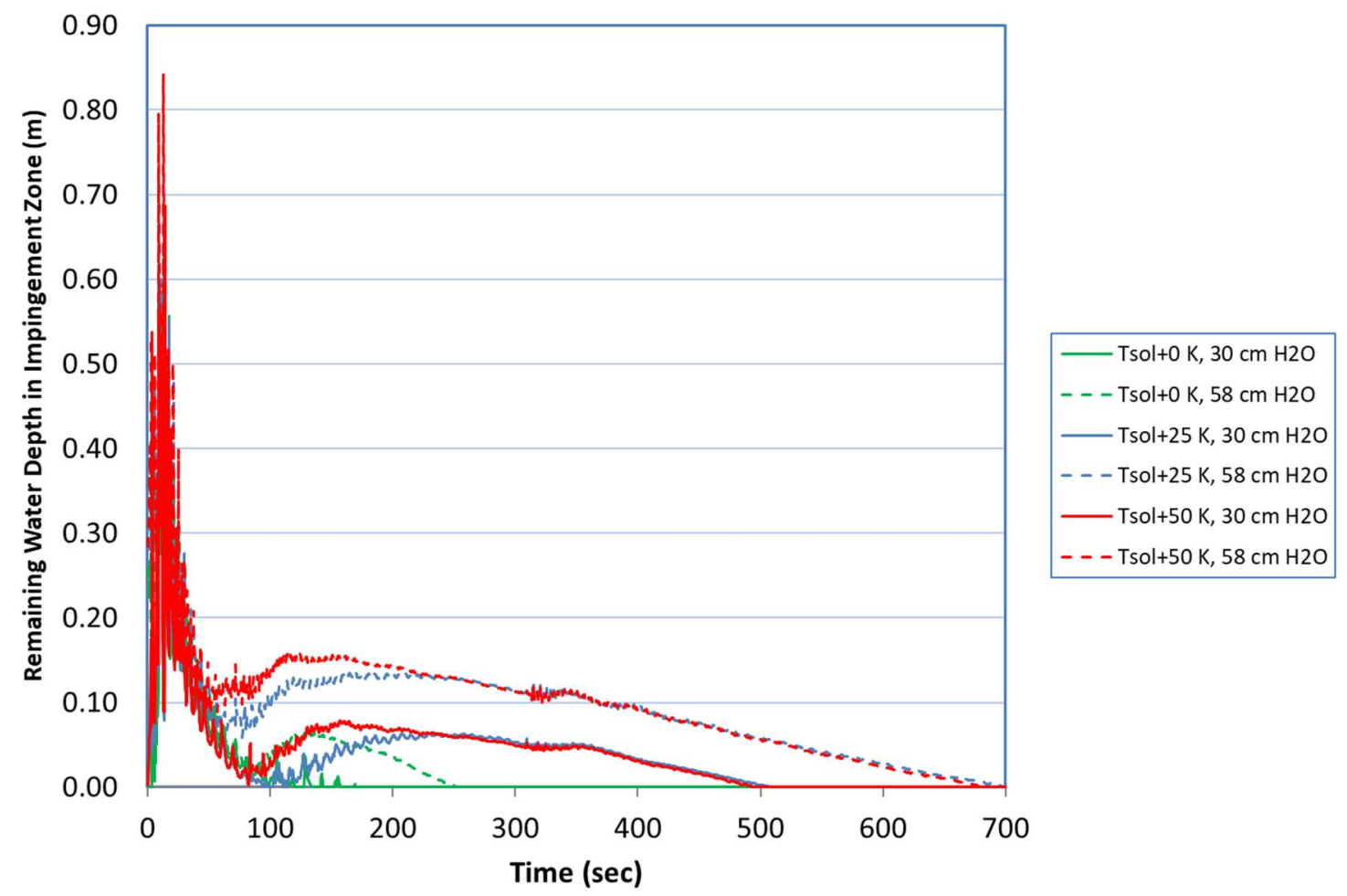

Figure 2-15. Remaining Water Depth in Jet Impingement Zone for MELCOR Cases.

\subsection{MAAP Melt Spreading Results}

To review, in this scenario vessel failure leads to discharge of a relatively low temperature, predominately oxidic core melt into the pedestal over a time interval of $\sim 53$ seconds. The melt composition is constant during the pour, unlike the MELCOR case. An additional difference is that the cavity is essentially dry at the time of vessel failure. The pour temperature is relatively constant at $\sim 2240 \mathrm{~K}$ during most of the pour duration (see Figure 2-6) and in the range where the metal phase is expected to be entirely liquid, while the oxide is solid. According to the MELTSPREAD property routines, the viscosity of the core debris at this temperature is $\sim 640 \mathrm{~Pa}$ sec, which is approximately half that predicted for the initial MELCOR melt pour, but still the same order of magnitude as molten glass. Thus, viscous effects are expected to be important during spreading for this scenario also.

Plots that show the cumulative floor area coverage as a function of time and final (postspread) debris distributions in containment for all nine MAAP cases are provided in Figures 2-16 and 2-17, respectively. A series of snapshots showing the dynamic evolution of melt depth and temperature during the spreading transient for the MAAP base case are provided in Figure 2-18. Finally, key thermal hydraulic results are tabulated in Table 2-5 for all cases. 


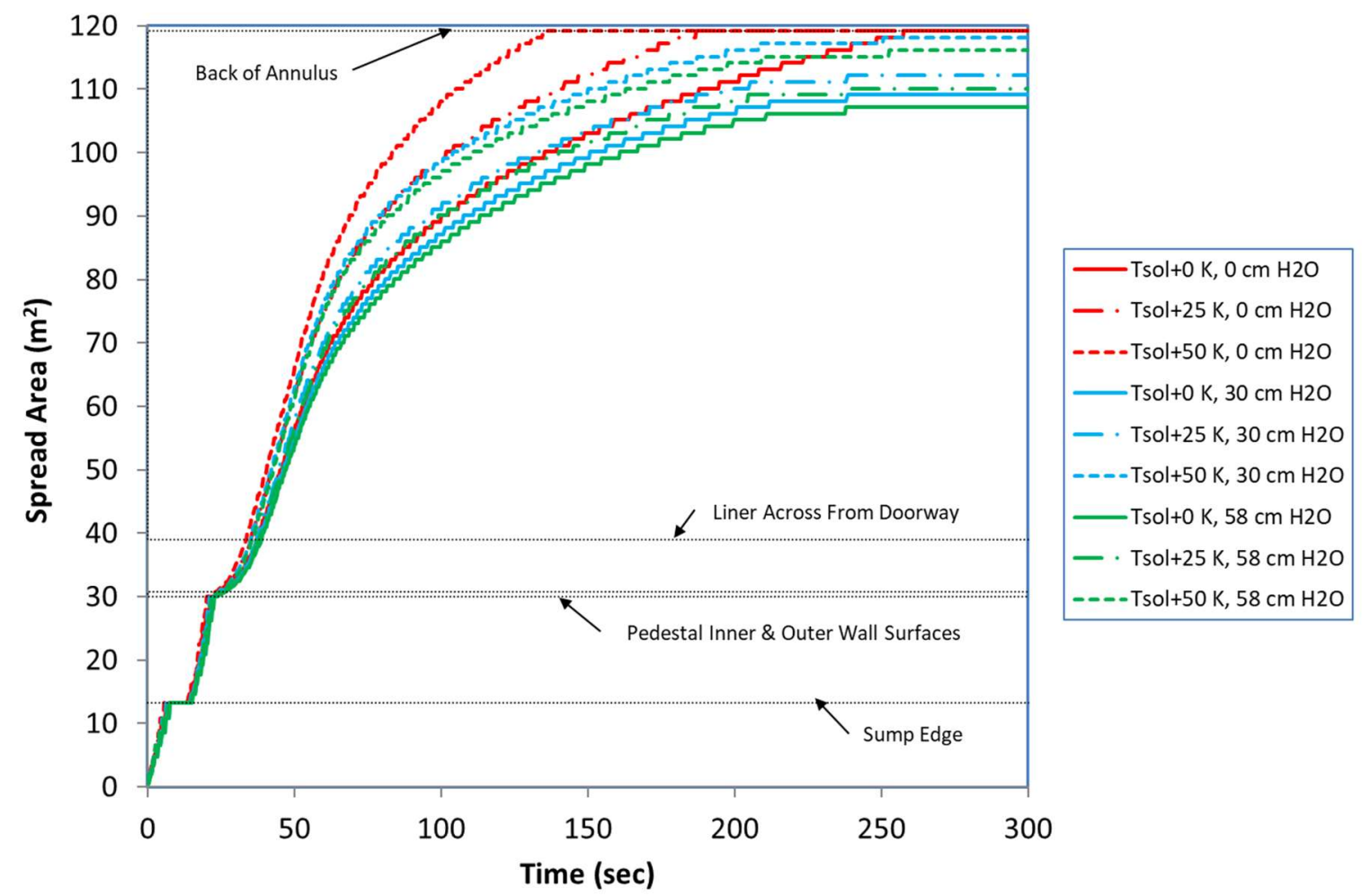

Figure 2-16. Basemat Floor Area Covered by Core Debris for the MAAP Cases.

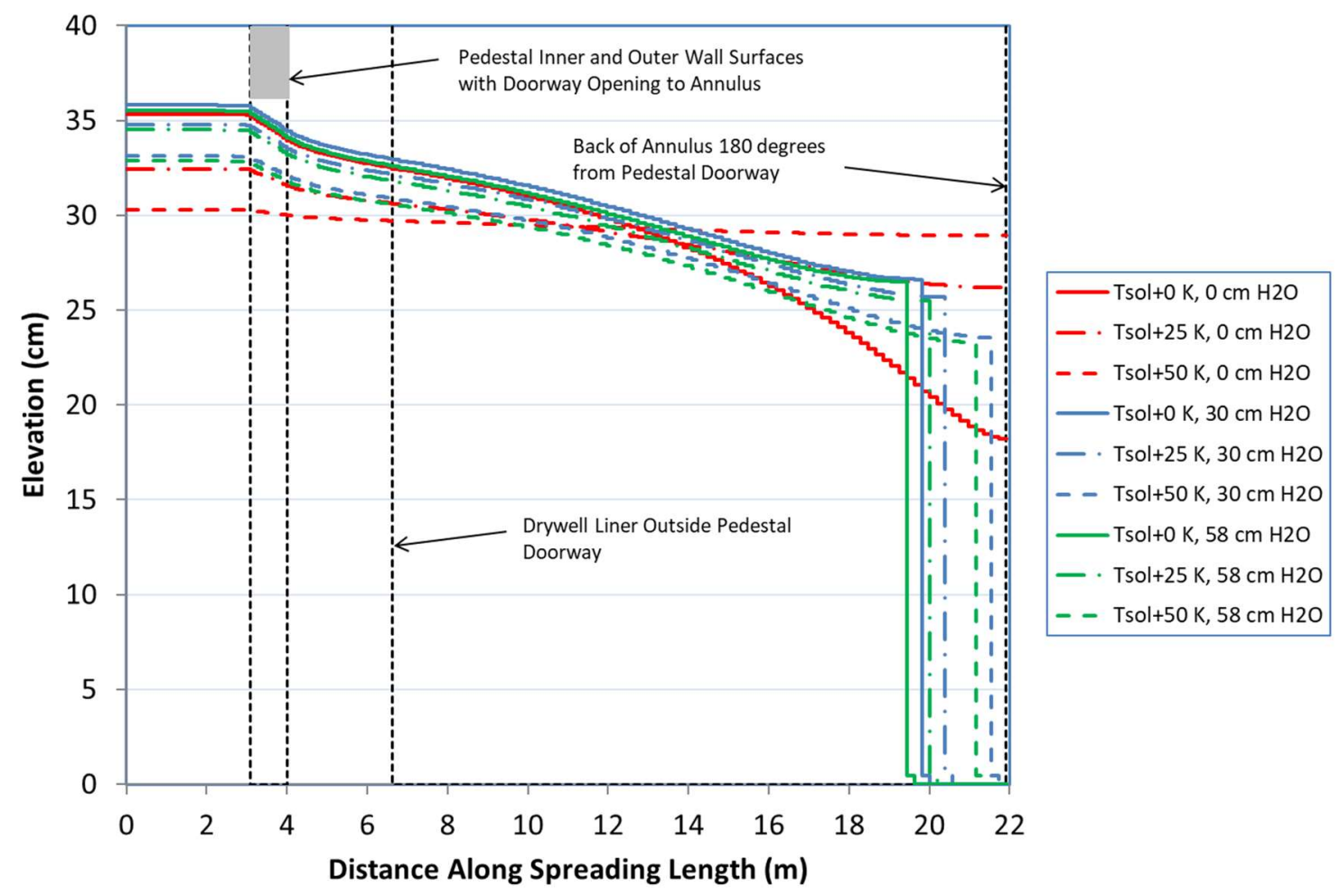

Figure 2-17. Debris Upper Surface Elevation Profiles for MAAP Cases at 300 seconds. 

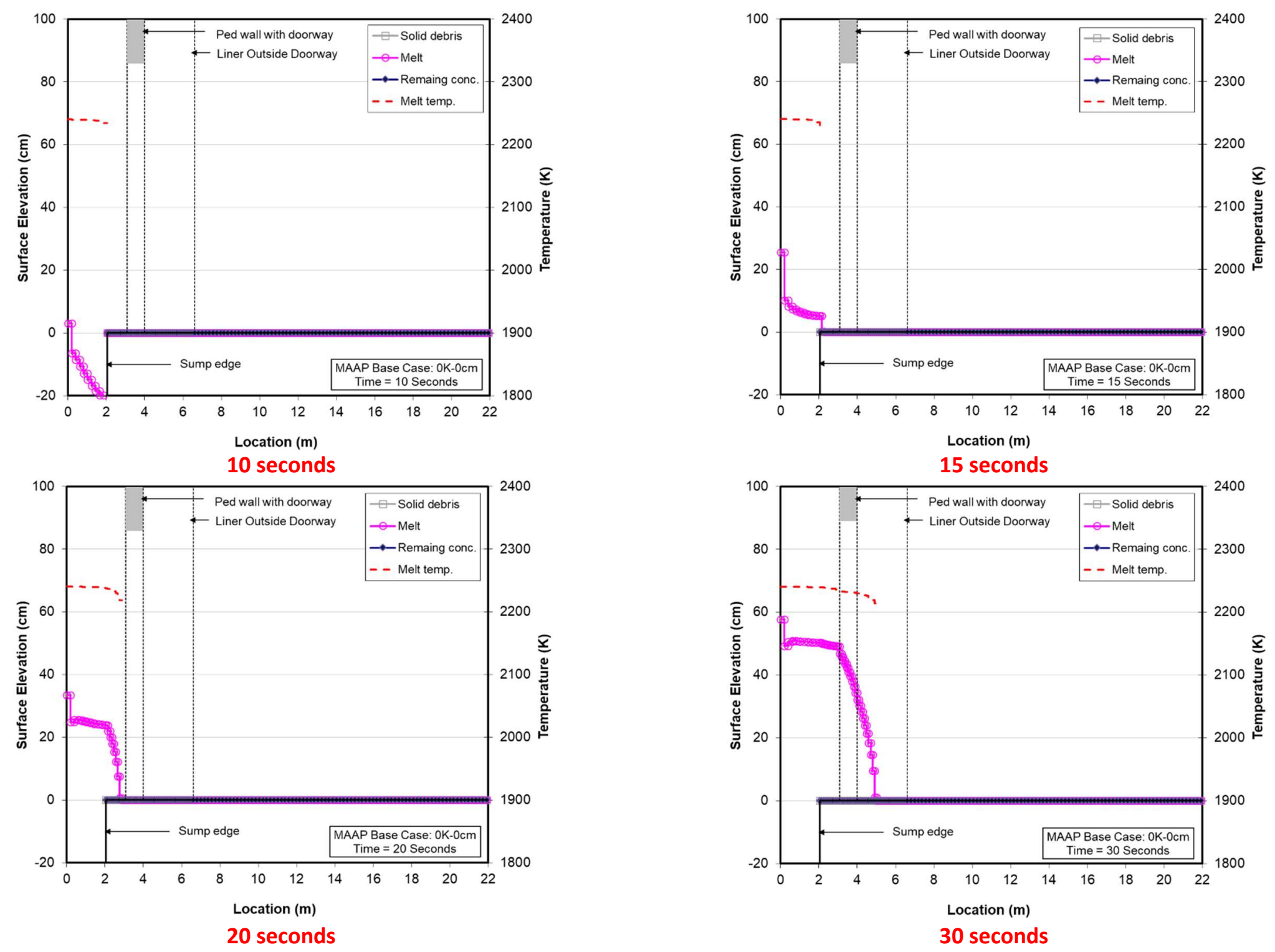

Figure 2-18. Temperature and Depth Profiles at Sequential Times for MAAP Base Case. 

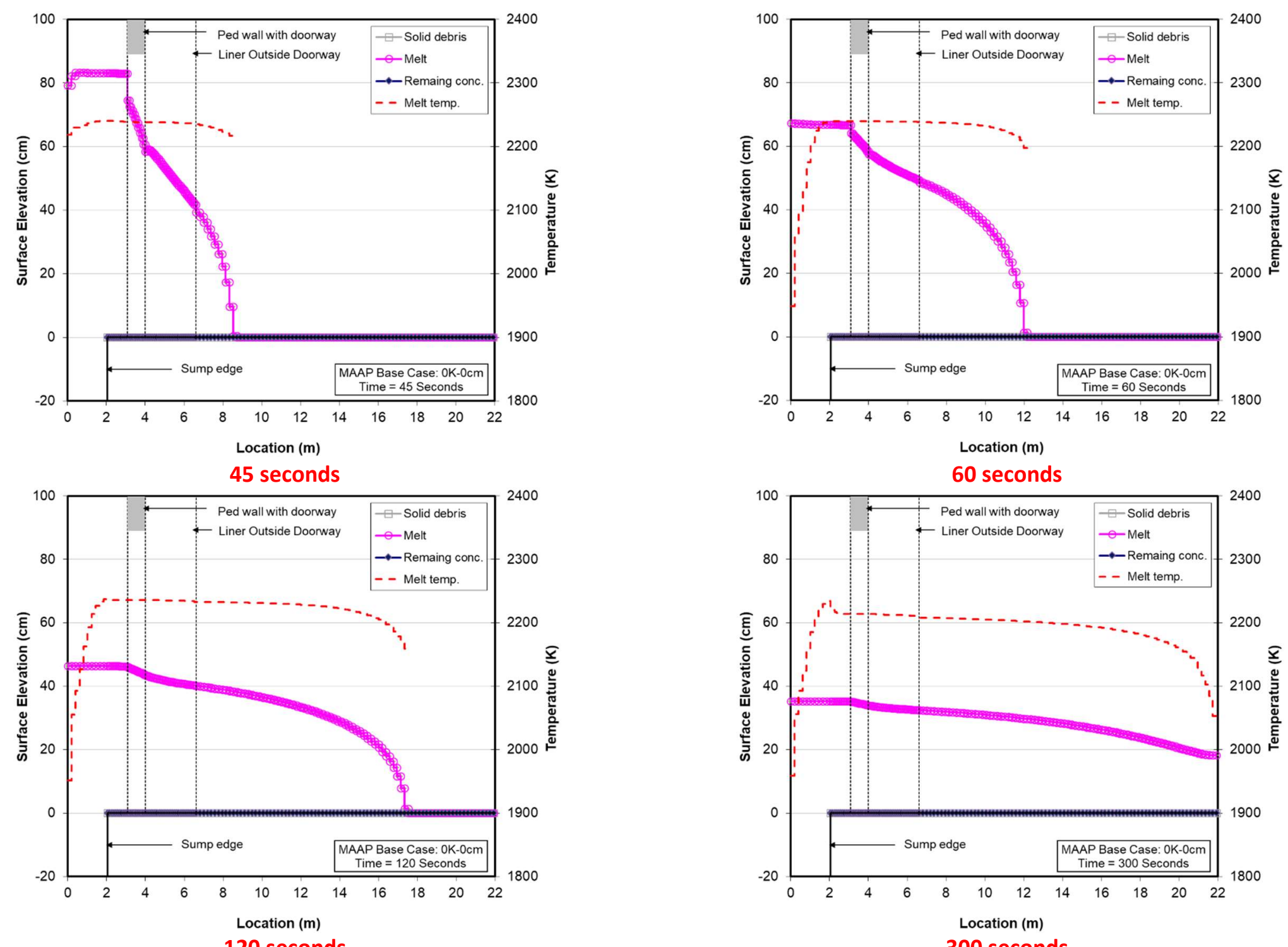

Figure 2-18 (Contd.). Temperature and Depth Profiles at Sequential Times for MAAP Base Case. 
Table 2-5. Key Results for MAAP Cases at 300 seconds.

\begin{tabular}{|c|c|c|c|c|c|c|c|}
\hline \multirow[b]{2}{*}{ Case } & \multicolumn{4}{|c|}{ Water/Steam Distribution After Spreading (kg) } & \multirow[b]{2}{*}{$\begin{array}{c}\text { Total Particle } \\
\text { Bed Mass } \\
\text { (kg) }\end{array}$} & \multirow{2}{*}{$\begin{array}{c}\text { Total Floor } \\
\text { Area Covered } \\
\text { by Core } \\
\text { Debris* } \\
\left(\mathrm{m}^{2} / \%\right)\end{array}$} & \multirow{2}{*}{$\begin{array}{c}\text { Debris Depth } \\
\text { Adjacent to } \\
\text { Drywell } \\
\text { Liner** } \\
\text { (cm) }\end{array}$} \\
\hline & $\begin{array}{c}\text { Steam from } \\
\text { Jet Frag. }\end{array}$ & $\begin{array}{l}\text { Total Steam } \\
\text { Production }\end{array}$ & $\begin{array}{c}\text { Water } \\
\text { Overflow } \\
\text { into Wetwell }\end{array}$ & $\begin{array}{c}\text { Water } \\
\text { Remaining } \\
\text { on Floor }\end{array}$ & & & \\
\hline $\begin{array}{c}0 \mathrm{~K}-0 \mathrm{~cm} \\
\text { (Base Case) }\end{array}$ & $\mathrm{N} / \mathrm{A}$ & N/A & N/A & N/A & $\mathrm{N} / \mathrm{A}$ & Complete & 32.5 \\
\hline $0 \mathrm{~K}-30 \mathrm{~cm}$ & 2274 & 15357 & 779 & 22282 & 6282 & 109.2/91.6 & 33.0 \\
\hline $0 \mathrm{~K}-58 \mathrm{~cm}$ & 5610 & 17681 & 27389 & 24080 & 12684 & $107.2 / 89.9$ & 32.6 \\
\hline $25 \mathrm{~K}-0 \mathrm{~cm}$ & $N / A$ & $N / A$ & $N / A$ & $N / A$ & $N / A$ & Complete & 30.6 \\
\hline $25 \mathrm{~K}-30 \mathrm{~cm}$ & 3178 & 17694 & 831 & 19893 & 6871 & $112.2 / 94.1$ & 32.2 \\
\hline $25 \mathrm{~K}-58 \mathrm{~cm}$ & 6160 & 20090 & 26982 & 22077 & 13310 & $110.2 / 92.4$ & 31.8 \\
\hline $50 \mathrm{~K}-0 \mathrm{~cm}$ & $N / A$ & $N / A$ & $N / A$ & $N / A$ & $N / A$ & Complete & 29.7 \\
\hline $50 \mathrm{~K}-30 \mathrm{~cm}$ & 3427 & 19820 & 951 & 17647 & 7149 & $118.2 / 99.1$ & 30.9 \\
\hline $50 \mathrm{~K}-58 \mathrm{~cm}$ & 6509 & 22303 & 27119 & 19720 & 13573 & $116.2 / 97.5$ & 30.6 \\
\hline
\end{tabular}

*Complete floor coverage is equal to $119.2 \mathrm{~m}^{2} ; * *$ Across from pedestal doorway. 
For the base case that is illustrated in Figure 2-18, the melt gradually fills the sump volume and then begins to spread as a thick layer (due the viscous nature of the oxidic material) first in the pedestal region and then out the pedestal doorway, eventually making contact with the shell at $\sim 37$ seconds. After contacting the shell, the flow is diverted (symmetrically by assumption) into the annulus where the debris eventually travels around the drywell annulus to completely cover the cavity floor by 258 seconds. After this time, the material continues to relocate from the pedestal to the drywell seeking a level configuration under the effects of gravity, but this occurs very slowly due to the viscous nature of the material. Due to the high viscosity and low spreading velocity, the local convective heat transfer coefficients are small. As a result, the code predicts no ablation during the spreading transient, although degassing occurs due to decomposition in the thermal boundary layer near the concrete surface.

Note in Figure 2-18 starting at 45 seconds that a low-temperature region forms in the melt near the sump center. This is due to the significant reduction in the pour temperature at this time; see Figure 2-6. Further note from Figure 2-6 that a pour temperature of $1820 \mathrm{~K}$ (viz. the steel liquidus) was assumed during this phase to maintain some fluidity to the melt. However, the actual pour temperature falls to $920 \mathrm{~K}$ near the end, for which the pour would consist of solid material. To examine the effect of this relatively cold, solid material relocating during this latter phase, this case was rerun with the melt pour temperature reduced to an average value of $1172 \mathrm{~K}$ calculated over the last several seconds of the transient. In this situation, the material in the center of the sump is calculated to freeze, leading to the accumulation of a $105 \mathrm{~cm}$ mound at the sump centerline, which is the receptor node for the melt pour in this analysis.

Referring to Figures 2-16 and 2-17, it is observed that the extent of melt spreading increases with increasing melt temperature regardless of whether the cavity is wet or dry. The presence or absence of water as an initial condition on the cavity floor also impacts spreading behavior for these MAAP pour conditions; i.e., the extent of spreading is reduced if water is present. A second observation is that spreading extent also decreases with increasing water depth, but the dependence is weak. The expected reason for this weak dependence was discussed earlier during the presentation of the MELCOR spreading results; refer to Section 2.4. Thus, all parametric trends found for these MAAP pour conditions are consistent with those found for MELCOR pour conditions. However, comparing the two sets of results, it is noted that spreading is more extensive for MAAP pour conditions, with melt penetrating a significant distance into the drywell for all cases. This is due to the higher pour temperature coupled with the prediction that the entire pour occurs within 53 seconds, as compared to 2400 seconds for the MELCOR pour.

Plots of the melt depth, temperature, and water level over the melt adjacent to the shell outside the pedestal doorway are shown in Figures 2-19, 2-20, and 2-21, respectively, while predictions of peak shell surface temperature at this location are shown in Figure 2-22. These cases are slightly easier to interpret relative to the MELCOR cases as the debris depth is below the downcomer inlet, and so the wet cases maintain water over the debris during the (limited) duration of these calculations. In general, an increase in melt temperature (which acts to increase 
shell temperature) results in a decrease in melt depth (which acts to decrease shell temperature), and so there are competing effects. For the dry scenario, the highest shell temperatures occur for the lowest melt temperature case, which implies that melt depth adjacent to the shell is the dominant parameter influencing shell thermal response for this case. For the wet cases, the 30 and $58 \mathrm{~cm}$ cases are noted to be virtually indistinguishable. Additional examination indicates that the wet cases exhibit higher temperatures at any given time in comparison to the dry cases, which further reinforces the concept that melt depth adjacent to the shell is the key parameter influencing thermal response.

Comparing the MELCOR peak shell temperature data in Figure 2-13 to the MAAP data in Figure 2-22 at a common time of 300 seconds indicates that the MELCOR peak temperatures are generally higher in comparison to the MAAP temperatures, despite the fact that the MAAP melt pour temperatures are higher (see Table 2-3). This can be attributed to the higher melt depths adjacent to the shell predicted for the MELCOR case (compare Figures 2-10 and 2-19).

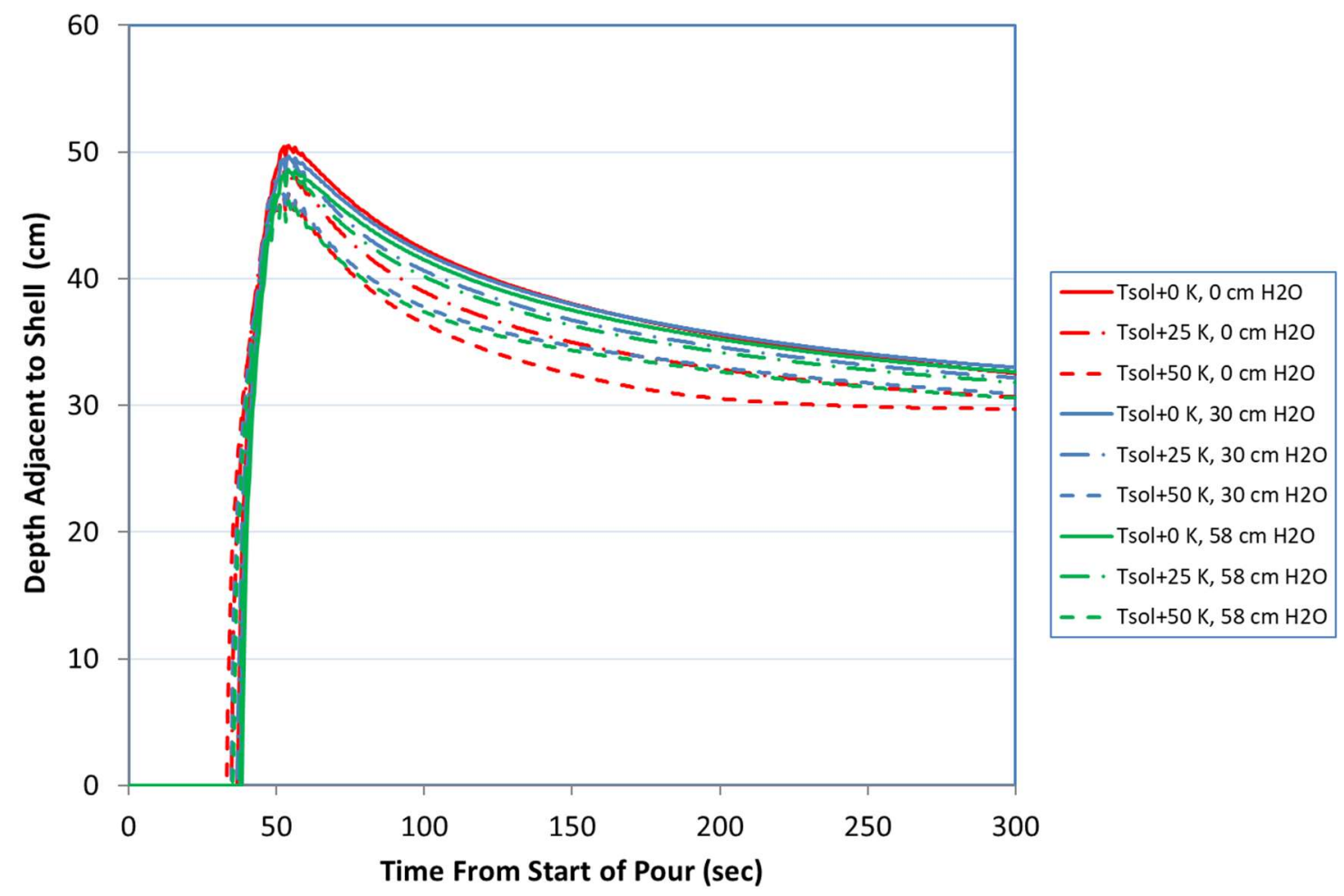

Figure 2-19. Core Debris Depth Adjacent to Shell Outside Pedestal Doorway for MAAP Cases. 


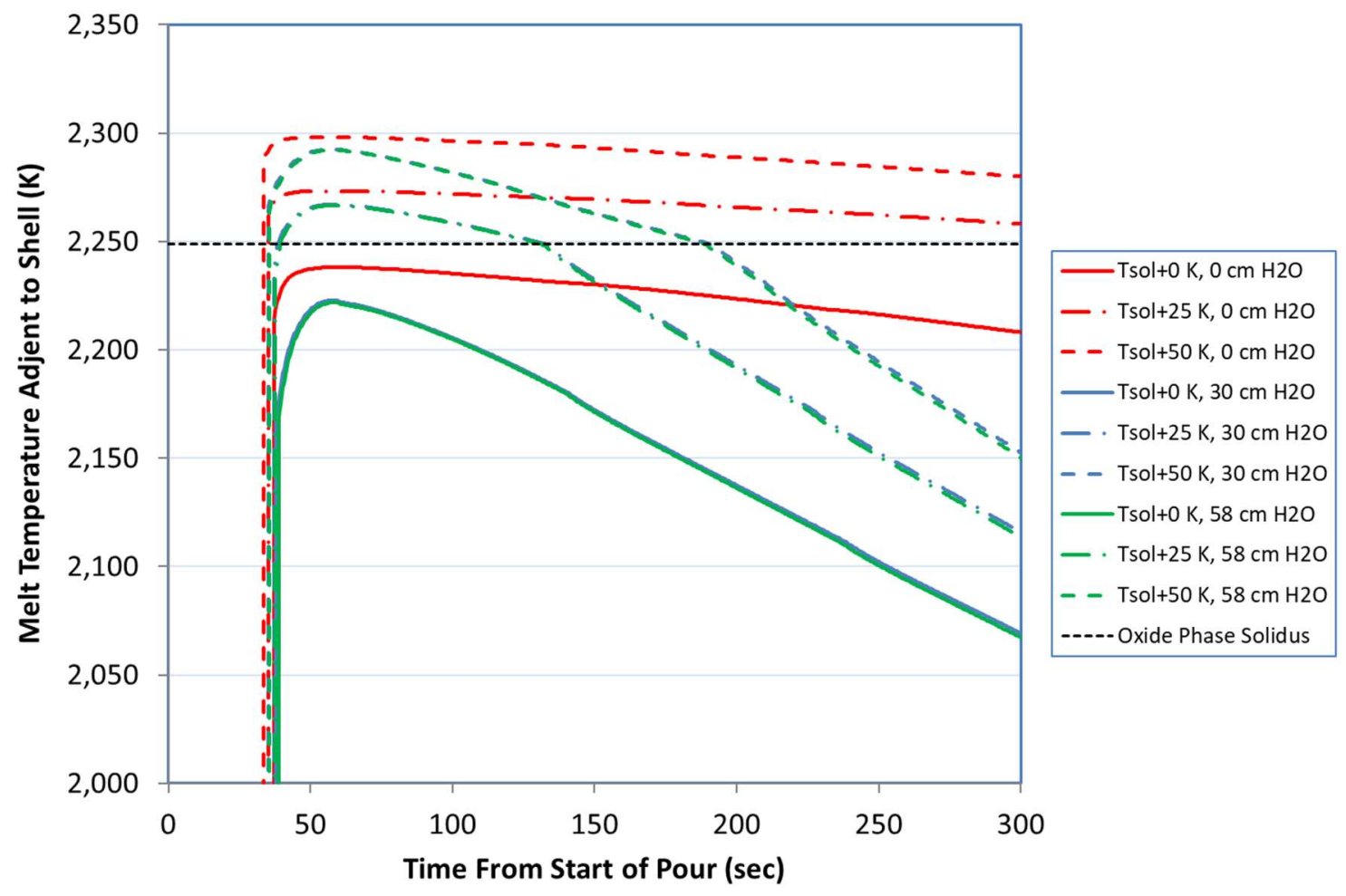

Figure 2-20. Core Debris Temperature Adjacent to Shell for MAAP Cases.

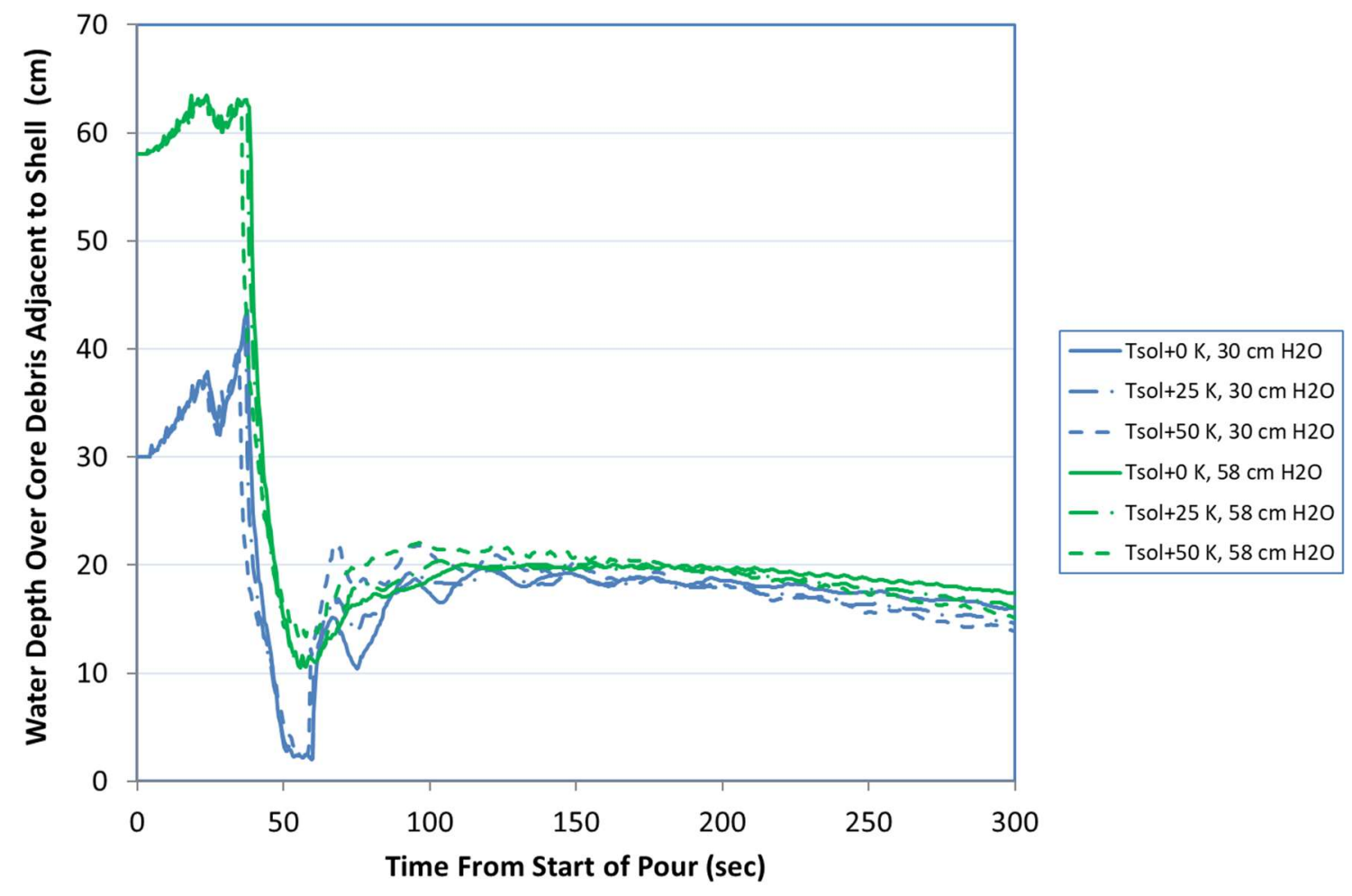

Figure 2-21. Water Depth over Core Debris Adjacent to Shell for MAAP Cases. 


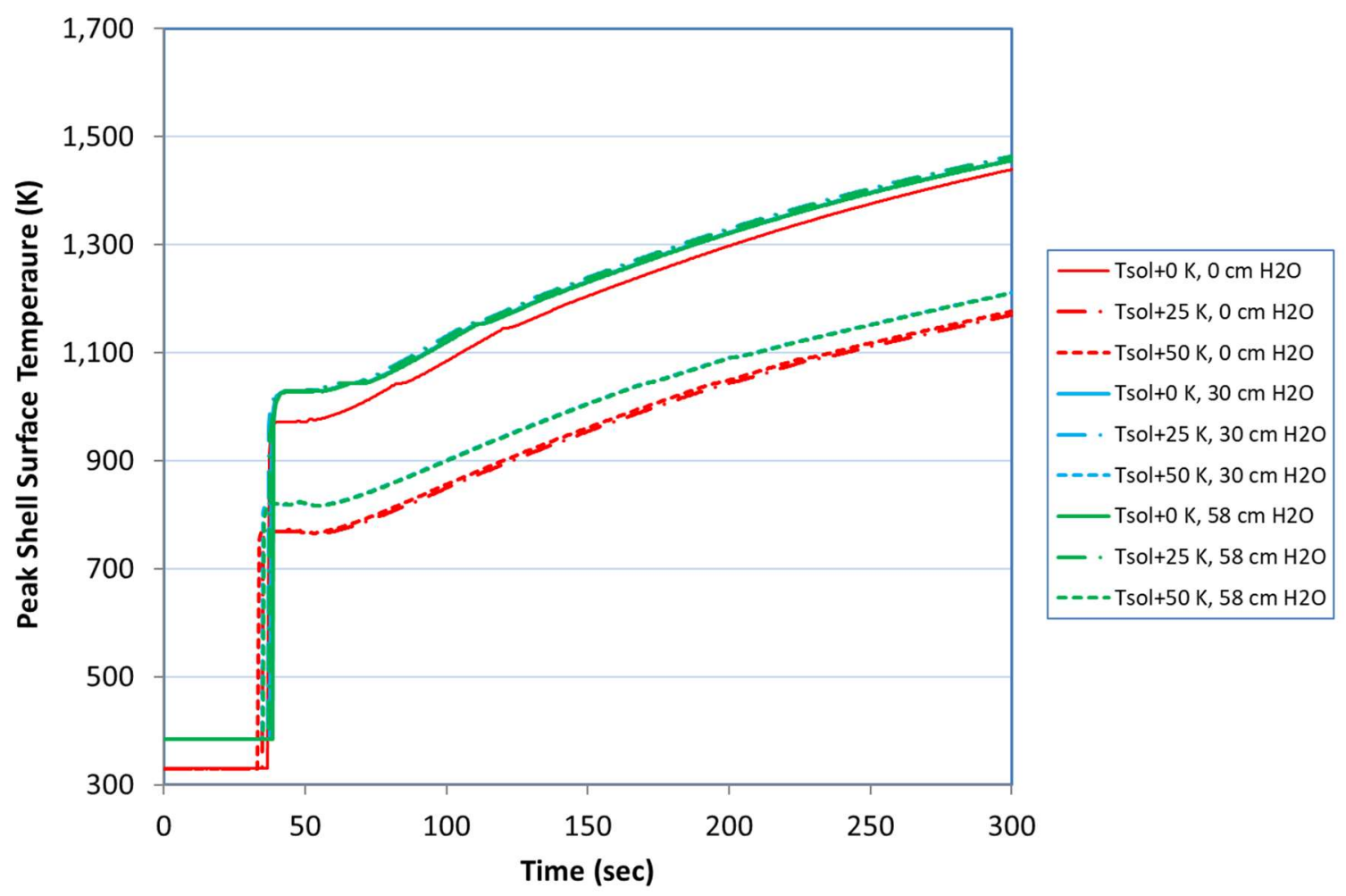

Figure 2-22. Peak Shell Surface Temperature for the MAAP Cases (the $58 \mathrm{~cm}$ water cases effectively overly the $30 \mathrm{~cm}$ water cases).

The final point to consider for the MAAP cases is the potential impact of particle bed formation due to melt stream breakup in water present on the containment floor on the overall spreading behavior. The predicted particle bed mass formed in the pedestal region by this mechanism is shown in Figure 2-23 for the flooded cavity cases. To support the discussion, the remaining water depth in the jet impingement zone (i.e. Node 1 in the spreading mesh, which is within the sump) is shown in Figure 2-24. Similar to the MELCOR case and as one would expect, the particle bed mass is found to increase with increasing initial water depth on the containment floor. For a given water depth, the particle bed mass is further found to decrease with decreasing melt pour temperature. This latter trend is due to the prediction that the spreading rate as well as the final spreading area both decrease with decreasing melt pour temperature. This results in deeper melt accumulations beneath the reactor vessel, thereby displacing the water that is causing jet fragmentation to occur. As can be seen from Figure 2-23, the initial particle bed formation rate is quite high for all cases, but the fragmentation rate rapidly decreases as material accumulates in the sump. The largest particle bed mass formed is noted from Figure $2-23$ to be $\sim 14$ MT. This mass amounts to $\sim 4.6 \%$ of the total pour mass (see Table $2-1$, which is slightly less than that predicted for the MELCOR pours. 


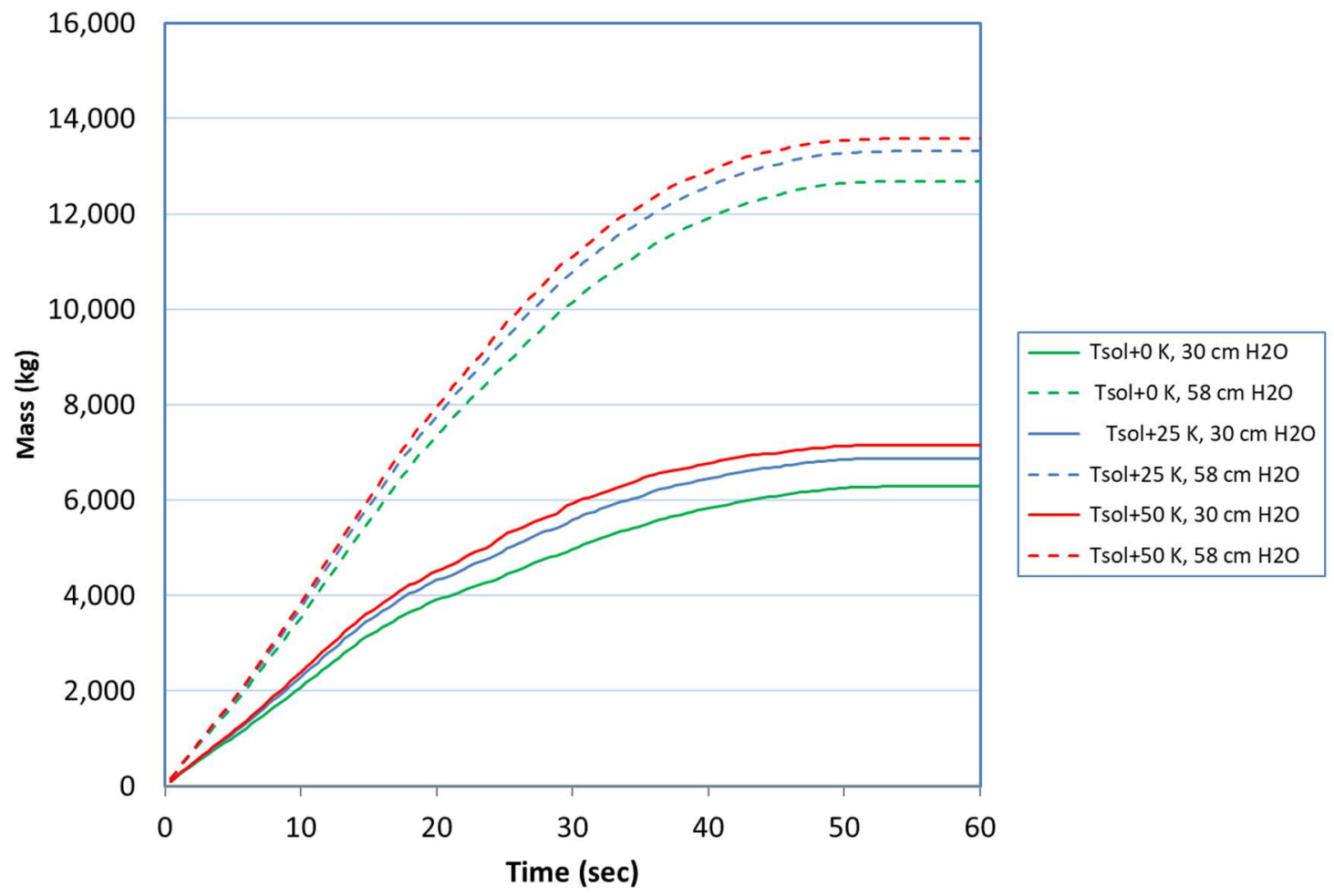

Figure 2-23. Particulate Mass Formed in Pedestal Region by Jet Fragmentation for MAAP Cases.

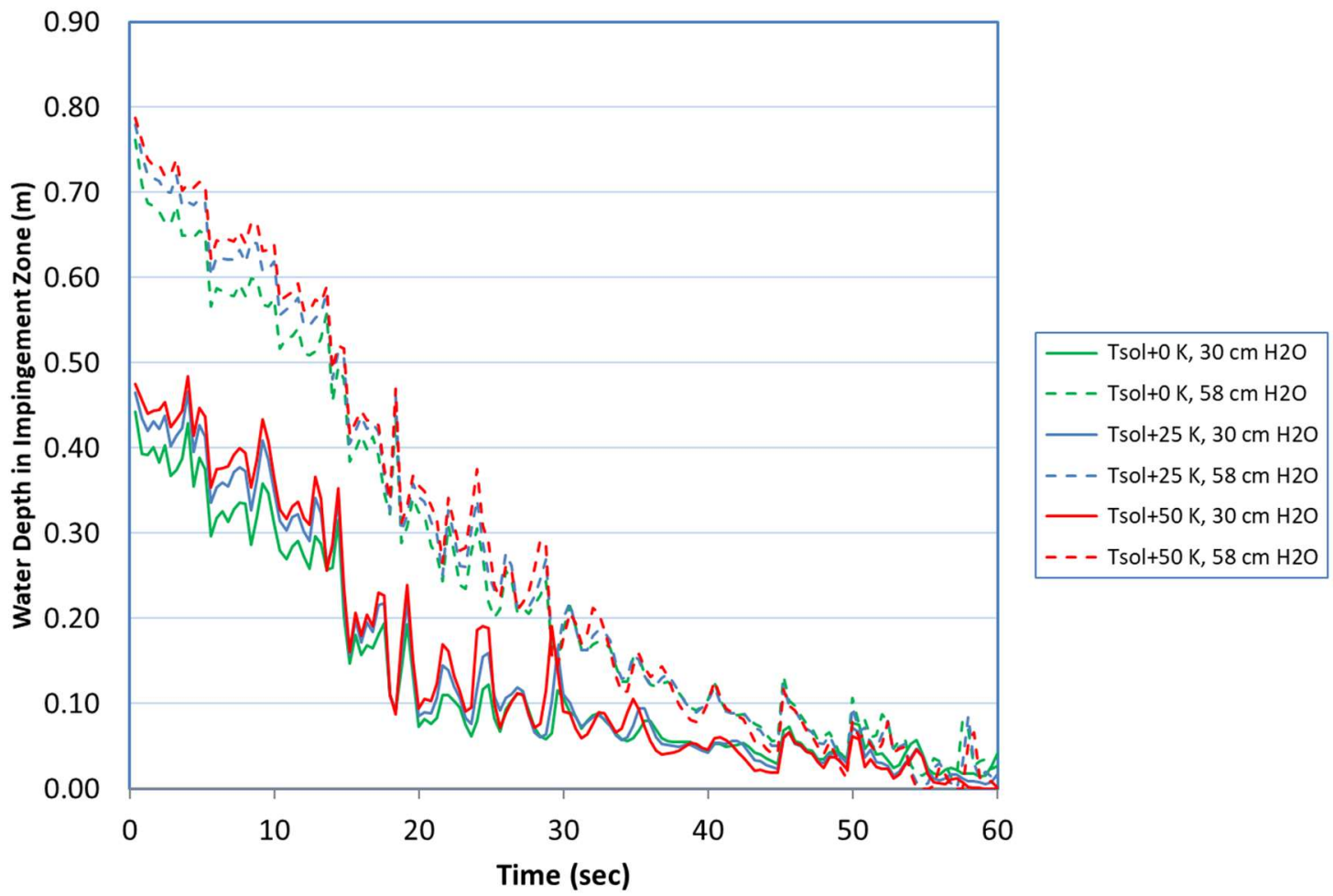

Figure 2-24. Remaining Water Depth in Jet Impingement Zone for MELCOR Cases. 


\subsection{CORQUENCH ANALYSES OF SAWA/SAWM}

\subsection{Modelling Assumptions}

Results from the MELTSPREAD [6] analyses of MAAP and MELCOR pours for Peach Bottom described in Section 2.0 were used to define initial conditions for long-term analysis with the upgraded version of CORQUENCH [7]. Specifically, in the MELTSPREAD simulation, 136 nodes were used to discretize the containment. In the CORQUENCH analysis, the MELTSPREAD discretization was collapsed into twelve nodes, as follows:

- The ten radial nodes used in the MELTSPREAD analysis for the sump were collapsed into a single node for the CORQUENCH analysis; a 2-D (radial-axial) cylindrical cavity erosion model was used for this node.

- The ten radial nodes used in the MELTSPREAD analysis for the balance of the pedestal floor were collapsed into a singular node; the 2-D (radial-axial) annular cavity erosion model was used for this node, with the side facing the sump treated as adiabatic (since lateral ablation at this interface is modeled in the sump simulation); ablation of the other wall was modeled, with this surface corresponding to the inner surface of the pedestal.

- The ten rectilinear nodes used in the MELTSPREAD analysis for the pedestal doorway were collapsed into a single node using the 2-D rectilinear cavity model with both sidewalls in contact with the pedestal wall undergoing ablation.

- The 26 annular nodes that constituted the $90^{\circ}$ sector outside the pedestal doorway in the MELTSPREAD simulation were collapsed into a single node; this node was modeled using the 1-D axial erosion model since the doorway opening adjacent to these nodes would not present a concrete wall boundary condition.

- Finally, the 80 rectilinear nodes used in the balance of the drywell annulus were collapsed into 8 nodes of uniform size. The width of these nodes was set equal to twice the drywell annular width as flow symmetry (with respect to the water coolant spreading model in CORQUENCH) is assumed. For the cases in which these nodes were occupied by melt (e.g., see Figure 2-8 for MELCOR distributions and 2-17 for MAAP distributions), each node was modeled using the 2-D rectilinear cavity erosion model with the side facing the drywell liner treated as adiabatic, and the other side (that corresponds to the pedestal outer wall) treated as undergoing ablation. Collapsed nodes not occupied by melt were treated as 'inactive' from the core-concrete interaction viewpoint, but were part of the floor area available for water harboring and relocation.

- Every other collapsed node in the annulus was assigned a downcomer to the torus for which water overflow would occur if the surface level exceeded $61 \mathrm{~cm}$ (24 inches).

- For the MELCOR simulation in which melt only flowed part way out of the pedestal doorway, all the nodes in the drywell annulus not occupied by melt (i.e., nodes 6-12) were treated as inactive, which means that water could collect and flow within these nodes (with the water inventory treated as adiabatic therein), but MCCI was not analyzed. The same assumption regarding the distribution of downcomers was made for these inactive nodes as was made for the MAAP case (see above bullet). 
With respect to treating the liner as adiabatic, this is admittedly a poor modelling assumption. However, CORQUENCH does not currently have the ability to evaluate heat transfer to the liner during MCCI. This is an upgrade that is outside the current scope of work.

Regarding other modelling assumptions made in this analysis, the specific limestonecommon sand concrete composition is the same as that used in the spreading calculations (see Table 2-2). CORQUENCH does not have a mechanistic containment modelling capability. Thus, the containment pressure was assumed to constant at $0.4 \mathrm{MPa}$ for all cases.

The phenomenological modelling assumptions were selected to be consistent with those used as part of the CORQUENCH validation activities [7] and are outlined here for completeness. Transient concrete heatup and decomposition was modelled using the approach originally developed by Corradini [19]. The heat transfer between the corium and concrete was modeled using the Bradley correlation [16] with the radial/axial power split multipliers set to 1.0; testing has shown [20] that this is valid for limestone-common sand concrete. In terms of melt eruption modeling, the melt entrainment coefficient was conservatively set at $0.02 \%$, which is at the lower end of reported values measured for this concrete type [20]. The particle beds formed by eruptions were assumed to have a porosity and average particle diameter of $40 \%$ and $2.8 \mathrm{~mm}$, respectively; these values are based on posttest examination results reported as part of the MACE program [21]. As with the validation calculations [7], the critical heat flux multipliers for determination of bulk cooling and film boiling breakdown were set at 0.5 . Water ingression was calculated using the modified Lister-Epstein model that was developed as part of the OECD/MCCI modeling activities [22] with the empirical multiplier in this model set at $C=9.0$. This is the value recommended on the basis of code validation studies [7]. Whenever unoxidized $\mathrm{Zr}$ cladding was calculated to be present in the melt, the $\mathrm{Zr}$ was assumed to be in solution with the core oxide phase, and condensed phase chemical reactions between $\mathrm{Zr}$ and $\mathrm{SiO}_{2}$ were calculated. The top crust thermal conductivity was calculated using the code property subroutines (as opposed to being defined as part of the code input). The effect of solids buildup in the melt on the corium viscosity was modeled with the Ishii-Zuber correlation [23] with the maximum solids fraction set at 1.0. The effective melt freezing temperature was based on the oxide phase solidus temperature. Melt void fraction was modeled using the Brockmann et al. [24] correlation.

For situations in which core debris has locally dried out or is not flooded with water, the debris is cooled by radiation heat transfer to overlying structure that is assumed to have an emissivity of 0.3 (typical of steel). In this phase of the analysis involving cavity flooding, it is assumed that the boundary temperature corresponds to saturation temperature at the containment pressure. Time-dependent decay heat in the core debris was calculated using the ANSI/ANS5.11994 standard [25] assuming 1384 effective full power days of irradiation time; the full power density at scram in this model was adjusted so that the decay heat levels shown in Table 2-1 are matched at the time of vessel failure for both the MAAP and MELCOR cases. Finally, all cases were run with a $5 \mathrm{~ms}$ second timestep, which has been found through testing to be adequate in terms of achieving a converged solution for all cases. 


\subsection{Definition of Parametric Cases for MAAP and MELCOR Scenarios}

The approach used for this parametric study is as follows. For both the MAAP and MELCOR 'base case' melt pour scenarios (see Table 2-3), the post-spreading core debris distributions calculated by MELTSPREAD were used to define the initial core debris distributions (i.e., melt, crust, and particle bed regions) as well as average melt temperature for each node in the collapsed CORQUENCH nodalization scheme. This work was expedited by using a small piece of software that was developed to automate this process; see Appendix D in [6]. The corresponding initial temperature and debris surface elevation distributions for the MAAP and MELCOR scenarios in the collapsed nodalization scheme are shown in Figures 3-1 and 3-2, respectively. As discussed in Section 2, the melt pour composition was constant for the MAAP pour over the duration of the pour phase, and the compositions in the post-spread debris for the MAAP case are also relatively uniform (minor differences are due to ingression of ablated concrete and metals oxidation). However, for the MELCOR pour, the initial pour composition was predominately oxidic, while the late phase composition was predominately metallic. This resulted in a skewed post-spreading composition distribution, with a majority of the metal retained in the pedestal, while the material in the doorway and on the drywell floor was predominately oxide; see Table 3-1.

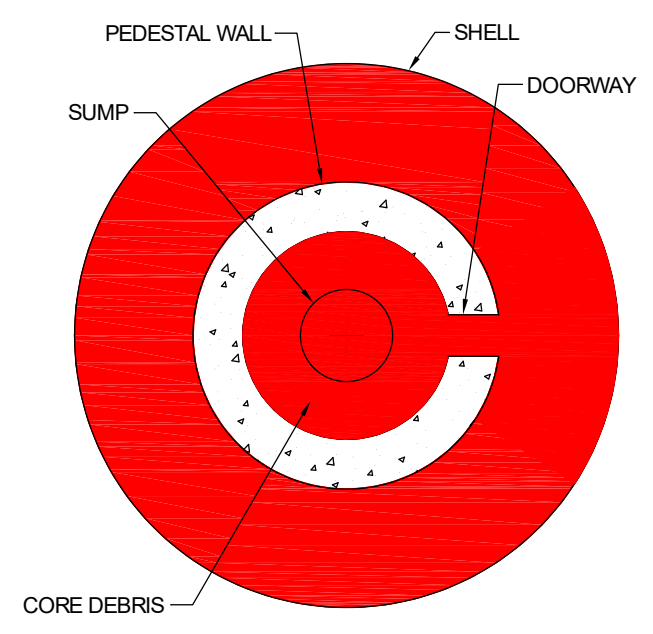

Plan View

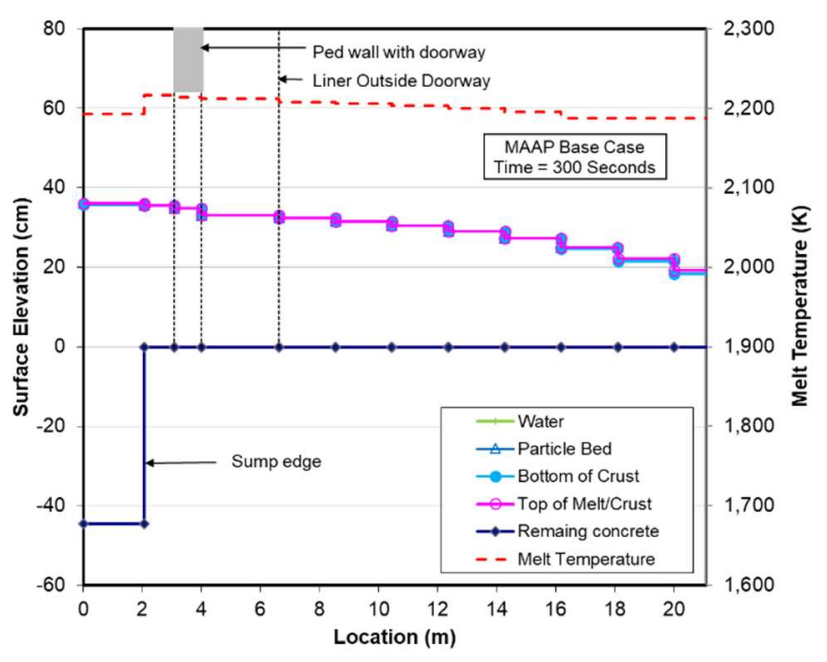

Elevation View

Figure 3-1. Initial Conditions for CORQUENCH Analysis Based on MELTSPREAD Results for MAAP Scenario. 


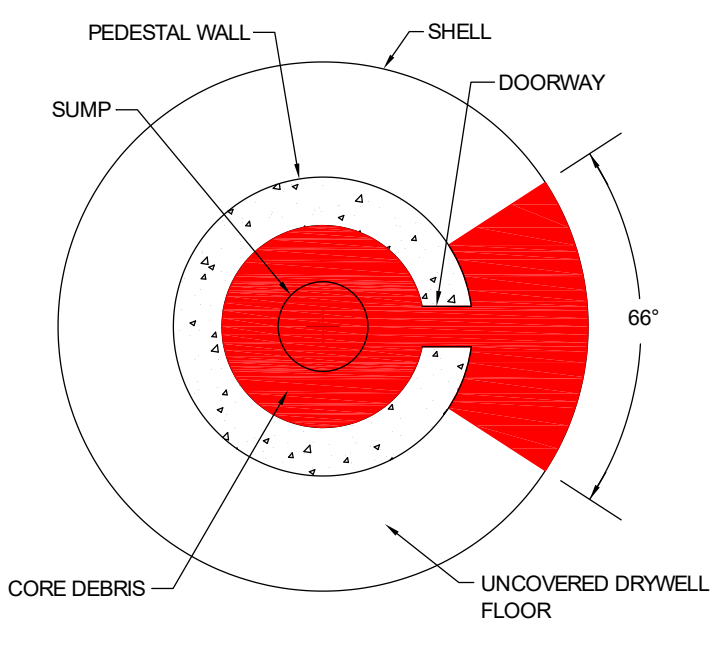

Plan View

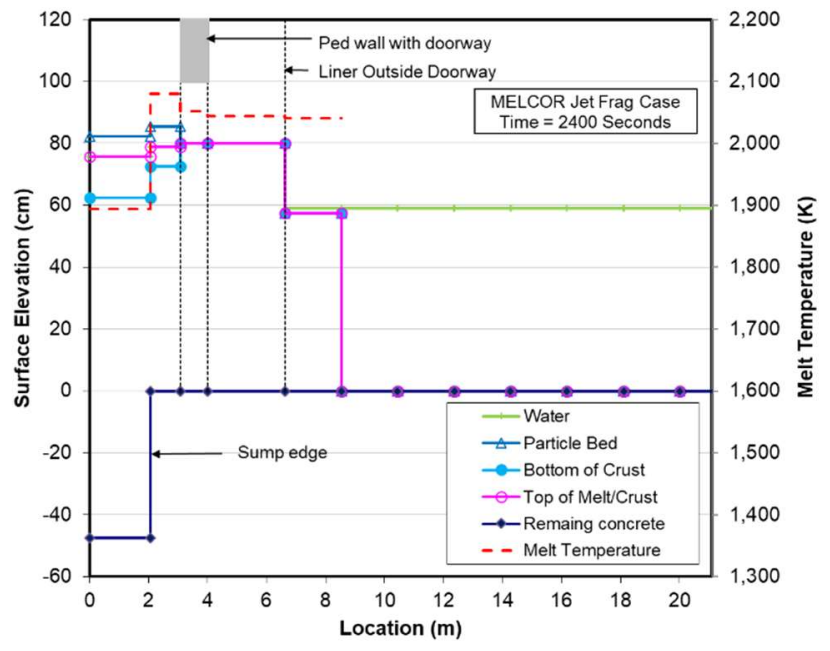

Elevation View

Figure 3-2. Initial Conditions for CORQUENCH Analysis Based on MELTSPREAD Results for MELCOR Scenario.

Table 3-1. Spatial Variation of Core Debris Composition for MELCOR Melt Pour Scenario.

\begin{tabular}{|c|l|c|c|}
\hline \multirow{2}{*}{ Node } & \multicolumn{2}{|c|}{ Location } & \multicolumn{2}{c|}{ Constituent in debris at location (wt\%) } \\
\cline { 3 - 4 } & & $\mathbf{U O}_{\mathbf{2}}$ & SS (Fe, Cr, Ni) \\
\hline 1 & Pedestal sump & 22.9 & 68.6 \\
\hline 2 & Pedestal floor (ring around sump) & 55.6 & 16.2 \\
\hline 3 & Pedestal doorway opening & 62.7 & 6.0 \\
\hline 4 & Floor area outside doorway & 67.3 & 3.5 \\
\hline 5 & Drywell floor adjacent to doorway & 70.0 & 2.5 \\
\hline
\end{tabular}

A few minor adjustments to the CORQUENCH input files were required for both the MAAP and MELCOR scenarios based on the results of the MELTSPREAD analyses. The reason is traceable to differences in the way the two codes model buildup of solids in the melt during spreading and core-concrete interaction. In particular, CORQUENCH calculates an effective bulk melt freezing temperature at each node based on the freezing points and volume fractions for the metal and oxide phases. Initial melt temperatures set by the user are then checked against these calculated bulk freezing temperatures, and if the specified initial melt temperature is not above the freezing temperature, an error message is written asking the user to increase the initial melt temperature to at least the freezing point so that the calculation can be initiated. This required the temperatures at the end of the spreading transient calculated by MELTSPREAD for the MELCOR scenario (i.e., see Figure 2-9 at 2400 seconds) to be increased for all nodes containing core debris (the result is shown in Figure 3-2) in order to initiate the CORQUENCH calculations. Conversely, for the MAAP scenario, the melt temperatures at the end of the transient calculated by MELTSPREAD at the very back of the annulus (i.e., see Figure 2-18 at 300 seconds) had to be increased slightly in order for the CORQUENCH runs to initiate. The criterion used in making these adjustments was that the melt temperature at each node had to be at least $10 \mathrm{~K}$ above the initial bulk freezing temperature calculated by CORQUENCH. If not, the temperature was set to $10 \mathrm{~K}$ above the freezing temperature. These adjustments are thought to have little effect on the final results as initial temperature impacts the 
amount of sensible energy in the melt which is minor relative to decay heat generation over the many hours of these calculations.

With the above steps accomplished, cases were set up for each pour scenario that parameterized on: i) the timing of water addition following completion of the melt spreading phase, and ii) the location in containment where the water was injected. The specific conditions that were analyzed are summarized in Table 3-2. In particular, water injection times were selected to be $0,1,2,3,4,6$, and 8 hours after completion of spreading. Referring to Section 2.1, for the MAAP scenario lower head failure occurs at 14.51 hours, leading to discharge of the core debris into containment. The spreading transient is effectively over 5 minutes after melt pour initiation. This point in time was selected to define the initial conditions for the CORQUENCH analysis. Thus, regarding the water injection times for the MAAP cases, ' $t=0$ ' corresponds to 14.59 hours into the accident sequence. Conversely, for the MELCOR scenario, the vessel fails at 12.95 hours, with the spreading transient effectively terminating at 2400 seconds after failure. Thus, ' $t=0$ ' for the water injection times for the MELCOR cases corresponds to 13.62 hours into the sequence.

For each scenario and water injection time, two cases were run, the first mocking up the condition in which water injection is through the core (with ' $\mathrm{CI}$ ' in Table 3-2 denoting 'Core Injection'). For these cases, the water was assumed to impact the upper surface of the core debris in the first node located at the center of the pedestal in the sump region. This would physically correspond to a situation in which the vessel lower head fails near the core radial centerline. One could assume that (and the user could adjust the input file to reflect the situation in which) water is injected at different node location(s) to simulate other vessel failure modes (e.g., nodes that vertically align near the outer diameter of the reactor vessel). However, this sensitivity has not been examined in this study. At higher injection flowrates (e.g., a few hundred gpm), it is likely that the specific location within the pedestal where water is injected is not that important, but this statement has not been verified as part of this study.

Aside from 'CI' cases, a second round of calculations was carried out to examine situations in which water is injected in the drywell (with 'DI' in Table 3-2 denoting 'Drywell Injection'). For these cases, the water is assumed to be uniformly distributed (effectively, as a spray) over all nodes in the drywell (i.e., Node 4 containing the core debris just outside the pedestal doorway, as well as the additional 8 nodes that constitute the balance of the drywell floor area; see Figures 3-1 and 3-2). Referring to Figure 3-2, for the MELCOR base case scenario the DI cases thus correspond to a situation in which water is initially injected over core debris that has partially spread out the pedestal doorway, with the balance of the water accumulating on the unaffected drywell floor area. However, for the MAAP base case scenario (Figure 3-1), DI results in flooding of core debris that has completely covered the drywell floor. 
Table 3-2. Timing of Water Injection (relative to completion of the transient spreading phase) and Injection Location for Parametric Studies.

\begin{tabular}{|c|c|}
\hline Case Descriptor & Conditions \\
\hline CI, $0 \mathrm{hr}$ & $\begin{array}{l}\text { - Water injection location: 'Core Injection' } \\
\text { - Timing of water injection: } 0 \text { hours after completion of spreading }\end{array}$ \\
\hline DI, $0 \mathrm{hr}$ & $\begin{array}{l}\text { - Water injection location: 'Drywell Injection' } \\
\text { - Timing of water injection: } 0 \text { hours after completion of spreading }\end{array}$ \\
\hline CI, $1 \mathrm{hr}$ & $\begin{array}{l}\text { - Water injection location: 'Core Injection' } \\
\text { - Timing of water injection: } 1 \text { hours after completion of spreading }\end{array}$ \\
\hline DI, $1 \mathrm{hr}$ & $\begin{array}{l}\text { - Water injection location: 'Drywell Injection' } \\
\text { - Timing of water injection: } 1 \text { hours after completion of spreading }\end{array}$ \\
\hline CI, 2 hr & $\begin{array}{l}\text { - Water injection location: 'Core Injection' } \\
\text { - Timing of water injection: } 2 \text { hours after completion of spreading }\end{array}$ \\
\hline DI, $2 \mathrm{hr}$ & $\begin{array}{l}\text { - Water injection location: 'Drywell Injection' } \\
\text { - Timing of water injection: } 2 \text { hours after completion of spreading }\end{array}$ \\
\hline CI, $3 \mathrm{hr}$ & $\begin{array}{l}\text { - Water injection location: 'Core Injection' } \\
\text { - Timing of water injection: } 3 \text { hours after completion of spreading }\end{array}$ \\
\hline DI, $3 \mathrm{hr}$ & $\begin{array}{l}\text { - Water injection location: 'Drywell Injection' } \\
\text { - Timing of water injection: } 3 \text { hours after completion of spreading }\end{array}$ \\
\hline $\mathrm{CI}, 4 \mathrm{hr}$ & $\begin{array}{l}\text { - Water injection location: 'Core Injection' } \\
\text { - Timing of water injection: } 4 \text { hours after completion of spreading }\end{array}$ \\
\hline DI, $4 \mathrm{hr}$ & $\begin{array}{l}\text { - Water injection location: 'Drywell Injection' } \\
\text { - Timing of water injection: } 4 \text { hours after completion of spreading }\end{array}$ \\
\hline CI, $6 \mathrm{hr}$ & $\begin{array}{l}\text { - Water injection location: 'Core Injection' } \\
\text { - Timing of water injection: } 6 \text { hours after completion of spreading }\end{array}$ \\
\hline DI, $6 \mathrm{hr}$ & $\begin{array}{l}\text { - Water injection location: 'Drywell Injection' } \\
\text { - Timing of water injection: } 6 \text { hours after completion of spreading }\end{array}$ \\
\hline CI, $8 \mathrm{hr}$ & $\begin{array}{l}\text { - Water injection location: 'Core Injection' } \\
\text { - Timing of water injection: } 8 \text { hours after completion of spreading }\end{array}$ \\
\hline DI, $8 \mathrm{hr}$ & $\begin{array}{l}\text { - Water injection location: 'Drywell Injection' } \\
\text { - Timing of water injection: } 8 \text { hours after completion of spreading }\end{array}$ \\
\hline
\end{tabular}

Aside from the location and timing of water injection, additional input needed for the analysis includes the water injection flowrate and temperature. For this work, the temperature of the injected water is taken to be $20 \mathrm{C}(293 \mathrm{~K})$. Regarding water injection flowrate, an initial Severe Accident Water Addition (SAWA) stage is modeled assuming a constant flowrate of 31.5 $\mathrm{kg} / \mathrm{sec}(500 \mathrm{gpm})$; the duration of this phase was taken to be 5 hours after onset of injection. The SAWA phase is followed by a Severe Accident Water Management (SAWM) phase in which the injection flowrate is reduced to $6.3 \mathrm{~kg} / \mathrm{sec}(100 \mathrm{gpm})$ for the balance of the calculation which, for all cases, was 72 hours. These values have been assumed as a basis for moving forward with this study, and could be adjusted in future work to study additional parametric effects.

\subsection{MELCOR SAWA/SAWM Modeling Results}

Representative results from the MELCOR melt pour cases are provided in Figures 3-3 and 3-4 for the ' 0 hour' CI and DI cases, respectively. These results have been integrated over all 12 nodes that constitute the cavity nodalization model and thus provide an overall indication 
of the evolution of several key features that include heat transfer, debris mass, and steam/water flowrate/mass distributions during the SAWA/SAWM stages of the accident sequence.
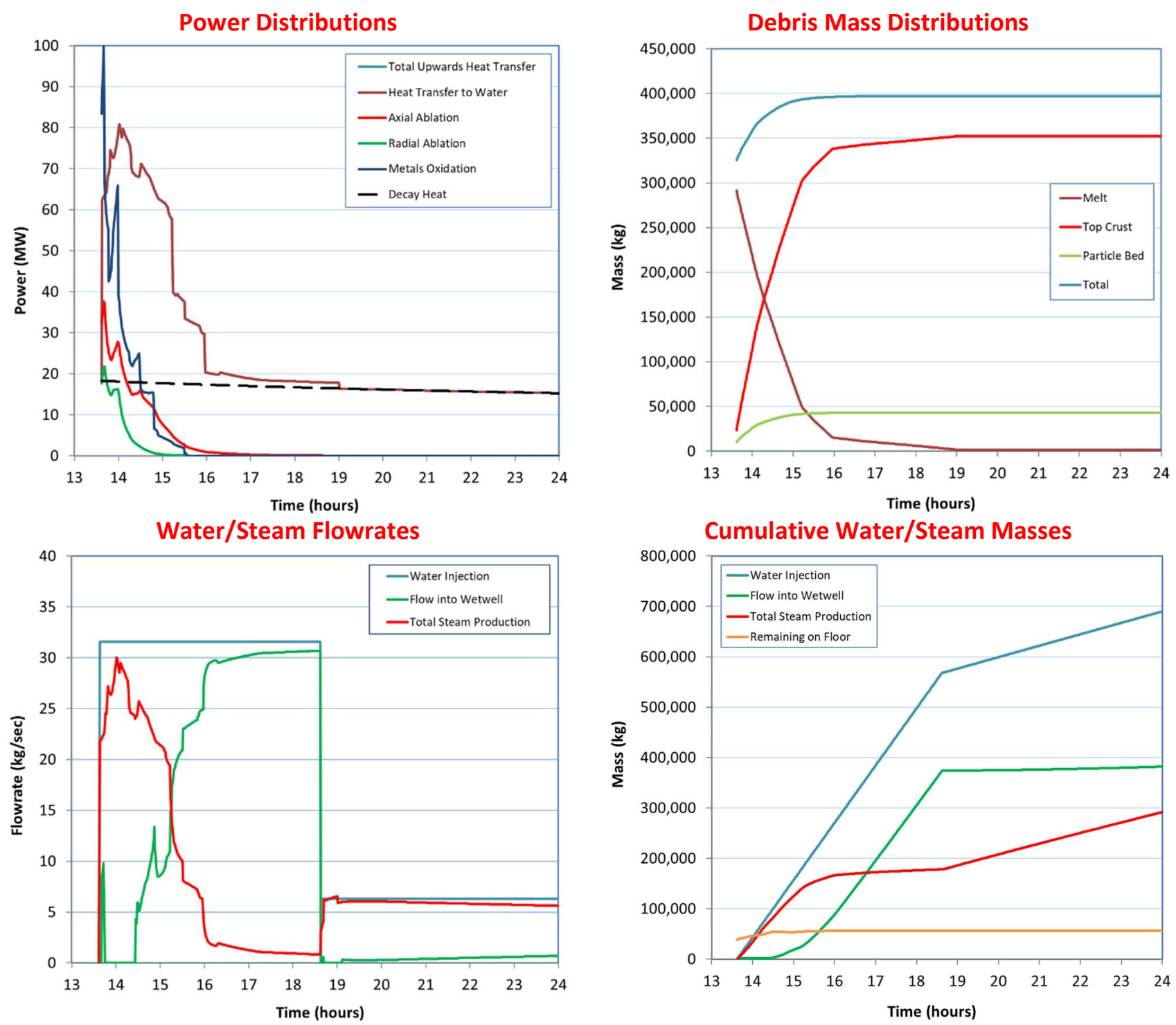

Figure 3-3. Integrated Power, Debris Mass, and Water/Steam Distribution Results for MELCOR 'CI, 0 hr' Case.

Referring to Figure 3-3, the core debris is noted to be quenched and thermally stabilized at $\sim 19$ hours into the accident sequence for this early flooding CI case, despite the relatively deep core debris accumulations calculated for the MELCOR pour scenario. This is evidenced in the simulation by the fact that heat transfer rate to water falls to match the decay heat level (indicating that the debris has been fully quenched to $\mathrm{T}_{\text {sat }}$ ), and the heat loss to concrete surfaces falls to zero. Efficient cooling of the deep debris accumulation in the sump is aided by the prediction of low core oxide content in this region (see Table 3-1). Since the fission product decay heat modeling in both MELTPSPREAD and CORQUENCH assumes that the decay heat is partitioned in direct proportion to the amount of fuel $\left(\mathrm{UO}_{2}\right)$ that is locally present, this results in a reduced decay heat level in the sump making the material easier to cool. The final debris 
distribution is dominated by porous crust cooled by water ingression, with a lesser amount of material in the form of a particle bed over the crust. SAWA for this case began at 13.62 hours (i.e., start of the calculation), and flow was reduced to implement SAWM at 18.62 hours. Thus, the prediction that the core debris was quenched at 19 hours indicates that the 5 hour time interval allowed for SAWA was reasonable for quenching and cooling the material for this case. During the SAWA stage, overflow into the wetwell was initially small, and increased as the sensible heat was gradually removed from the debris.
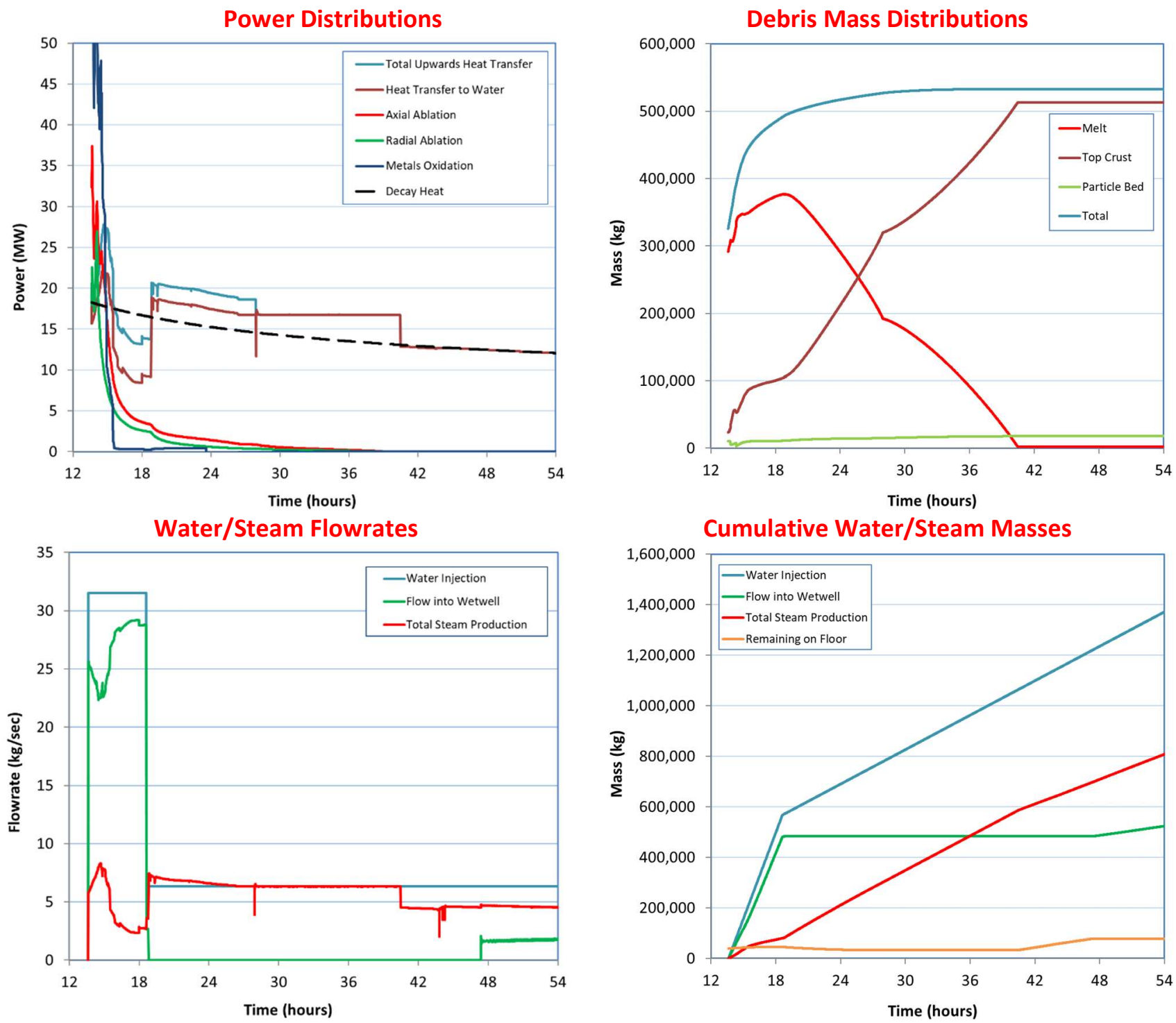

Figure 3-4. Integrated Power, Debris Mass, and Water/Steam Distribution Results for MELCOR 'DI, 0 hr' Case.

Referring to Figure 3-4, quite different behavior is noted for the MELCOR DI case. In particular, the core debris is not quenched and thermally stabilized until $\sim 41$ hours into the accident sequence. Moreover, the power distribution plot indicates that water injected into the drywell is not able to flow through the pedestal doorway and begin to cool the core debris therein until $\sim 19$ hours. This is partially due to the prediction that the initial core debris elevations in the 
pedestal, pedestal doorway, and on the drywell floor outside the doorway are all above the water height that is essentially fixed at the downcomer inlet elevation of $61 \mathrm{~cm}$ (Figure 3-2). However, as explained below, as concrete ablation proceeds, slumping of the debris upper surface elevations occurs due to concrete densification upon melting. This eventually causes the debris elevations to fall below the maximum water height of $61 \mathrm{~cm}$ at $\sim 19$ hours. However, as previously noted for this case, SAWA was initiated at 13.62 hours, with a flow reduction to implement SAWM at 18.62 hours. Thus, the flow is reduced at approximately the same time that water flow into the pedestal is able to occur. At the reduced flowrate, the cooling process is water starved, and so water is not able to fully cover the core debris in the sump until $\sim 28$ hours, thereby reaching the desired state in which the material is fully covered with water.

As a result of these effects, prior to $\sim 19$ hours, most of the water that is injected is able to bypass the core debris and simply overflow into the wetwell. Also note that since the pedestal region remains dry up until this time, the crust material initially present over the debris in the pedestal re-melts fairly quickly, causing the particle bed material formed by jet fragmentation during the melt spreading phase to be subsumed back into the melt. During the time interval from the implementation of SAWM up to $\sim 47$ hours, there is no additional overflow of water into the wetwell as all injected water is converted to steam until the debris is quenched at $\sim 41$ hours, after which time the water level in the drywell gradually rises to the downcomer inlets.

Regarding debris slumping behavior, the principal parameters affecting this process are: i) initial concrete density, ii) the mass of gas liberated (lost) from the concrete during ablation (i.e., $\mathrm{CO}_{2}$ and $\mathrm{H}_{2} \mathrm{O}$; see Table 2-2), and iii) the density of the concrete slag that remains after decomposition of the gas-bearing concrete constituents [i.e., calcium hydroxide, $\mathrm{Ca}(\mathrm{OH})_{2}$; calcium carbonate, $\mathrm{CaCO}_{3}$; and dolomite, $\left.\mathrm{MgCa}\left(\mathrm{CO}_{3}\right)_{2}\right]$. Specifically, the volumetric contraction upon melting can be found from the equation:

$$
\left\{\begin{array}{c}
\text { Fractional Concrete Volume } \\
\text { Reduction During Ablation }
\end{array}\right\}=1-\frac{\left(1-\chi_{g}\right) \rho_{\text {con }}}{\rho_{\text {slag }}}
$$

where, for the limestone-common sand composition used as part of this study,

$$
\begin{array}{lll}
\chi_{g} & = & \text { concrete gas mass fraction }=0.24(\text { see Table } 2-2), \\
\rho_{\text {con }} & = & \text { initial concrete density }=2540 \mathrm{~kg} / \mathrm{m}^{3}, \text { and } \\
\rho_{\text {slag }}= & \text { density of slag remaining after ablation }=2780 \mathrm{~kg} / \mathrm{m}^{3}
\end{array}
$$

Note that the initial concrete and slag densities provided above were calculated by the CORQUENCH property routines [7] given the concrete composition shown in Table 2-2. Substitution of this data into the above equation yields a volume contraction upon melting of $\sim 31 \%$, which is considerable and indicative of limestone concrete due to the large gas content of this material. The impact of this slumping behavior on the evolution of the surface elevations for the MELCOR DI case is shown in Figure 3-5. For situations in which the core debris is locally covered by water, then melt eruptions form porous particle beds that would allow water to flow through them fairly freely. Depletion of the melt zone to form these particle beds further accelerates the rate of surface elevation decline. 


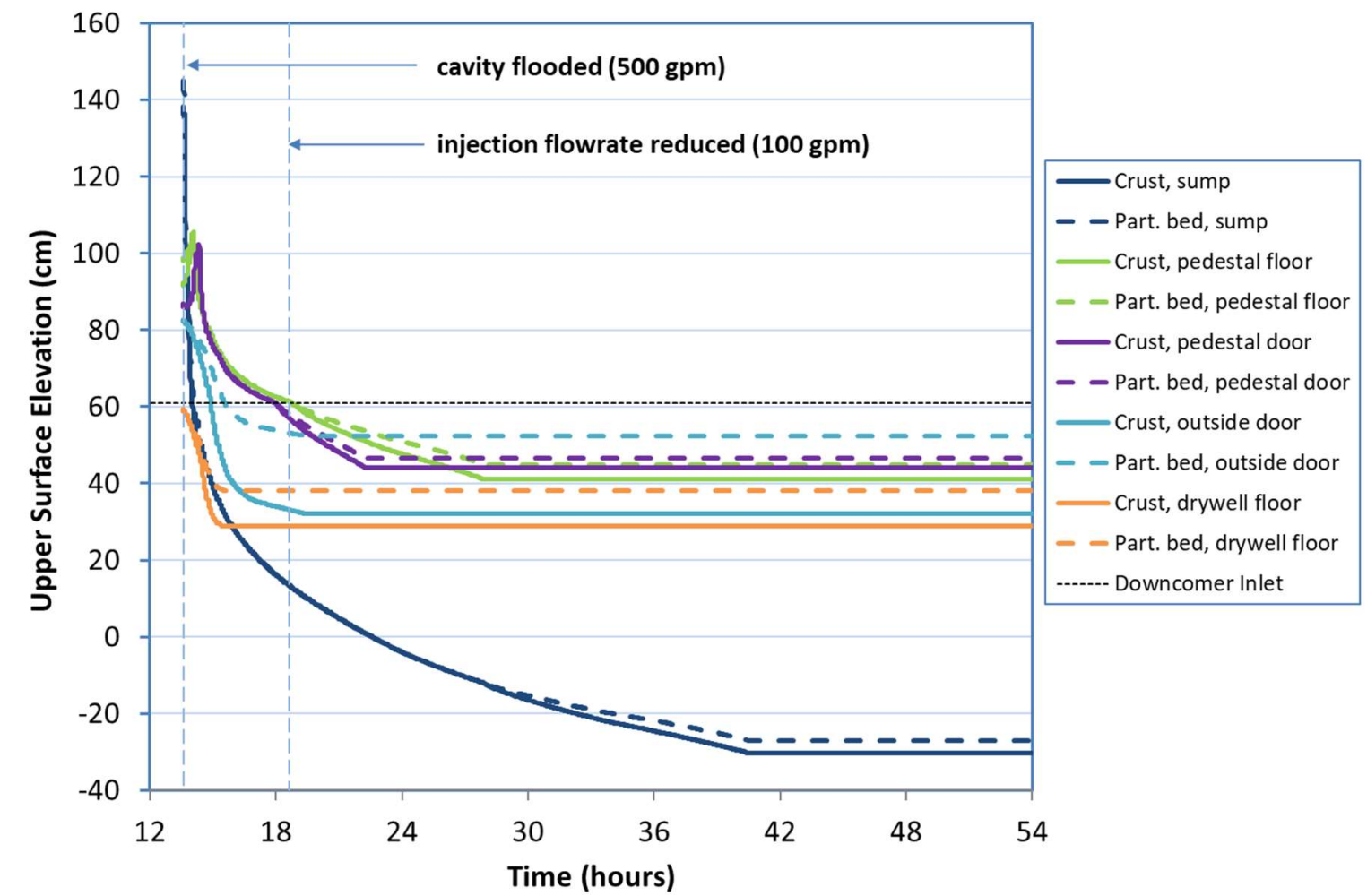

Figure 3-5. Upper Surface Elevations of Core Debris in Pedestal and Drywell Regions for the MELCOR 'DI, 0 hr' Case (includes effect of melt void fraction due to gas sparging).

Note that the impact of concrete slumping would not be as significant for plants built with siliceous concrete since the gas content of that concrete type is much less compared to limestone-common sand. Depending upon the location of water injection, this can affect the cooling behavior of the core debris, as discussed above.

The effect of delaying water injection on the time to stabilize the core debris for the MELCOR CI and DI cases is shown in Figure 3-6, while the corresponding impact on ablation depth in the sump and the area outside the pedestal doorway are shown in Figures 3-7 and 3-8, respectively. As one would expect, delaying water injection extends the time to complete debris quench further out into the accident sequence. However, note that in the range of parameters investigated in this study, the core debris was predicted to be stabilized within the 72 hour study window for all cases. Differences in stabilization time and the extent of sump ablation for the CI and DI cases are most dramatic for low delay times, with CI being the clearly desired route based on the above discussion. However, ablation outside the pedestal doorway was similar for the CI and DI cases, primarily due to the prediction that both are covered by water regardless of injection pathway. From Figures 3-6 and 3-7 it is noted that the time to stabilization and the extent of sump ablation merge after 3-4 hours of injection delay. This is due to the prediction that, after this time interval, slumping of the core debris due to concrete densification upon melting, combined with melt eruptions, is generally sufficient to allow water to flood back into the pedestal and start the cooling process therein even if drywell injection is utilized. 


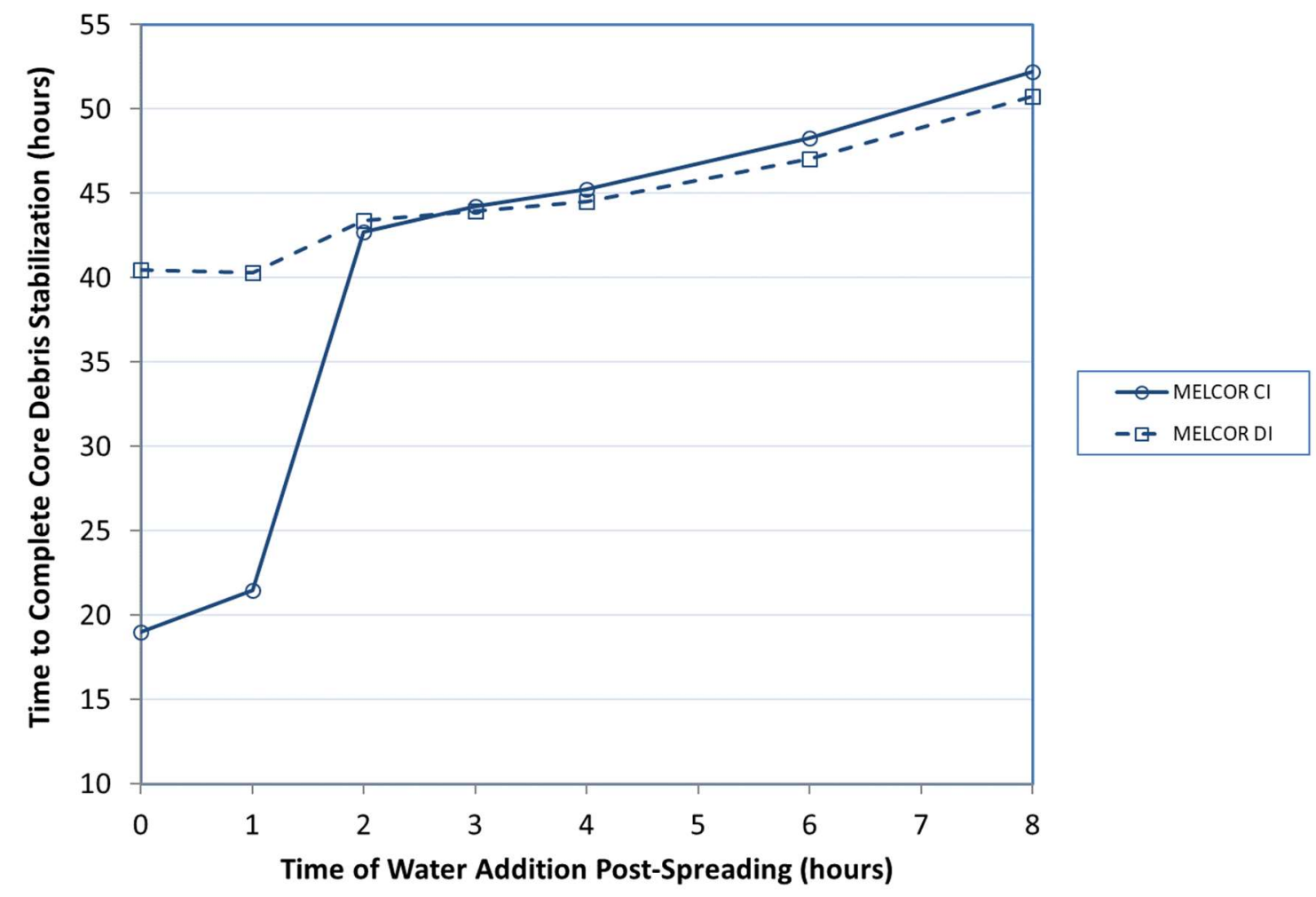

Figure 3-6. Debris Stabilization Times for MELCOR CI and DI Cases.

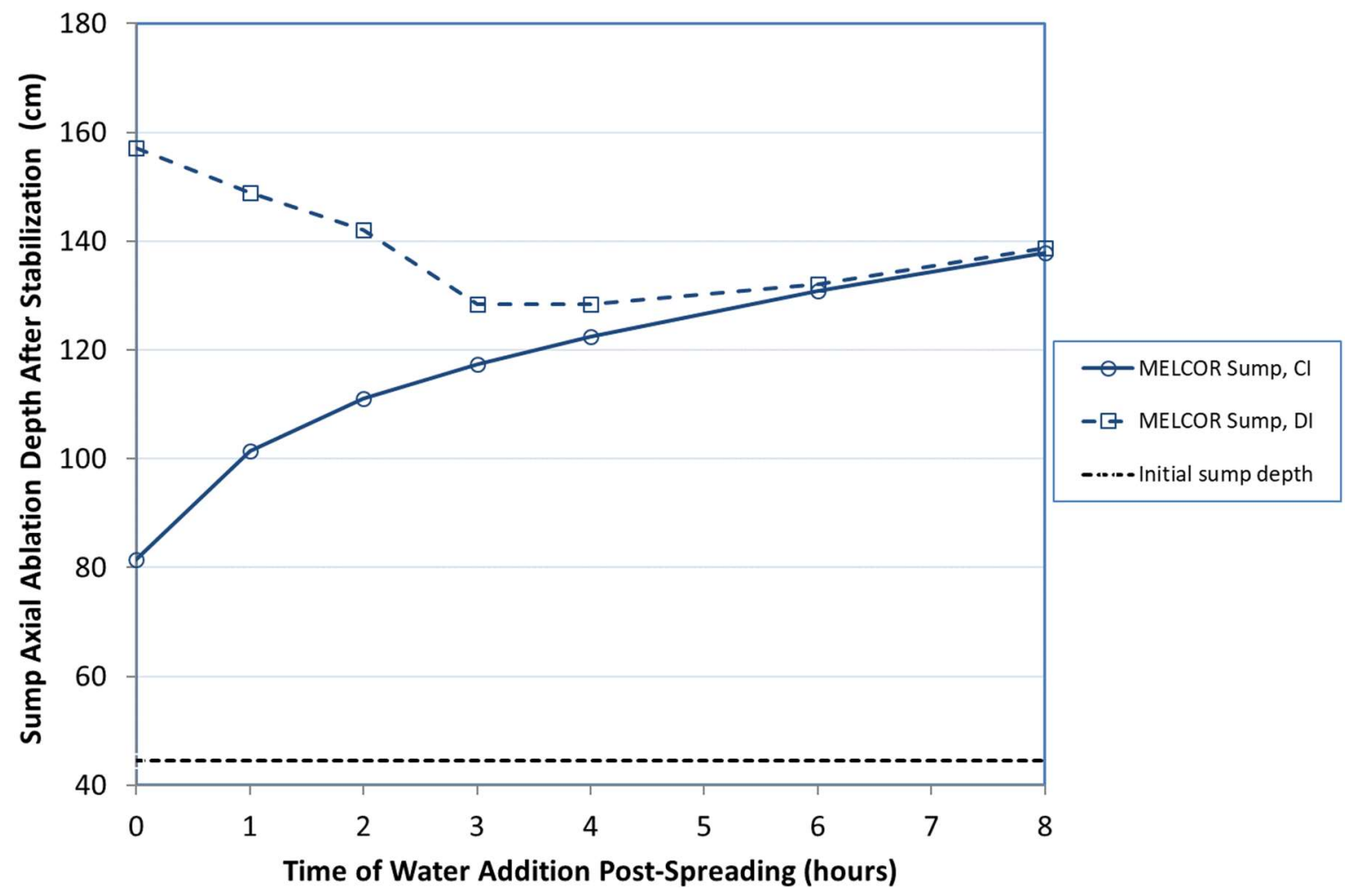

Figure 3-7. Sump Axial Ablation Depths at Stabilization for MELCOR CI and DI Cases. 


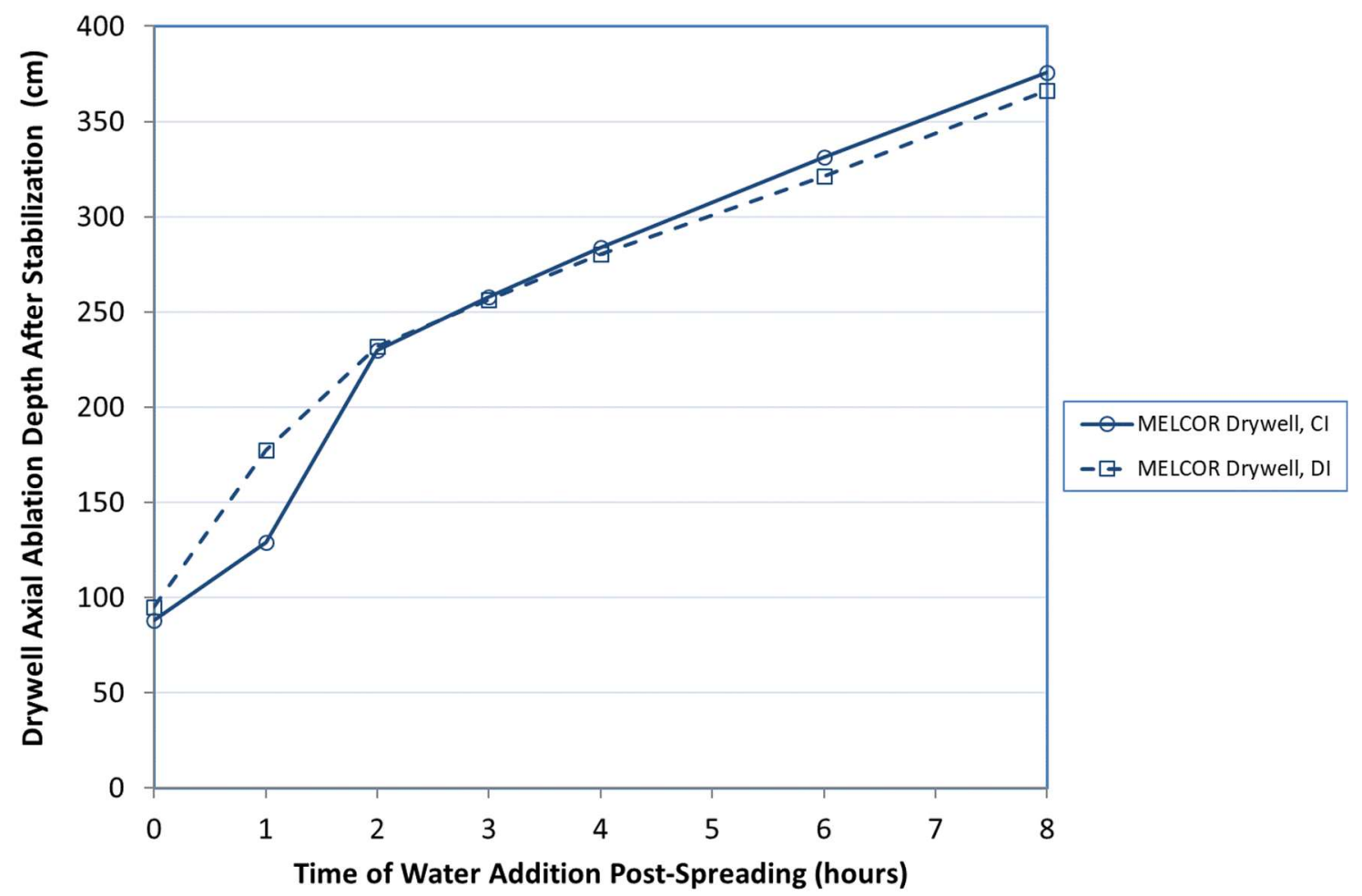

Figure 3-8. Axial Ablation Depths Outside Pedestal Door for MELCOR CI and DI Cases.

Additional detail regarding the water overflow behavior into the wetwell for the MELCOR cases is provided in Figure 3-9. The flat plateaus in the wetwell water level are indicative of situations in which SAWM is implemented before the debris is fully quenched. This results in a water-limited cooling process in which all injected water is converted to steam. As can be seen from Figure 3-9, for the CI cases the overall duration of these plateaus increases systematically with the delay time to water injection. This is due to dry ablation prior to water injection that allows additional concrete to ingress into the melt, and this effect has been experimentally shown [22] to degrade the water ingression cooling mechanism, and the modeling reflects this behavior [7].

Additional examination of Figure 3-9 indicates the opposite trend for the DI cases; i.e., the duration of the plateau decreases with increasing injection delay. As noted earlier, the debris surface elevations are reduced by concrete densification upon melting as ablation proceeds, and since ablation rates are higher for dry cavity situations, the longer the injection is delayed, the sooner deep accumulations of material within the pedestal can be reflooded, thereby allowing the cooling process to proceed.

The impact of flooding location and injection time on the extent of non-condensable gas production (i.e. $\mathrm{H}_{2}, \mathrm{CO}, \mathrm{CO}_{2}$ ) is shown in Figure 3-10. The results indicate that for delay times of less than 6 hours, CI reduces the amount of gas production, and that the difference becomes quite large as the delay is reduced (e.g., factor of $\sim 3$ for the 0 hour delay case). However, for longer delays (i.e., 6-8 hours), the results are indistinguishable due reasons discussed above. 


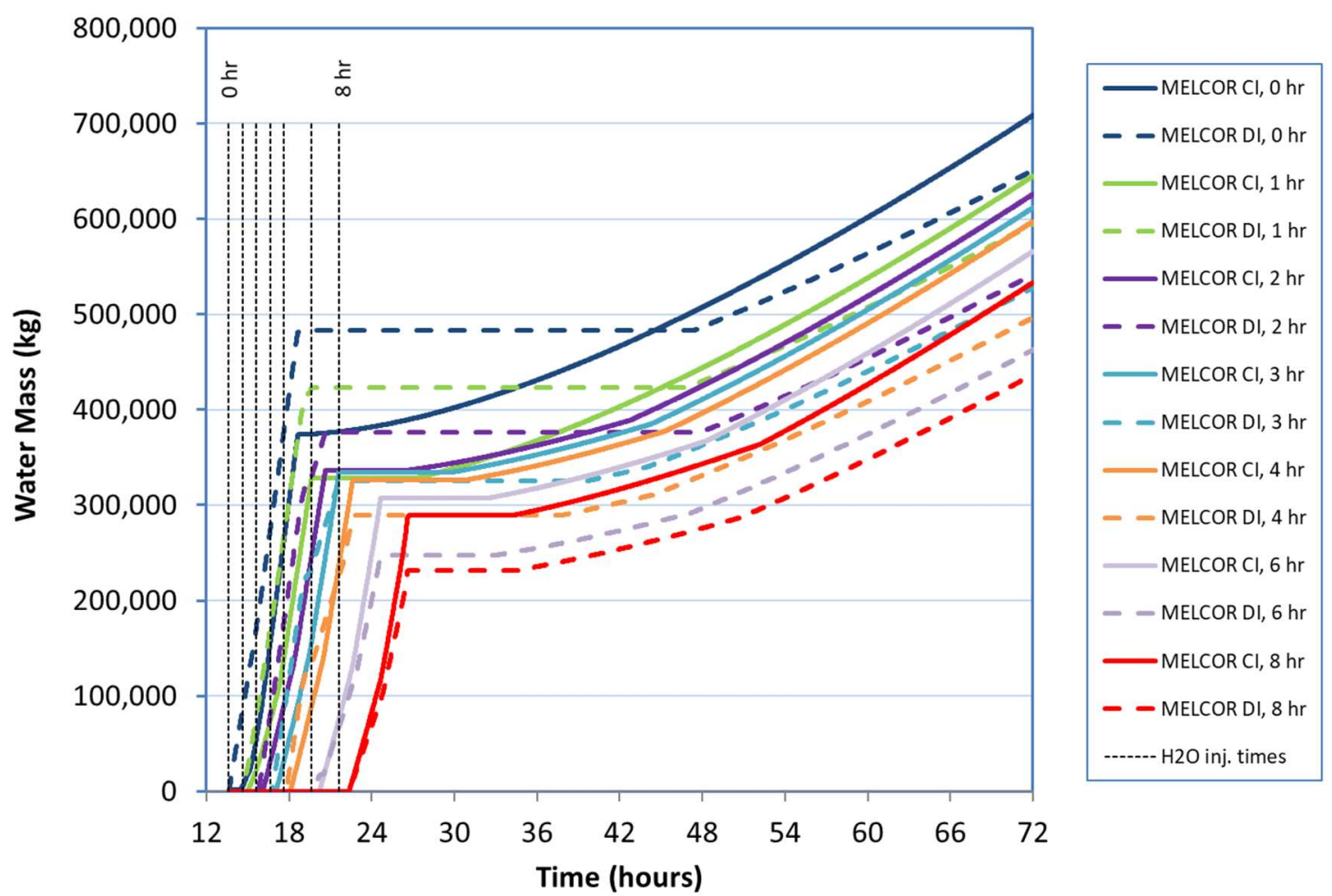

Figure 3-9. Predicted Water Overflow into the Wetwell for MELCOR Parametric Cases.

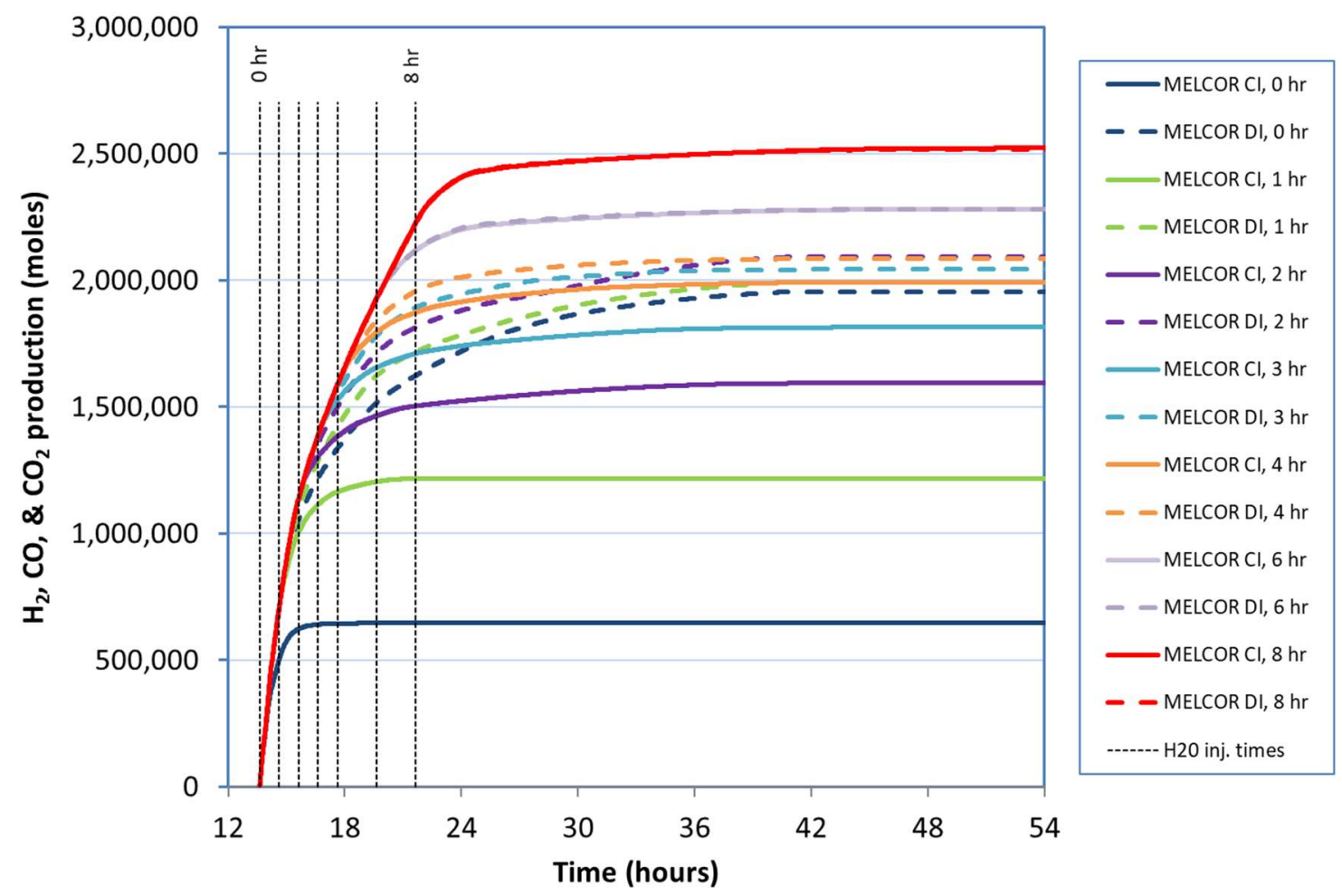

Figure 3-10. Predicted Non-condensable Gas Production for MELCOR Parametric Cases. 


\subsection{MAAP SAWA/SAWM Modeling Results}

Representative results from the MAAP melt pour cases are provided in Figures 3-11 and 3-12 for the ' 0 hour' CI and DI cases, respectively. As noted for the MELCOR cases, these results have been integrated over all 12 nodes used in the cavity nodalization model and thus provide an overall indication of the evolution of several key features that include heat transfer, debris mass, and steam/water flowrate/mass distributions during the SAWA/SAWM stages of the accident sequence.
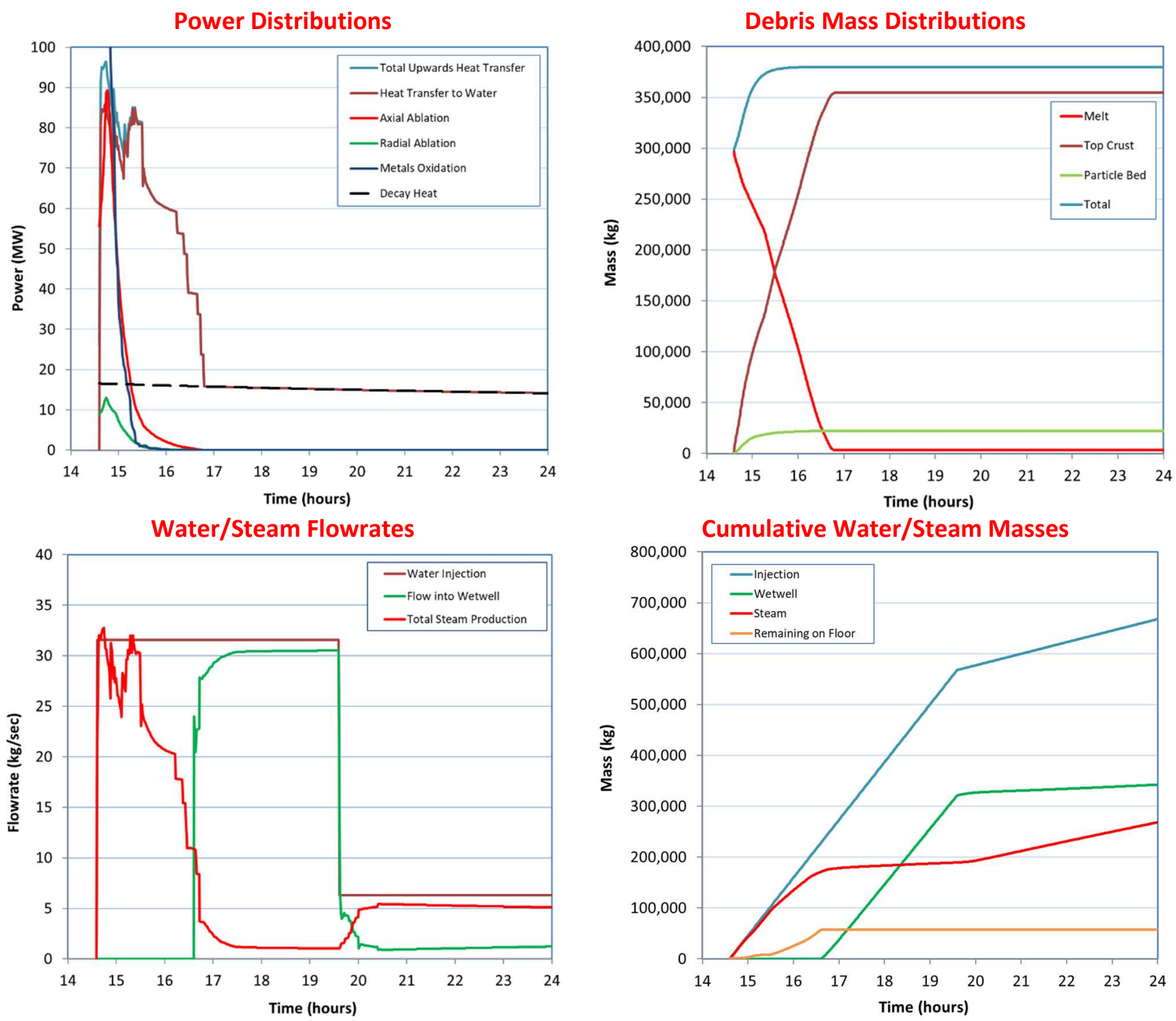

Figure 3-11. Integrated Power, Debris Mass, and Water/Steam Distribution Results for MAAP 'CI, 0 hr' Case. 

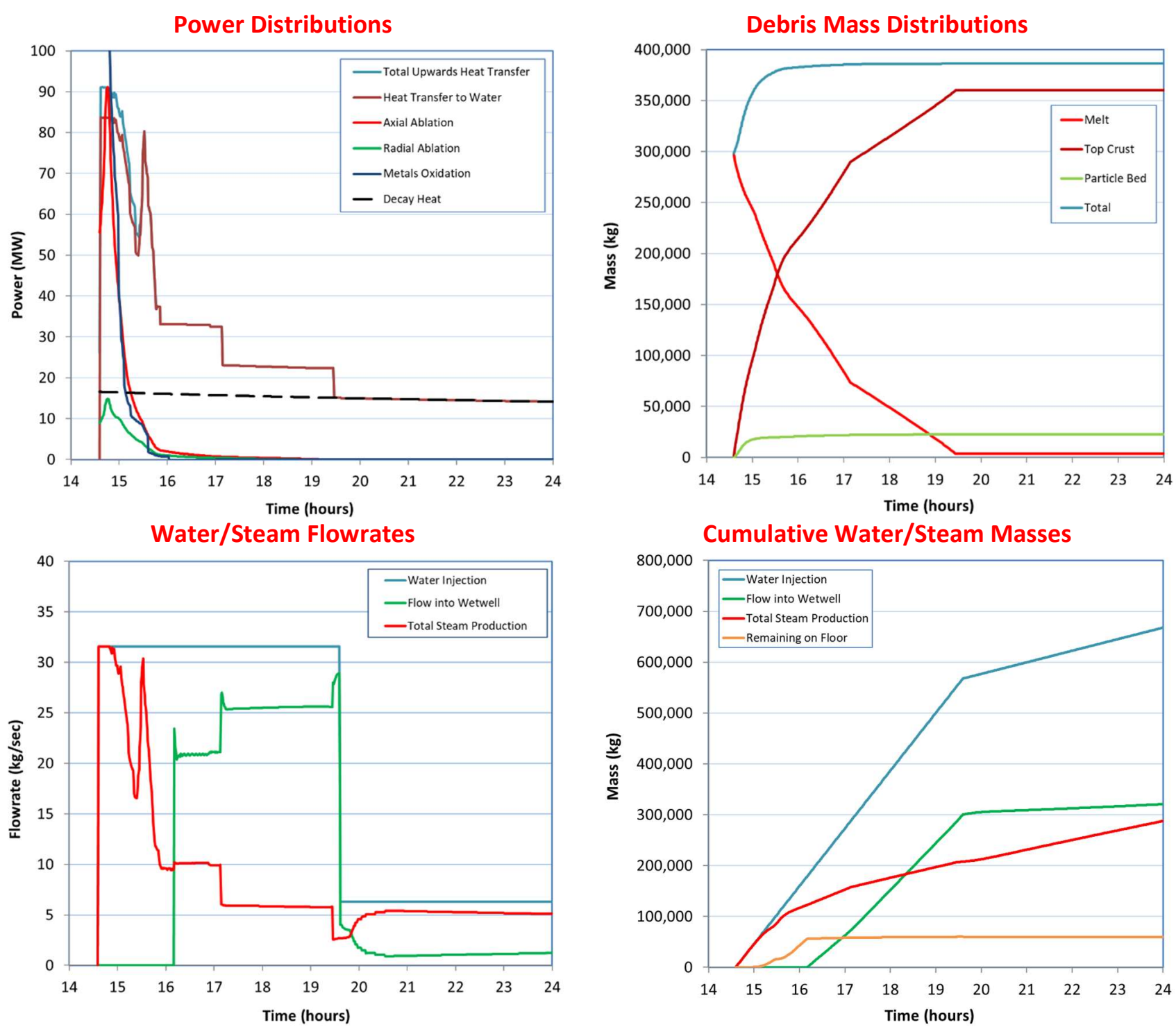

Figure 3-12. Integrated Power, Debris Mass, and Water/Steam Distribution Results for MAAP 'DI, 0 hr' Case.

Referring to Figure 3-11, the core debris is noted to be quenched and thermally stabilized at $\sim 17$ hours into the accident sequence for this early flooding CI case. This is generally similar to the stabilization time calculated for the analogous MELCOR case, despite the prediction that the MAAP melt depths are much shallower compared to the MELCOR distribution (e.g., see Figures 3-1 and 3-2). The reason for this is principally due to the non-uniform melt composition distribution for the MELCOR case; see Table 3-1. In particular, the deepest accumulations for both cases are in the sumps, but for the MELCOR case, the sump contains a relatively small fission product fraction (viz. proportional to fuel content based on MELTSPREAD-

CORQUENCH modeling approach), with the majority of the fission products concentrated in the core debris located in the pedestal doorway and on the drywell floor. In this region, the melt depths and compositions are similar to that calculated for the material in the sump for the MAAP scenario; hence, similar debris stabilization times are calculated. 
As for the MELCOR scenario, the final debris distribution is dominated by crust material cooled by water ingression, with a lesser amount of material in the form of a particle bed formed by melt eruptions over the crust material. SAWA for this case began at 14.59 hours (i.e., start of the calculation), and flow was reduced to implement SAWM at 19.59 hours. Thus, the prediction that the core debris was quenched at 17 hours indicates that the 5 hour time interval allowed for SAWA was more than adequate for quenching and cooling the core debris in this case.

Comparing Figures 3-11 and 3-12 indicates that, unlike the MELCOR scenario, the overall debris cooling behavior is somewhat similar for the CI and DI cases. The commonality is principally due to the prediction that for the MAAP scenario the initial core debris distribution lies significantly below the downcomer inlet elevation of $61 \mathrm{~cm}$ (see Figure 3-1), thereby allowing water to freely flow between the pedestal and drywell regions, regardless of injection location. One minor difference is that in the DI case, the injected water is (by assumption) uniformly distributed over the large drywell floor area of $\sim 87 \mathrm{~m}^{2}$, which can be compared to $30 \mathrm{~m}^{2}$ in the pedestal region. This large surface area, coupled with the prediction that core debris has completely covered this area in the MAAP scenario, results in a situation in which the cooling rate is water starved at the SAWA injection rate of 500 gpm over the first 20 minutes of the transient. However, after this time the debris cooling rate in the drywell has fallen to the point where water is able to accumulate and start flowing into the pedestal, eventually submerging the material therein. Dry ablation in the sump up to this time results in concrete ingress that degrades the water ingression cooling rate [7,22]; this results in a delay in the debris stabilization time from $\sim 17$ hours for the CI case to $\sim 19.5$ hours for this DI case.

The effect of delayed water injection on the time to stabilize the core debris for the MAAP cases is shown in Figure 3-13, while the corresponding impact on ablation depth in the sump and the area outside the pedestal doorway are shown in Figures 3-14 and 3-15, respectively. The MELCOR results presented earlier are also provided for comparison. Delayed injection is again found to extend the time to complete debris quench further out into the accident sequence, and to increase the extent of ablation in the sump and in the pedestal regions.

In comparison to the MELCOR results, the trends for the MAAP cases are noted to be more systematic and easier to interpret. This is due to two simplifying factors relative to the MELCOR scenario: i) the fission product decay heat is uniformly distributed throughout the core debris, and ii) the debris surface elevation profile provides an initial flow path for flooding regardless of the injection pathway. One significant difference between the MAAP and MELCOR scenarios is that ablation in the drywell is much smaller for the MAAP cases, which is due to the much shallower melt depth in that region compared to the MELCOR scenario.

Additional detail regarding water overflow behavior into the wetwell for the MAAP cases is provided in Figure 3-16. The lack of a plateau occurring in the accumulated overflow mass for any of these cases indicates that the 5 hour SAWA period was of sufficient duration to quench and thermally stabilize the core debris before the flowrate was reduced. This is in contrast to several of the MELCOR cases (particularly the DI cases; see Figure 3-9) in which the 5 hour 


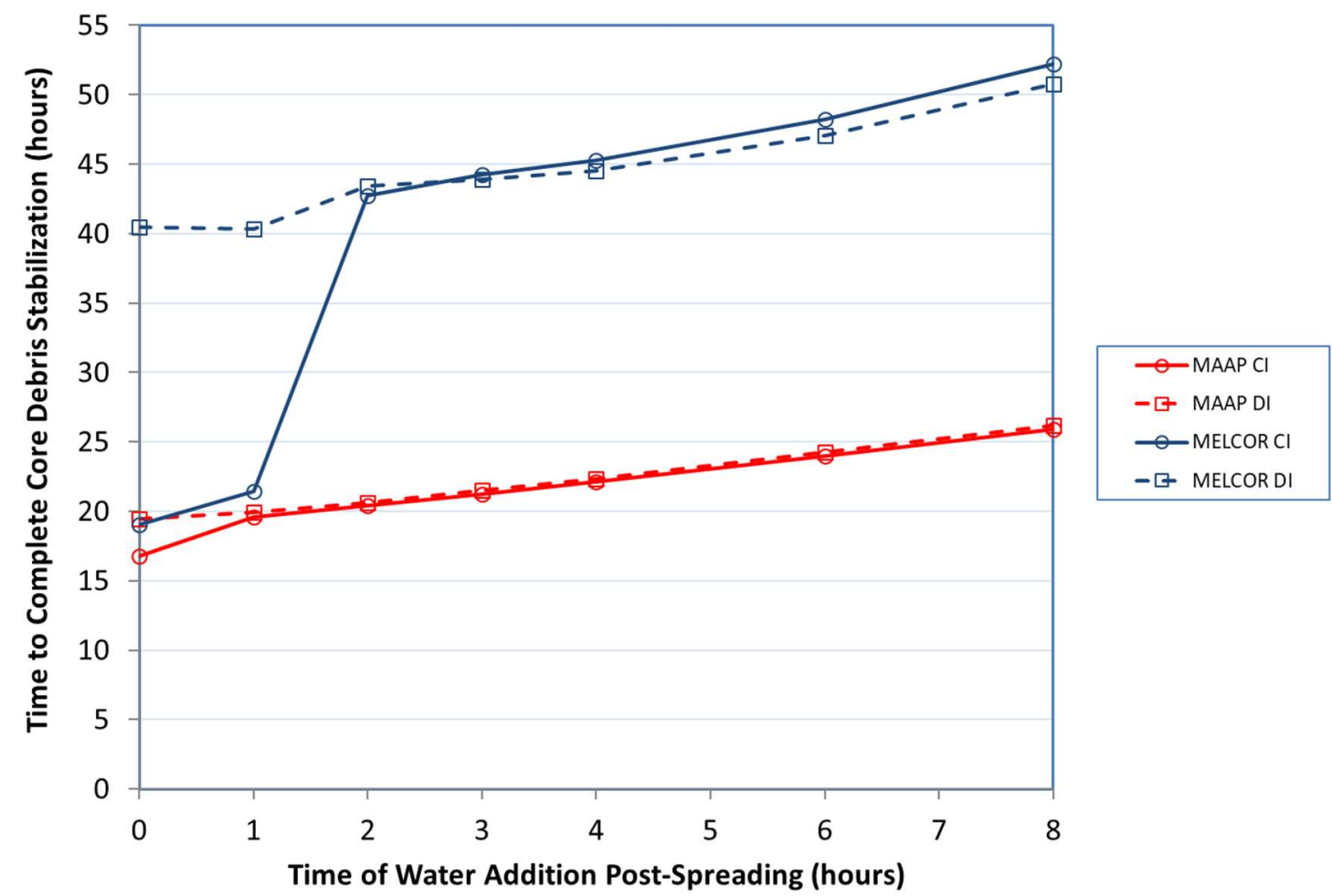

Figure 3-13. Comparison of Debris Stabilization Times for MAAP and MELCOR CI and DI Cases.

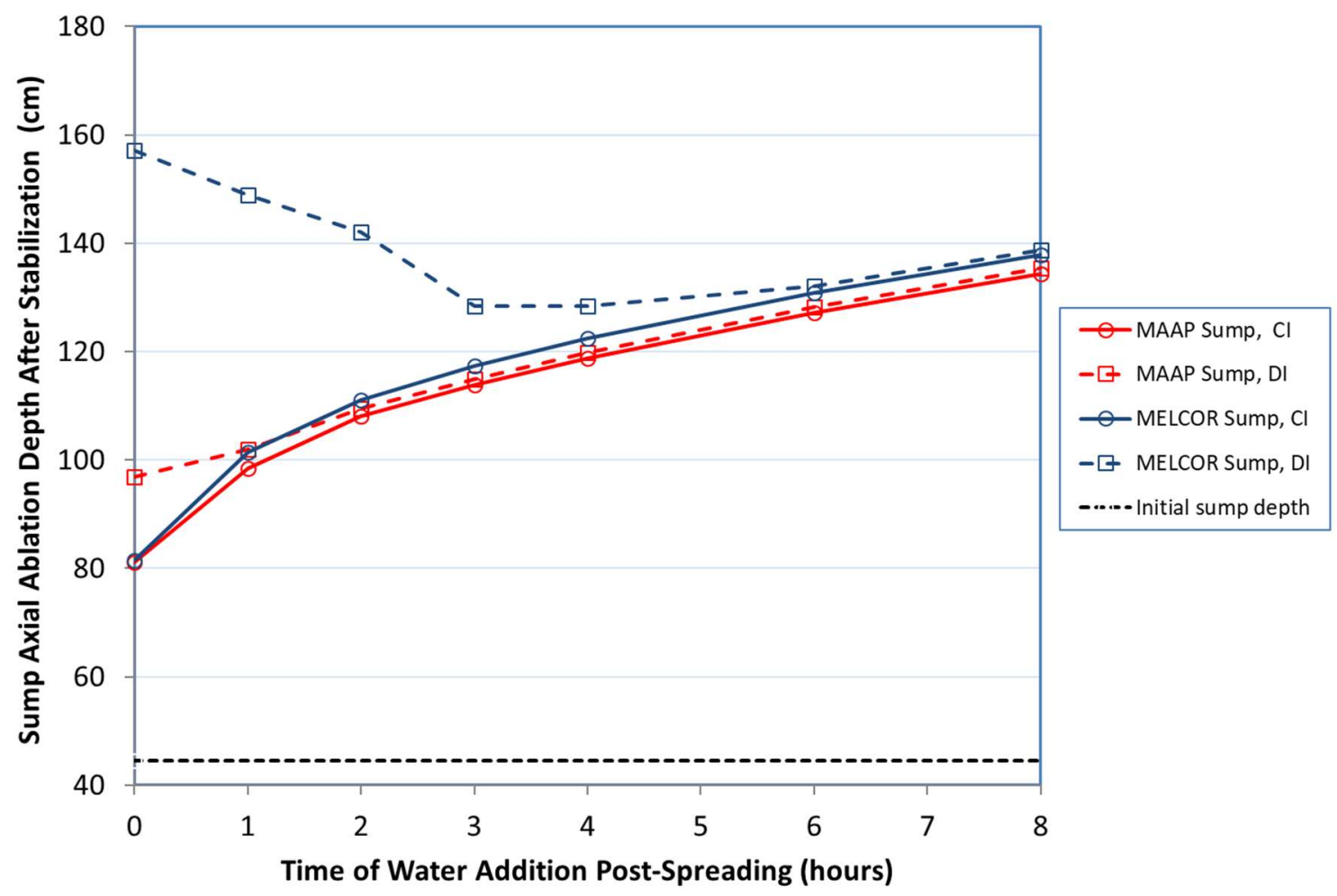

Figure 3-14. Comparison of Sump Axial Ablation Depths at Stabilization for MAAP and MELCOR CI and DI Cases. 


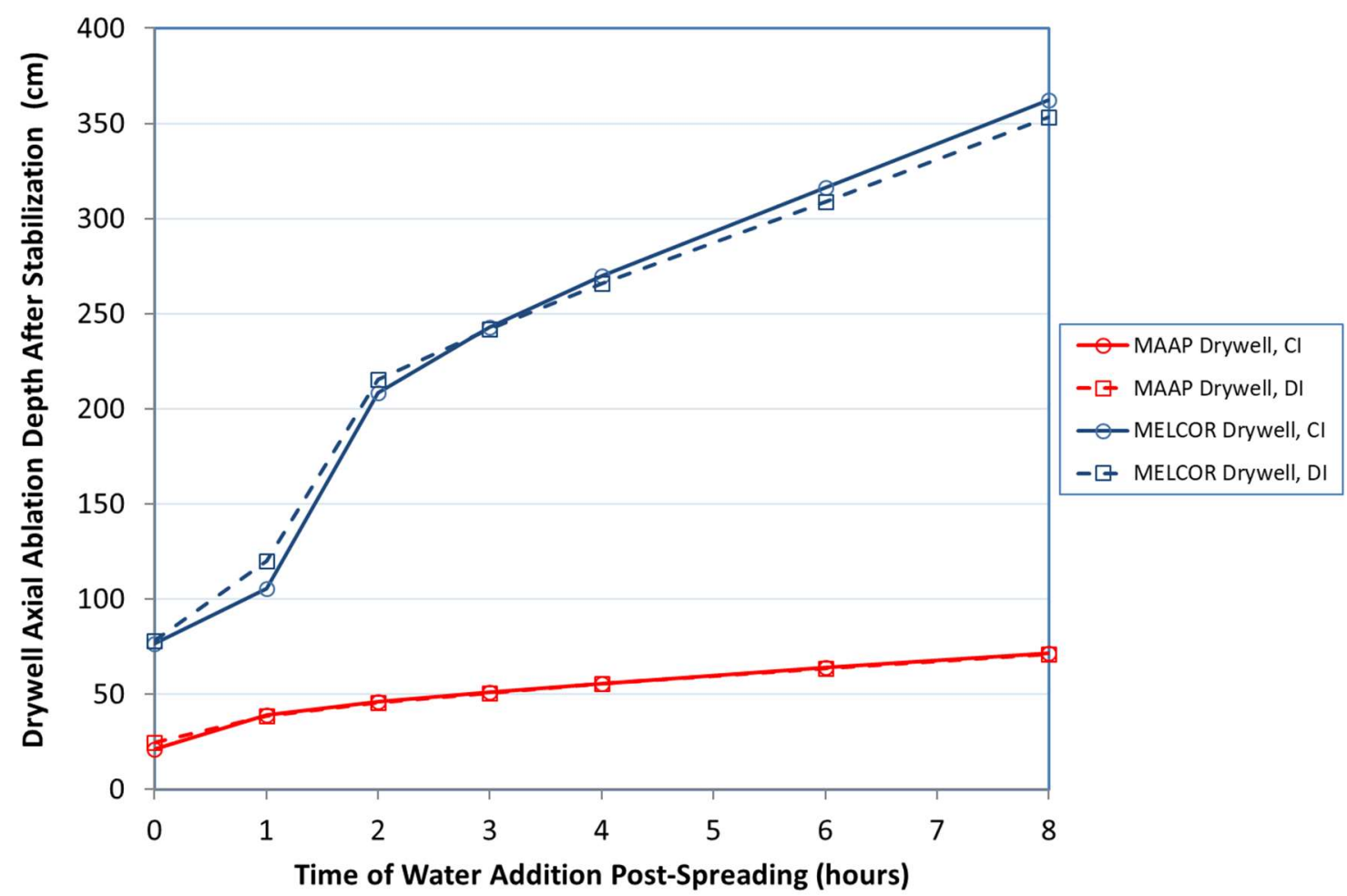

Figure 3-15. Comparison of Axial Ablation Depths Outside Pedestal Door for MAAP and MELCOR CI and DI Cases.

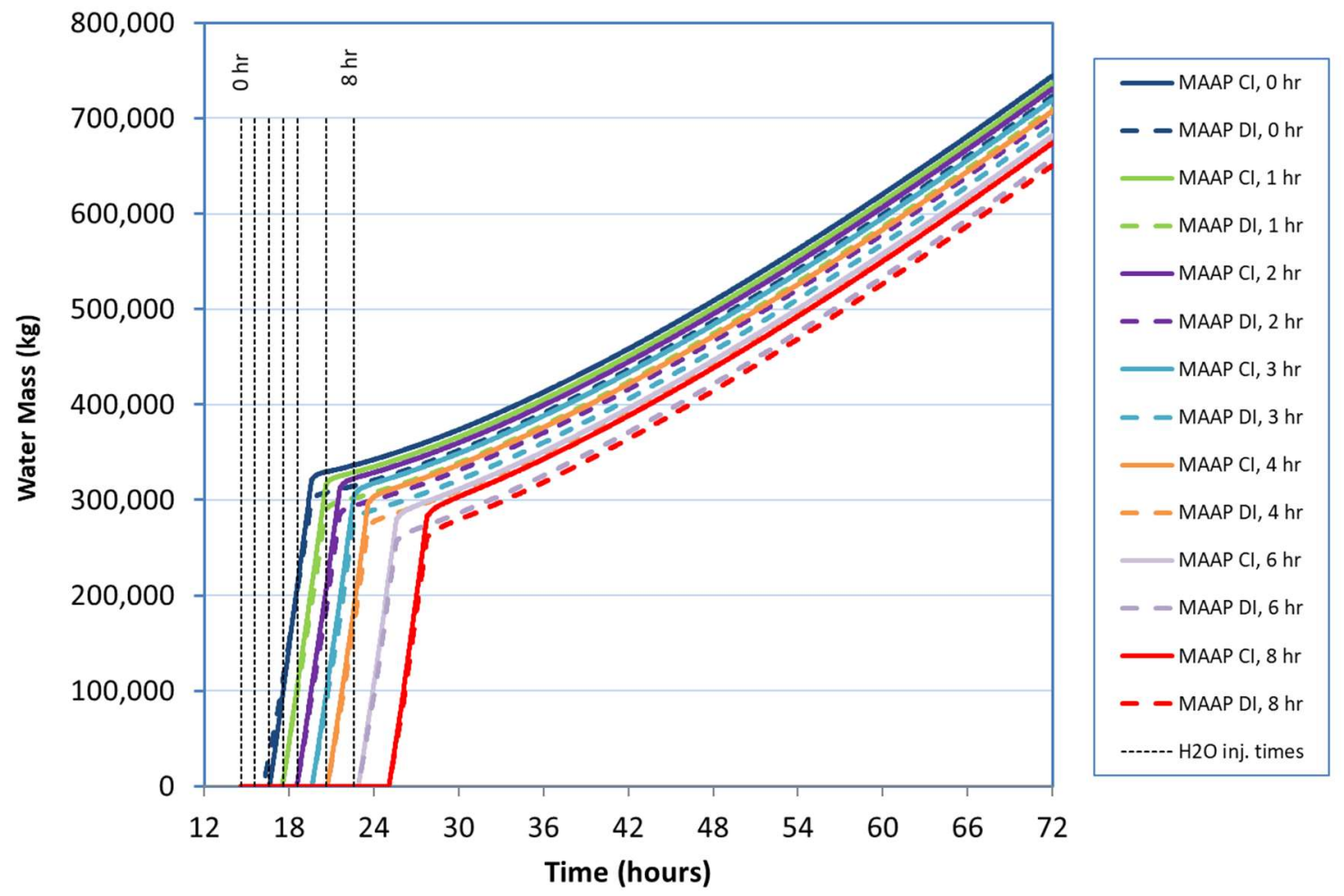

Figure 3-16. Predicted Water Overflow into the Wetwell for MAAP Parametric Cases. 
SAWA period was not long enough to achieve complete debris stabilization, resulting in periods of reduced cooling relative to that which could be achievable given an unlimited water supply. During these periods, all injected water was vaporized, resulting in no overflow into the wetwell.

The impact of flooding location and injection time on the extent of non-condensable gas production (i.e. $\mathrm{H}_{2}, \mathrm{CO}, \mathrm{CO}_{2}$ ) for the MAAP cases is shown in Figure 3-17. The results indicate a systematic increase in the amount of gas production as the time to injection is increased, as one would expect. CI also reduces the amount of gas production relative to DI for the $0 \mathrm{hr}$ injection case, but for later times, the differences are minor.

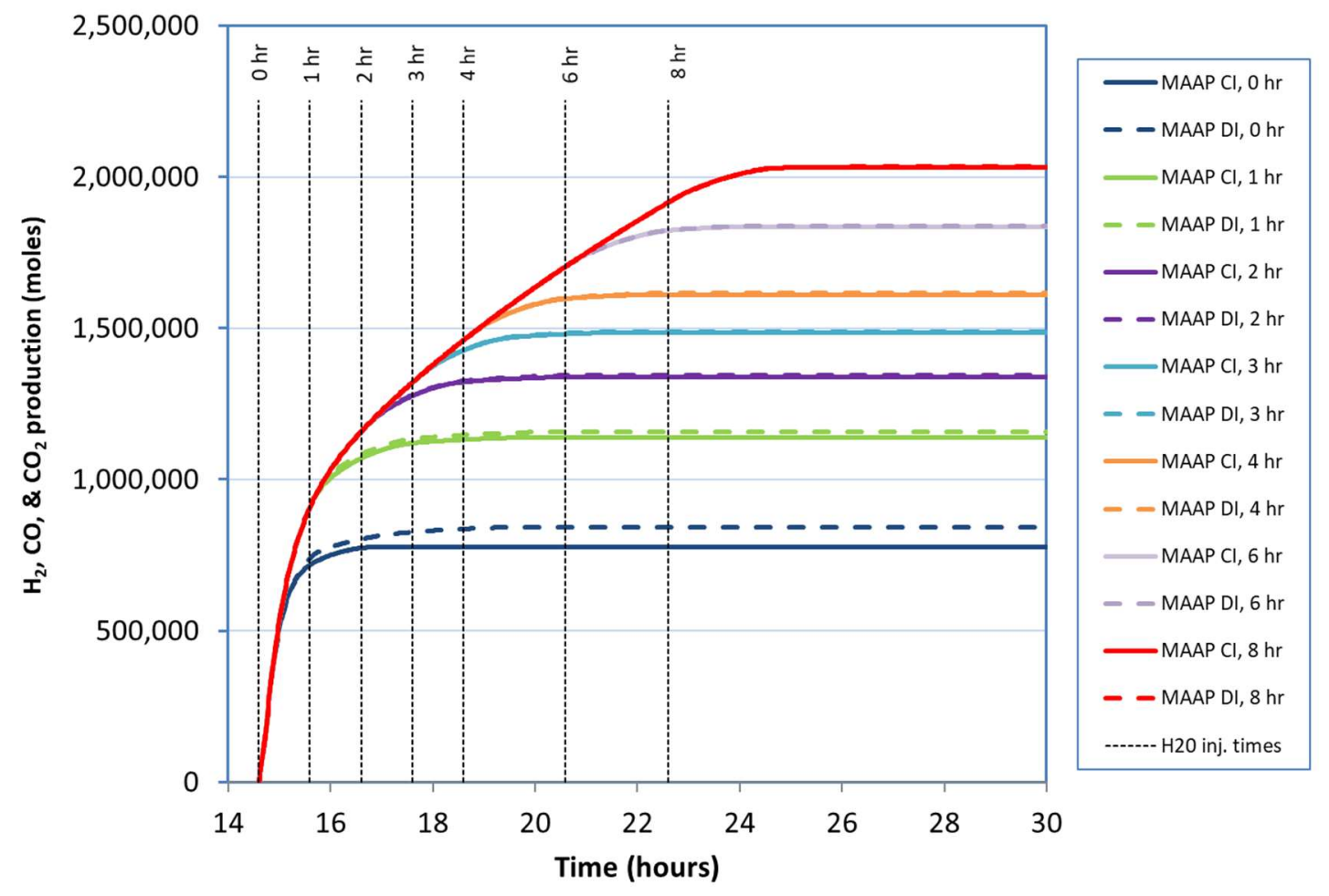

Figure 3-17. Predicted Non-condensable Gas Production for MAAP Parametric Cases. 


\subsection{MODELING LIMITATIONS}

Although significant progress has been made over the course of this work in terms of developing more realistic models for evaluating ex-vessel core debris spreading, coolability, and water management, several modeling limitations were identified as the work moved forward that should be kept in mind in terms of interpreting the results provided herein.

With respect to MELTSPREAD, quite deep (i.e., $80 \mathrm{~cm}$ or more) debris accumulations were predicted. Accumulations of this depth will likely reheat possibly leading to crust failure at the leading edge and subsequent spreading. This effect is currently not modeled. If it was, shallower melt accumulations may be predicted that would be easier to flood and to cool. There may be data available in the geological literature regarding lava flows from volcanoes (both dry and under water) that could be used to guide this model development.

With respect to CORQUENCH, the following items are noted:

- Regarding core-concrete interactions, radial/axial power split is currently modeled using empirical multipliers based on test observations. There is a need to deploy a phenomenological model for this behavior in order to mechanistically account for 2-D cavity erosion differences for different concrete types. A model has recently been developed by Kang and Corradini [26] that is an excellent candidate for implementation.

- Particle beds formed by jet fragmentation and melt eruptions may reduce (via hydraulic pressure drop) the ability of water to flow over the core debris from the injection point(s). The beds are currently assumed to be transparent with respect to water flow, and a model for hydraulic flow resistance should be implemented to account for this effect.

- Under dry cavity conditions, there is also a need to implement a particle bed heatup and re-melting model. Currently, it is assumed that these beds are able to dissipate heat to containment atmosphere via convection and remain intact. This assumption is suspect.

- There is a need to implement a remeshing strategy to account for the fact that sump nodes can consume adjacent nodes; currently the model assumes that nodes are 'isolated'.

- In order to adequately model deep accumulations such as sumps that exhibit 2-D behavior, there is also a need to implement an intermodal heat-mass-momentum modeling capability so that they can be treated using a multi-nodal approach, and other effects such as metal/oxide phase segregation/relocation can be treated.

- One finding from this work is that melt spatial composition can vary significantly in situations where metal and oxide phases pour separately. The assumption has been made in previous work, as well as in this study, that the fission products producing the decay heat predominately reside in the oxide phase in direct proportion to the amount of fuel $\left(\mathrm{UO}_{2}\right)$ that is locally present. Given the results obtained herein, it is important to reexamine this assumption to determine if the modeling needs to be improved to include decay heat partitioning between the metal and oxide phases. 


\subsection{REVIEW AND SUMMARY}

The overall objective of this work was to apply upgraded MELTSPREAD (MS) melt spreading [6] and CORQUENCH (CQ) core debris coolability [7] models in order to perform a parametric case study on SAWA/SAWM based on the Peach Bottom nuclear power plant geometry to provide insights on cavity flooding strategies.

Ex-vessel melt pour conditions predicted by the MAAP and MELCOR codes for an SBO sequence were provided by EPRI/Jensen Hughes and Sandia National Laboratories, respectively, and utilized as input for the melt spreading analyses. In relation to earlier studies conducted soon after the accidents at Fukushima Daiichi [3], the melt pour conditions predicted by updated versions of these two codes have grown closer together, with both codes predicting relatively cold melt pours with the oxide phase essentially solid, but with the metal (predominately steel) phase fully molten. Based on MS and CQ property routines, this effectively results in slurrytype melt pour conditions for both cases with a melt viscosity consistent with that of molten glass. Predicted melt pour rates by both codes have also grown closer together, but differences remain. In particular, following vessel failure 14.51 hours, MAAP predicts a relatively short melt pour time of $\sim 1$ minute with a uniform melt composition. For MELCOR, following vessel failure at 12.95 hours, the initial melt pour is predominatly oxide, $(\mathrm{U}, \mathrm{Zr}) \mathrm{O}_{2-\mathrm{x}}$, and this pour occurs over a time interval of $\sim 5$ minutes. This is followed by a slow pour of predominately metal (viz., stainless steel) lasting an additional $\sim 30$ minutes. For the MAAP scenario, the cavity is initially dry, and MS predicts complete spreading to cover the entire pedestal and drywell floor areas, with (collapsed) debris upper surface elevations ranging $\sim 35 \mathrm{~cm}$ over the floor in the pedestal region to $\sim 20 \mathrm{~cm}$ in the back of the drywell annulus 180 degrees from the pedestal doorway. In contrast, for the MELCOR scenario the initial water level on the drywell floor is 58 $\mathrm{cm}$ (viz. just below the downcomer inlet elevations of $61 \mathrm{~cm}$ ), and MS predicts partial spreading out the pedestal doorway and covering part of the drywell floor (equivalent to 66 degrees of the available 360 degree floor area) for this case. An additional finding for the MELCOR pour, which significantly impacts the long-term debris coolability behavior, is that a large accumulation of metal develops in the pedestal region (predominately the sump), with much of the core oxide material bearing the fission products located in the pedestal doorway and outside on the drywell floor. The collapsed debris surface elevation in the pedestal is $\sim 80 \mathrm{~cm}$, and this material is covered with a particle bed formed by jet fragmentation (discussed below) that is $\sim 8$ $\mathrm{cm}$ deep. The collapsed melt depths in the dooway and immediately outside the doorway on the drywell floor are in the range of $60-80 \mathrm{~cm}$. It is noteworthy that deep accumulations of core debris have recently been discovered in the pedestal regions for Units 2 and 3 at Fukushima Daiichi [10].

As part of the melt spreading study, a set of parametric calculations were performed examining the effects of initial water depth on the pedestal floor $(0,30$, and $58 \mathrm{~cm}$ cases) and initial melt temperature (MAAP and MELCOR predictions, plus 25 and $50 \mathrm{~K}$ melt superheat conditions relative to oxide solidus, so still slurry flow conditions). As one would expect, the code predicts additional floor area coverage as the melt temperature increases. Another finding 
is that the presence/absence of water on the cavity floor has a fairly significant impact on the extent of spreading for these slower, slurry type pour conditions, with less spreading occuring with water present. However, the impact of initial water depth in the range studied (i.e. 30 and $58 \mathrm{~cm}$ water depths) was found to be fairly weak, with only a small reduction in spreading distance predicted with increasing water depth. This is thought to be due to the fact that the downcomers in the Mark I containment effectively cap the peak water level at the inlet elevation as long as the wetwell vent path is preserved, coupled with the prediction that the advancing melt front pushes water down the floor path, resulting in a relatively consistent water depth boundary condition as seen by the melt for both cases.

Application of the melt jet fragmentation model indicates that the degree of fragmentation increases with increasing water depth, as one would expect. However, the collection of calculations performed herein indicates that the overall degree of fragmenation is relatively small in the range of water depths investigated (which includes an additional $45 \mathrm{~cm}$ of water present in the sump over the depths stated above); i.e., $5 \%$ for both MAAP and MELCOR melt pour conditions. Specifically, the fragmented particle bed mass was found to be $\sim 15$ MT out of a total pour mass of $\sim 300$ MT for both cases. This relatively small degree of fragmentation integrated over the entire duration of the pour is due to local effects that include water heatup and boiloff in the melt impingement zone (i.e., depletion), as well as core debris accumulation (mounding) beneath the reactor vessel that also acts to reduce the available water depth in the impingement zone.

The melt spreading analysis further indicates that the shell would heat significantly by contact with core debris for both the MAAP and MELCOR pour scenarios, and in a few of the MELCOR cases, the shell surface temperature reached the melting point. However, the shell was not predicted to be ablated through (i.e., fail by penetration) in any of the cases considered herein. The high temperatures predicted for the MELCOR case was due to two factors: i) the melt depth adjacent to the shell exceeded the downcomer inlet elevation, resulting in dryout of the shell above the region in contact so that fin-cooling is reduced, and ii) the assumption was made that the cavity was not flooded during the spreading transient, so that fin-cooling could not be enhanced by contact with injected water to mitigate shell heating.

The results of the shell heatup analysis thus indicate the need to supply water to the reactor cavity as soon as possible after vessel failure to protect the shell. This finding is consistent with the major conclusions reached in an earlier study by Theofanous et al. [18].

The above spreading results were used as input to a SAWA/SAWM study that was carried out with the upgraded multi-nodal version of CQ [7] that also features a new, detailed water inventory modeling capability. The post-spreading melt composition and temperature profiles calculated with MS for the MAAP and MELCOR base case pours (i.e., dry cavity spreading for MAAP and $58 \mathrm{~cm}$ initial water level for MELCOR) were used to define initial conditions for the long-term core concrete interaction and debris coolabilty analysis with CQ. In terms of parametrics, the location of cavity flooding [i.e., Core Injection (CI) vs. Drywell Injection (DI)] as well as the delay time in water injection following completion of spreading 
(i.e., $0,1,2,3,4,6$, and 8 hours) were varied for both the MAAP and MELCOR post-spreading debris distributions. Finally, a water injection strategy was selected for the purposes of this work that assumed a SAWA injection flowrate of $31.5 \mathrm{~kg} / \mathrm{sec}$ (i.e. $500 \mathrm{gpm}$ ) for a period of 5 hours, followed by implementation of a SAWM injection flowrate of $6.3 \mathrm{~kg} / \mathrm{sec}$ (i.e., $100 \mathrm{gpm}$ ) for the balance of the calculation out to 72 hours.

For the MAAP scenario, the time to complete debris quench and thermal stabilization for the $\mathrm{CI}$ and DI cases were fairly consistent due to the relative uniformity in the post spread melt with an elevation profile that was well below the Peach Bottom downcomer inlet elevation of 61 $\mathrm{cm}$. Thus, regardless of injection pathway, water is able to flow and cover all the core debris as long as the injection flowrate is sufficient to meet or exceed the integrated steaming rate from the covered debris. For the 0 hour injection case, CI performed slightly better in terms of limiting ablation in the sump and reducing time to complete quench (at 16.8 hours into the accident sequence). This is due to the prediction that for the DI case, the injected water is completely boiled off in the drywell for a period of $\sim 20$ minutes, thereby allowing dry ablation in the sump to proceed that incorporates concrete slag into the core debris in that area; this process is known to degrade the coolability of core material via the water ingression cooling mechanism [7,22]. The net effect for the DI case is that complete debris quench is delayed until 19.5 hours. However, for cases with delays in water injection, concrete ingress occurs in all regions where melt is present, and this effect negates any significant differences between CI and DI scenarios. In the range of parameters investigated, times to core debris stabilization ranged from 16.5 hours for the 0 hour CI case to $\sim 25$ hours for both the CI and DI cases involving an 8 hour delay until water injection. For all MAAP cases, the arbitrarily assumed 5 hour SAWA time interval was found to be sufficient to quench and stabilize the core debris without leading to a situation in which the cooling rate would be water limited. Ablation depths in the sump relative to the drywell floor elevation (and including the initial $45 \mathrm{~cm}$ depth of the sump itself) ranged from 80$95 \mathrm{~cm}$ for the 0 hour injection cases to $\sim 135 \mathrm{~cm}$ for the 8 hour delay cases. The corresponding ablation depths in the drywell outside the pedestal doorway are much less, ranging from $\sim 20 \mathrm{~cm}$ to $\sim 70 \mathrm{~cm}$ over the delay time range.

With respect to non-condensable (i.e. $\mathrm{H}_{2}, \mathrm{CO}, \mathrm{CO}_{2}$ ) gas production for the MAAP scenario, the results indicate a systematic increase in the amount of gas production as the time to injection is increased, as one would expect. CI also reduces the amount of gas production relative to DI for the $0 \mathrm{hr}$ injection case, but for later times, the differences are minor.

For the MELCOR scenario, more complicated behavior was found due to the prediction of deep debris accumulations that initially exceed the downcomer inlet elevations, coupled with the additional prediction that the post-spread melt composition distribution is highly nonuniform, with the metals concentrated in the sump and on the pedestal floor. Due to the fact that MS and CQ modeling assumes that the fission products are partitioned throughout the debris in direct proportion to the fuel $\left(\mathrm{UO}_{2}\right)$ level, this leads to a situation in which the decay heat loading in the sump where the core debris is the deepest is relatively low, while the loading within the doorway and outside on the drywell floor is relatively high. 
Principally due to the non-uniform debris distribution, significant differences are noted in the time to quench the core debris and the extent of axial erosion in the sump for the CI and DI cases for short injection delays (i.e., 0 and 1 hour cases), with CI being clearly the most beneficial. This is due to the fact that water is able to flow over the core debris on its way to the drywell when CI is used, thus providing beneficial cooling (and fission product scrubbing) of all the debris as part of the process. However, when DI is used, only a limited amount of debris that is located outside the pedestal doorway is initially covered with water, with the balance accumulating on the uncovered region of the drywell floor and simply spilling over into the wetwell. This is due to the prediction that the core material in the pedestal doorway effectively forms a dam that prevents water backflow into the pedestal.

An interesting finding is that as ablation proceeds, there is a tendency for the debris upper surface elevation to be reduced due to concrete densification upon melting, which can be significant for the limestone-common sand concrete type used in this analysis for Peach Bottom (i.e., $\sim 31$ vol\% reduction per unit volume ablated). Thus, even for DI cases, a point is reached several hours after vessel failure in which dry ablation in the sump/pedestal/drywell regions results in surface elevation reductions to the point where water is able to flow into the pedestal and begin the debris cooling process. This effect becomes significant with injection delays in the 2-4 hour range. After this delay, sump ablation depths and time to debris stabilization tend to merge for the CI and DI cases, since by this time the surface elevation profiles fall below the elevation of the downcomer inlets, thereby allowing surface flooding via either injection pathway. Note that this concrete slumping effect would not be as significant for plants built with siliceous concrete since the gas content of that material is much less compared to the limestonecommon sand concrete used at Peach Bottom.

The results of this analysis for the MELCOR scenario indicates that a 5 hour SAWA injection interval is sufficient to ensure debris quench and stabilization for the 0 hour CI case, but periods of undercooling are observed as the delay time to injection increases. This is due to the fact that the effectiveness water ingression cooling mechanism degrades as more concrete is introduced into the melt, thus requiring a longer time to quench the debris, particularly for these MELCOR-type deep accumulations. However, for the DI cases, the opposite trend is noted. In particular, the longest period of undercooling due to the SAWM reduction in flow occurs for the 0 hour injection case, and this is due to the prediction that it takes several hours for the surface elevations to decline to the point at which the core debris in the pedestal can be flooded. Thus, by the time the flow is reduced, only limited flooding in the pedestal has occurred at a flowrate sufficient to effectively cool the material. As the delay to injection increases, slumping has already occurred, thus allowing more of the water injected at the higher flowrate to gain access to the core debris in the pedestal.

Taken as a whole, the results of the MELCOR scenario reinforce the idea that flooding of the cavity using CI as soon as possible after vessel failure yields the greatest benefit in terms of rapidly quenching and stabilizing the core debris. If DI is used, the results indicate that stabilizaton will take longer and result in more concrete ablation. One observation based on the 
current results is that it may be worth considering a reduced SAWA injection flowrate over a longer period of time (yielding the same total injected volume) to maintain cooling of core debris in the drywell while minimizing overflow into the wetwell until the coolant is able to access the debris in the pedestal.

In the range of parameters investigated for the MELCOR scenario, times to core debris stabilization ranged from 19 hours for the 0 hour CI case to 52-54 hours for CI and DI cases involving an 8 hour delay until water injection. For the 0 hour cases, ablation depths in the sump relative to the pedestal-drywell floor elevation (again noted to include the initial $45 \mathrm{~cm}$ depth of the sump itself) were $\sim 80 \mathrm{~cm}$ for the CI case, and $\sim 155 \mathrm{~cm}$ for DI case. As flooding delay increases, the CI and DI predictions tend to merge at a level of $\sim 140 \mathrm{~cm}$ for an 8 hour injection delay. Conversely, ablation outside the pedestal doorway is similar for both CI and DI cases due to the fact that the debris in this region is flooded as soon as water is injected regardless of injection pathway. Ablation depths here range from $\sim 80 \mathrm{~cm}$ with no delay up to $~$ $3.5 \mathrm{~m}$ with an 8 hour delay. As noted earlier, based on the current modeling assumptions and analysis results for $\mathrm{MS}$, it is calculated that a large fraction of the core debris containing the fission products would flow out of the pedestal door and accumulate as a fairly thick layer $(\sim 80$ $\mathrm{cm})$ in this region of the drywell. Thick accumulations of core debris with significant decay heat are the most difficult to cool.

With respect to non-condensable gas production for the MELCOR scenario, the results indicate that for delay times of less than 6 hours, CI reduces the amount of gas production, and that the difference becomes quite large as the delay is reduced (e.g., factor of $\sim 3$ for the 0 hour delay case). However, for long delays (i.e., 6-8 hours), the results are indistinguishable due reasons discussed above. 


\subsection{REFERENCES}

1. Nuclear Energy Institute, "Industry Guidance for Compliance with Order EA-13-109," NEI 13-02, Rev. 2, December 2014 (ADAMS Accession No. ML13316A853).

2. E.J. Leeds, EA-13-109, "Issuance of Order to Modify Licenses with Regard to Reliable Hardened Containment Vents Capable of Operation under Severe Accident Conditions," USNRC, June 6, 2013.

3. K. R. Robb, M. W. Francis, and M. T. Farmer, "Enhanced Ex-Vessel Analysis for Fukushima Daiichi Unit 1: Melt Spreading and Core-Concrete Interaction Analyses with MELTSPREAD and CORQUENCH," ORNL/TM-2012/455 (2013).

4. M. T. Famer (editor), R. Bunt, M. Corradini, P. Ellison, M. Francis, J. Gabor, R. Gauntt, C. Henry, R. Linthicum, W. Luangdilok, R. Lutz, C. Paik, M. Plys, C. Rabiti, J. Rempe, K. Robb, and R. Wachowiak, "Reactor Safety Gap Evaluation of Accident Tolerant Components and Severe Accident Analysis," ANL/NE-15/4, March 2015.

5. M. T. Farmer and K. R. Robb, "Status Report on Ex-Vessel Coolability and Water Management," ANL/NE-16/18, September 15, 2016.

6. M. T. Farmer, "The MELTSPREAD Code for Modeling of Ex-Vessel Core Debris Spreading Behavior Code Manual - Version 3.0," ANL-18/30, September 2018.

7. M. T. Farmer, "The CORQUENCH Code for Modeling of Ex-Vessel Corium Coolability under Top Flooding Conditions Code Manual - Version 4.1-beta," ANL-18/22, August 2018.

8. "Modular Accident Analysis Program (MAAP), version 5.05 - Beta", EPRI, Palo Alto, CA, January, 2017, 3002009328.

9. L.L. Humphries, R.K. Cole, D.L. Louie, V.G. Figueroa, M. F. Young, "MELCOR Computer Code Manuals," SAND2015-6691, August 2015.

10. J. Rempe et al., "U.S. Efforts in Support of Examinations at Fukushima Daiichi - 2018 Evaluations," ANL -18/24, September 2018.

11. H. Martin, "Heat and Mass Transfer Between Impinging Gas Jets and Solid Surfaces," Advances in Heat Transfer, 31, 1 (1977).

12. T. G. Theofanous et al., "Bubble-Induced Circulation and Associated Boundary Heat Transfer," Nuclear Engineering and Design, 121, 93 (1990).

13. http://www.tepco.co.jp/en/nu/fukushimanp/handouts/2017/images/handouts_170202_01-e.pdf.

14. B. W. Spencer. S. K. Wang, C. A. Blomquist, L. M. McUmber, and J. P. Schneider, "Fragmentation and Quench Behavior of Corium Melt Streams in Water," NUREG/CR6133, ANL-93/32 (February 1994). 
15. D. Magallon, I. Huhtiniemi, and H. Hohmann, "Lessons Learnt from FARO/TERMOS Corium Melt Quenching Experiments," OECD/CSNI Specialist Meeting on Fuel Coolant Interactions, NEA/CSNI/R(97)26, JAERI-Tokai-Mura, Japan, 19-21 May 1997.

16. D. R. Bradley, "Modeling of Heat Transfer Between Core Debris and Concrete," ANS Proceeding 1988 National Heat Transfer Conference, Houston, TX, July 24-27, 1988.

17. M. Ramacciotti, C. Journeau, F. Sudreau, and G. Cognet, "Viscosity Models for Corium Melts," Nuclear Engineering and Design, Vol. 204, pp. 377-389, 2001.

18. T. G. Theofanous et al., "The Probability of Liner Failure in a Mark-I Containment," NUREG/CR-5423, 1991.

19. M. L. Corradini, "A Transient Model for the Ablation and Decomposition of Concrete," Nucl. Tech., 62, 263 (1983).

20. M. T. Farmer, S. Lomperski, D. J. Kilsdonk, and R. W. Aeschlimann, “OECD MCCI Project Final Report," OECD/MCCI-2005-TR06 (2006).

21. M. T. Farmer, R. W. Aeschlimann, D. J. Kilsdonk, and B. W. Spencer, "Results of MACE Test M3b Posttest Debris Characterization,” EPRI/ACEX-TR-C32 (2000).

22. S. Lomperski and M. T. Farmer, "Experimental Evaluation of the Water Ingression Mechanism for Corium Cooling," Nucl. Eng. Design, 237, 905 (2006).

23. M. Ishii and N. Zuber, "Drag Coefficient and Relative Velocity in Bubbly, Droplet or Particulate Flows,” AlChE Journal, 25, 843 (1979).

24. J. E. Brockmann, F. E. Arellano, and D. A. Lucero, "Validation of Models of Gas Holdup in the CORCON Code," NUREG/CR-5433 (1989).

25. American National Standard for Decay Heat Power in Light Water Reactors, ANSI/ANS5.1-1994, American Nuclear Society, August 1994.

26. K. M. Kang and M. L. Corradini, "Phenomenological Modeling Approach to Anisotropic Ablation in Molten Core-Concrete Interactions," Nuclear Tech., Vol. 196, p. 511-523, December 2016. 


\section{Argonne}

NSE Division

Argonne National Laboratory

9700 South Cass Avenue, Bldg. \#208

Argonne, IL 60439

www.anl.gov

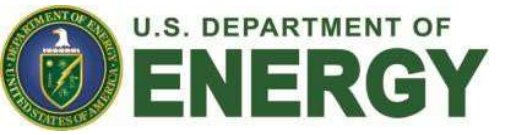

Argonne National Laboratory is a U.S. Department of Energy laboratory managed by UChicago Argonne, LLC 